\title{
Modeling of Solid Oxide Fuel Cells
}

\author{
by \\ Won Yong Lee \\ B.S. Mechanical Engineering \\ Seoul National University, 2001 \\ SUBMITTED TO THE DEPARTMENT OF MECHANICAL ENGINEERING IN \\ PARTIAL FULFILLMENT OF THE REQUIREMENTS FOR THE DEGREE OF \\ MASTER OF SCIENCE IN MECHANICAL ENGINEERING \\ AT THE \\ MASSACHUSETTS INSTITUTE OF TECHNOLOGY
}

SEPTEMBER 2006

(C) 2006 Massachusetts Institute of Technology. All rights reserved.

The author hereby grants to MIT permission to reproduce and to distribute publicly paper and electronic copies of this thesis document in whole or in part in any medium now known or hereafter created.

Signature of Author

Department of Mechanical Engineering August 19, 2006

Certified by

Ahmed F. Ghoniem

Professor

Thesis Supervisor

Accepted by.

Lallit Anand

Chairman, Department Committee on Graduate Students 


\title{
Modeling of Solid Oxide Fuel Cells
}

\author{
By \\ Won Yong Lee \\ Submitted to the Department of Mechanical Engineering \\ on 19 August 2006 in partial fulfillment of the requirements \\ for the degree of Master of Science in Mechanical Engineering
}

\begin{abstract}
A comprehensive membrane-electrode assembly (MEA) model of Solid Oxide Fuel Cell (SOFC)s is developed to investigate the effect of various design and operating conditions on the cell performance and to examine the underlying mechanisms that govern their performance. We review and compare the current modeling methodologies, and develop an one-dimensional MEA model based on a comprehensive approach that include the dustygas model(DGM) for gas transport in the porous electrodes, the detailed heterogeneous elementary reaction kinetics for the thermo-chemistry in the anode, and the detailed electrode kinetics for the electrochemistry at the triple-phase boundary. With regard to the DGM, we corrected the Knudsen diffusion coefficient in the previous model developed by Multidisciplinary University Research Initiative[1]. Further, we formulate the conservation equations in the unsteady form, allowing for analyzing the response of the MEA to imposed dynamics. As for the electrochemistry model, we additionally analyzed all the possibilities of the rate-limiting reaction and proposed rate-limiting switched mechanism. Our model prediction agrees with experimental results significantly better than previous models, especially at high current density.
\end{abstract}

Thesis Supervisor: Ahmed F. Ghoniem

Title: Professor 


\section{Acknowledgements}

First, I would like to thank Professor Ghoniem for his guidance and support through the past two years.

I owe a great deal to my colleagues, Daehyun Wee, Jean-Christphe Nave, Murat Altay, Fabrice Schlegel and Raymond Speth. Daehyun Wee shared his valuable time for the discussion on the topics in this thesis. I also thank Sangmok Han, who has provided valuable help on formatting this thesis.

I am very grateful to my parents, Hak-Joon Lee and Ok-Ja Kim for their love, support and guidance. I also thank other members of my family, including grandmother, my sister Myung-Sook Lee and brother-in-law Joon-Gu Kim for their incredible understanding and emotional support.

Finally, special thanks to my right knee. Even though it suffered from three times surgeries, the right knee has supported me continuously with patient. Through the surgeries, I realized how valuable the health, the friendship, and the modesty are. Without the awareness of these, it was impossible to withstand everything that I have been through during the past two years. 


\section{Contents}

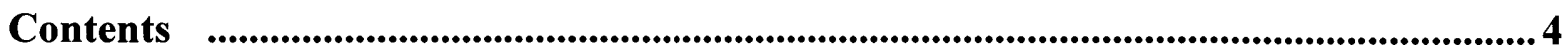

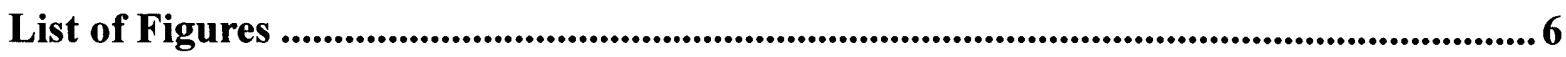

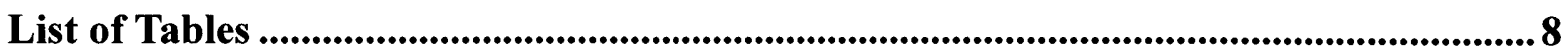

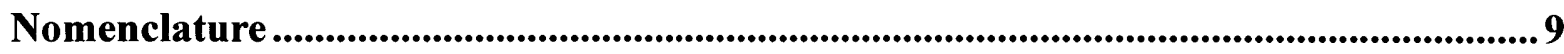

Chapter 1 Introduction ................................................................................................................. 12

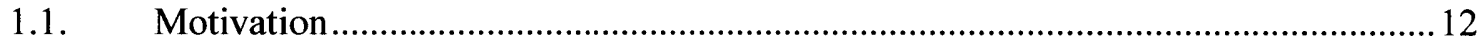

1.2. Introduction to Fuel Cells ................................................................................ 13

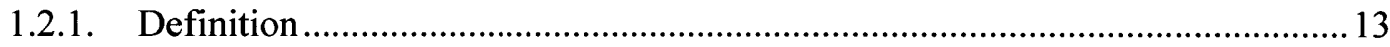

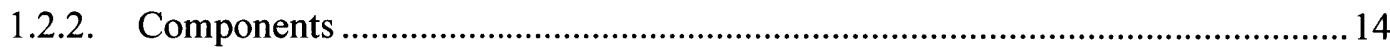

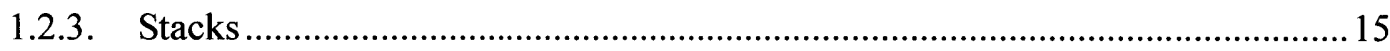

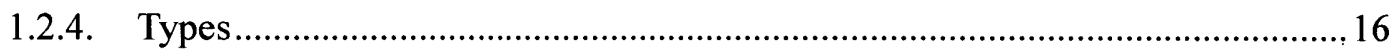

1.3. Solid Oxide Fuel Cell....................................................................................... 17

1.3.1. Advantages and Disadvantage of SOFC ........................................................ 17

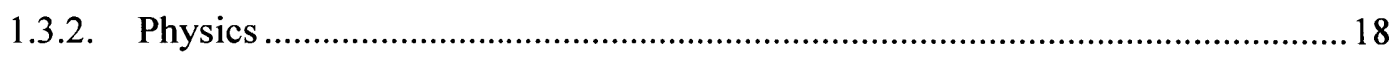

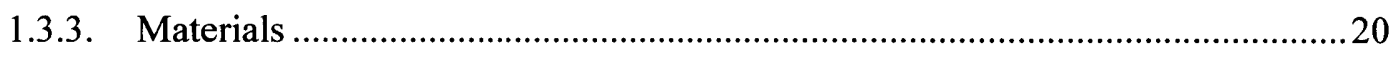

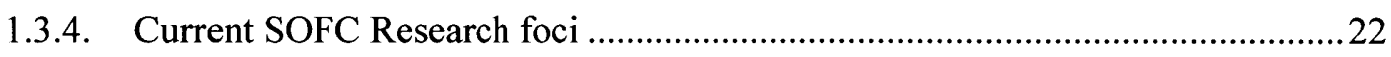

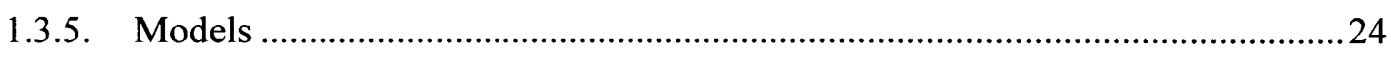

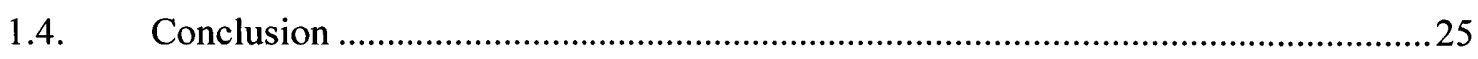

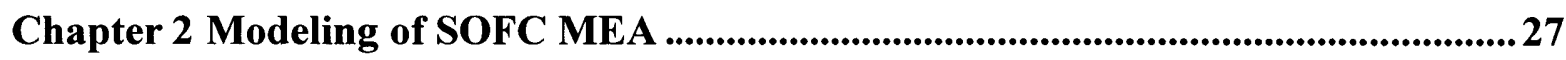

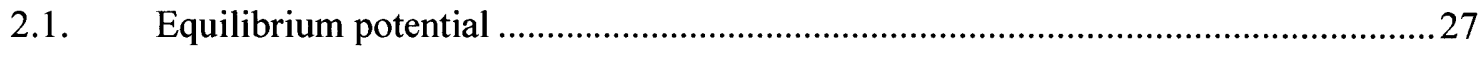

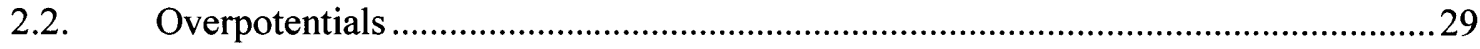

2.2.1. Concentration Overpotential..............................................................................31

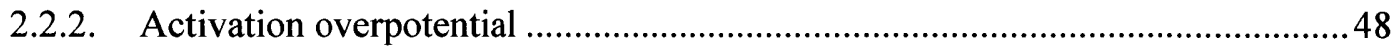

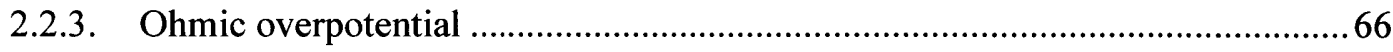

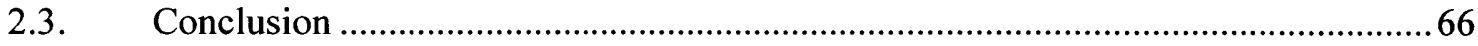

Chapter 3 The Simulation of SOFC MEA ……........................................................................68

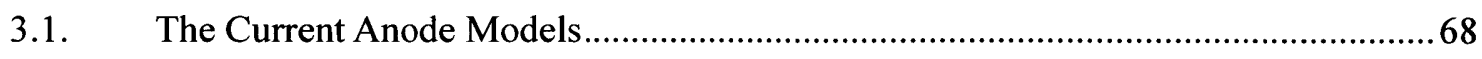

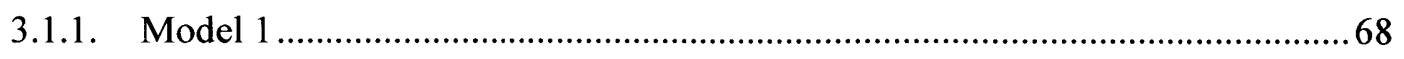




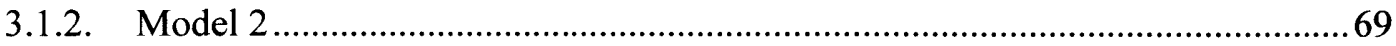

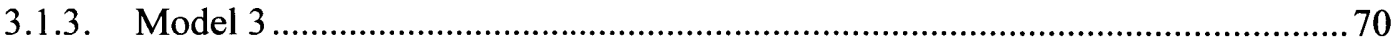

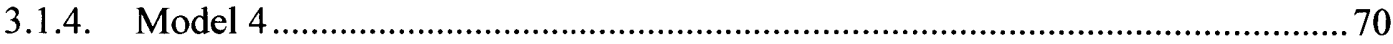

3.1.5. Comparison of Current Anode Models ............................................................. 71

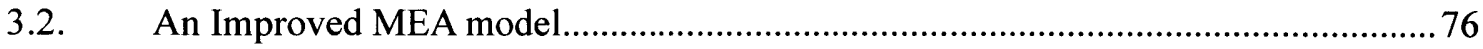

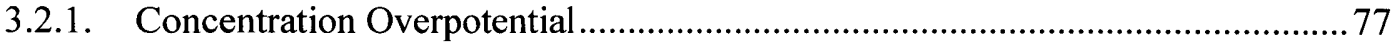

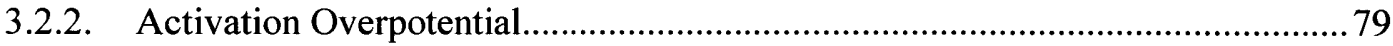

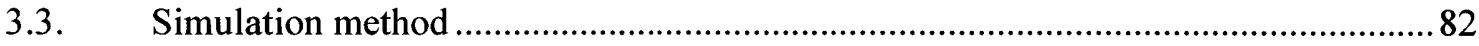

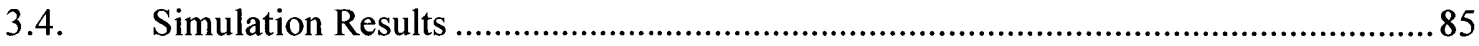

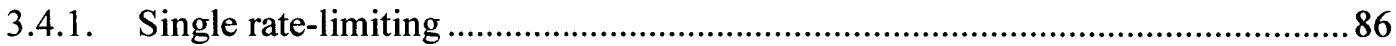

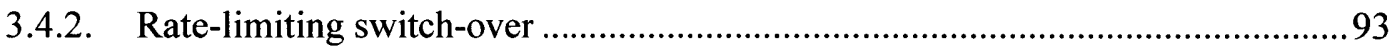

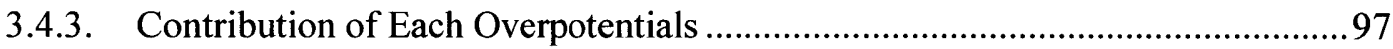

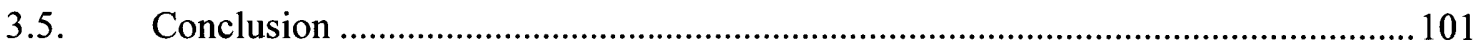

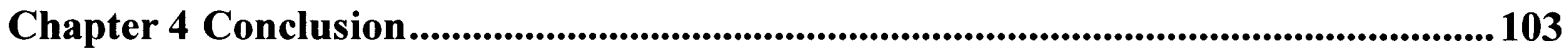

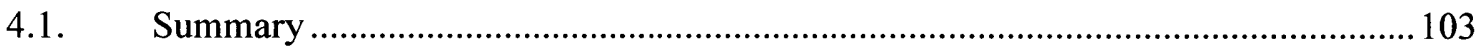

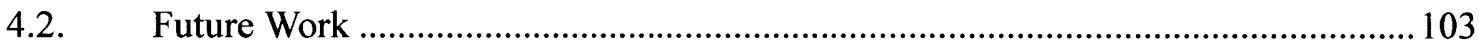

Reference 


\section{List of Figures}

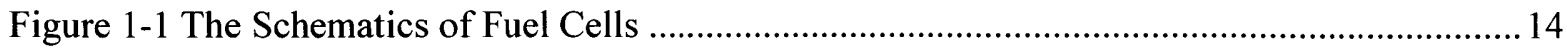

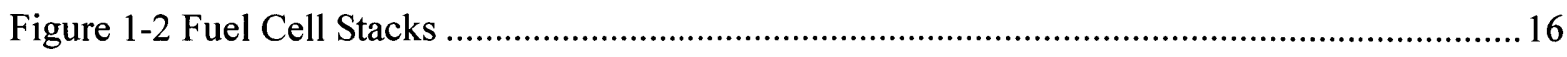

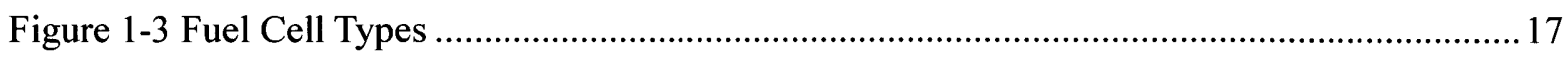

Figure 1-4 The Schematics of Solid Oxide Fuel Cell .................................................................. 19

Figure 2-1 The Schematics of Fuel Cell in the Equilibrium State ...............................................29

Figure 2-2 Typical Current-Voltage(I-V) Performance Curve...................................................... 30

Figure 2-3 The Schematics of Fuel Cell in the Non-equilibrium state ......................................... 32

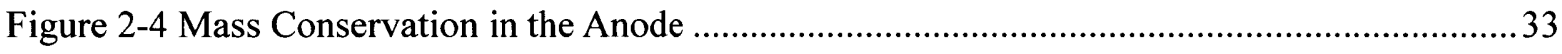

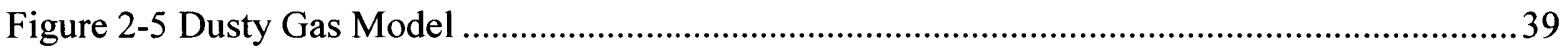

Figure 2-6 The Schematics of Elementary Heterogeneous Chemistry .......................................... 44

Figure 2-7 The Schematics of the Detailed Anode Kinetics..........................................................52

Figure 2-8 The Schematics of the Detailed Cathode Kinetics.......................................................63

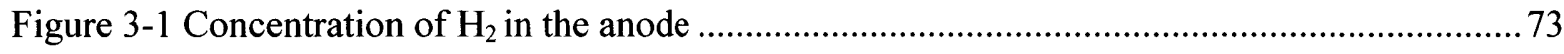

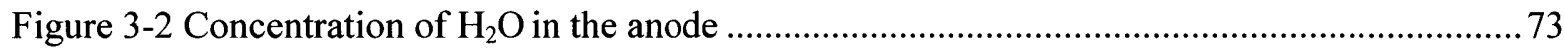

Figure 3-3 Concentration of $\mathrm{CO}$ in the anode ............................................................................... 74

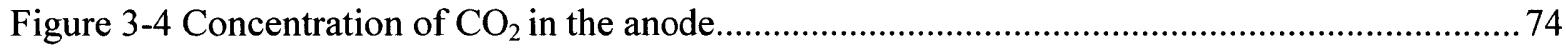

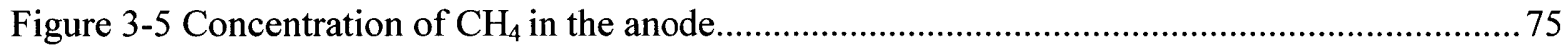

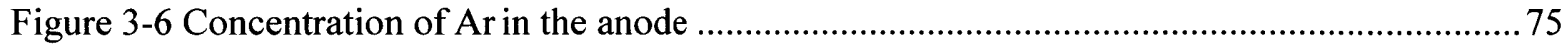

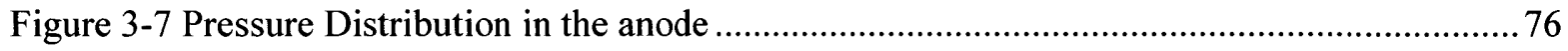

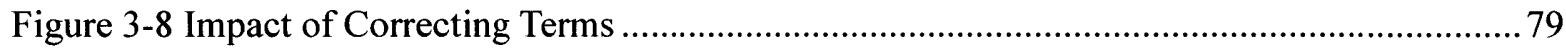

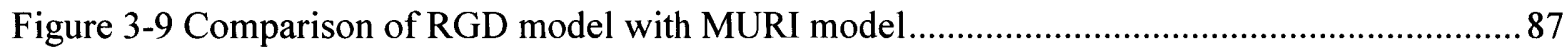

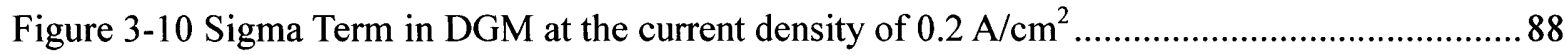

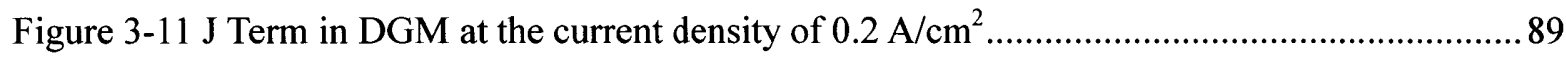

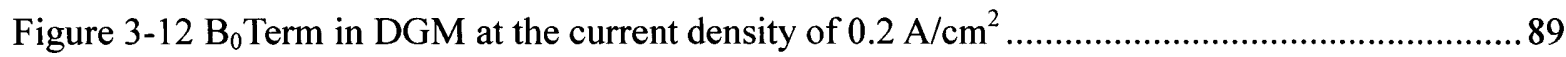

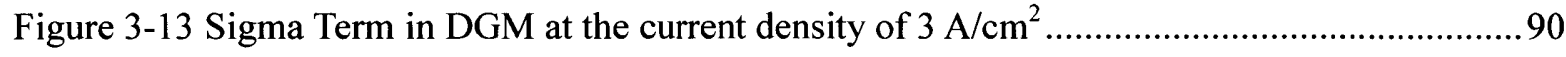

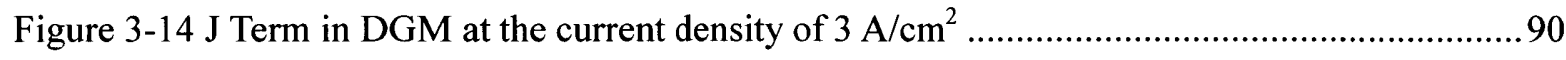

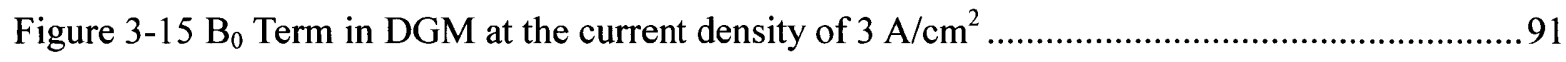

Figure 3-16 Comparison between the Experimental Data, the RGD Model and the MURI Model..92

Figure 3-17 Comparison between RGD Model and Experimental Results by Jiang and Virkar.......92 
Figure 3-18 Rate-limiting Switch-over..

Figure 3-19 Comparison between RGD Model and Experimental Results by Jiang and Virkar.......95

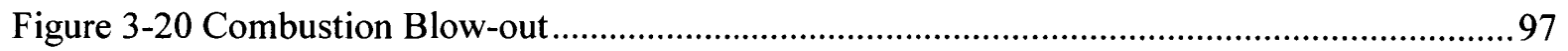

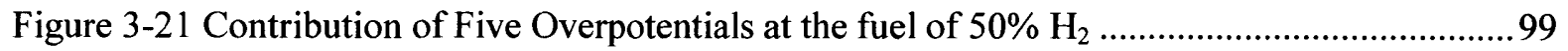

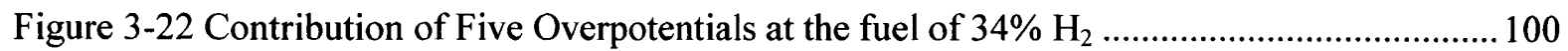

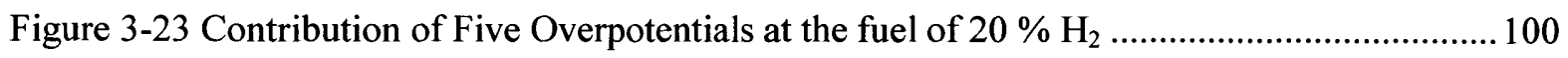

Figure 3-24 Comparison between Singe rate-limiting and Rate-limiting Switch-over ................... 101

Figure 4-1 Schematics of Button Cell Experimental Set-up....................................................... 106 


\section{List of Tables}

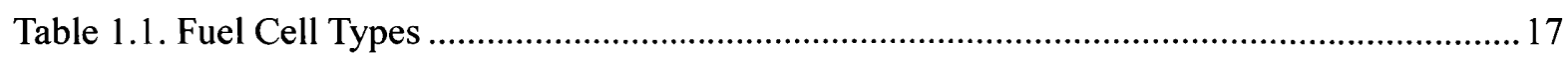

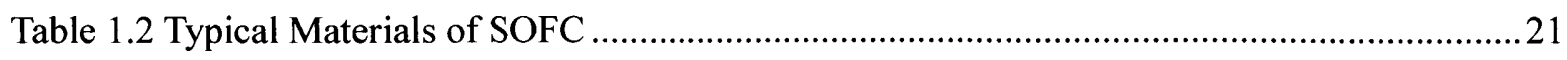

Table 2.1 Detailed Heterogeneous Elementary Chemical Reactions.............................................47

Table 2.2 Butler-Volmer Form for Each Rate-limiting Reaction .................................................60

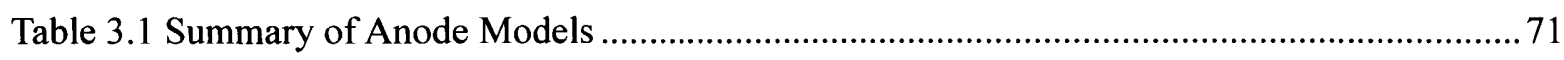

Table 3.2 Operating Conditions and Anode Parameters ......................................................... 71

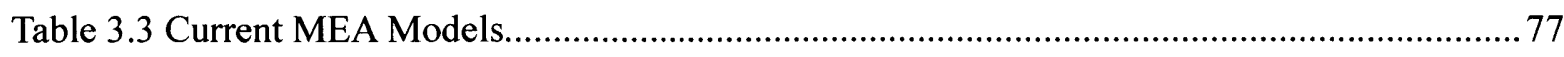

Table 3.4 Activation Overpotential for Switch-Over Mechanism ...............................................94

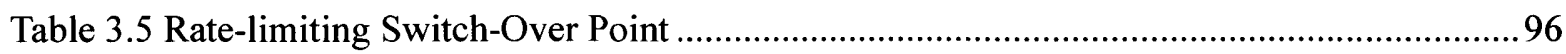




\section{Nomenclature}

\begin{tabular}{|c|c|c|}
\hline Symbol & Meaning & Common Units \\
\hline$A_{s}$ & Specific catalyst area per unit volume of electrode & {$[1 / \mathrm{m}]$} \\
\hline$B_{o}$ & Permeability & {$\left[\mathrm{m}^{2}\right]$} \\
\hline$c_{k}$ & Concentration of gas species $\mathrm{k}$ & {$\left[\mathrm{mol} / \mathrm{m}^{3}\right]$} \\
\hline$c_{\text {surf }, k}$ & Concentration of surface species $\mathrm{k}$ & {$\left[\mathrm{mol} / \mathrm{m}^{2}\right]$} \\
\hline$c_{t}$ & Total molar concentration. & {$\left[\mathrm{mol} / \mathrm{m}^{3}\right]$} \\
\hline$d_{0}$ & Characteristic pore diameter & {$[\mathrm{m}]$} \\
\hline$d_{m}$ & Diameter of molecules & {$[\mathrm{m}]$} \\
\hline$d_{p}$ & Diameter of matrix particle & {$[\mathrm{m}]$} \\
\hline$D_{i j}$ & Ordinary binary diffusion coefficients & {$\left[\mathrm{m}^{2} / \mathrm{s}\right]$} \\
\hline$D_{i}^{e}$ & Effective diffusion coefficient of species $i$ & {$\left[\mathrm{~m}^{2} / \mathrm{s}\right]$} \\
\hline$D_{i B}^{e}$ & Effective bulk diffusion coefficient of species $i$ & {$\left[\mathrm{~m}^{2} / \mathrm{s}\right]$} \\
\hline$D_{i M}^{e}$ & Effective Knudsen diffusion coefficient of species i & {$\left[\mathrm{m}^{2} / \mathrm{s}\right]$} \\
\hline$E$ & Activation energy & {$[\mathrm{kJ} / \mathrm{mol}]$} \\
\hline$F$ & Faraday Constant & $96,485[\mathrm{C} / \mathrm{mol}]$ \\
\hline$\hat{g}$ & Molar gibbs energy & {$[\mathrm{J} / \mathrm{mol}]$} \\
\hline$\hat{h}$ & Molar enthalpy & {$[\mathrm{J} / \mathrm{mol}]$} \\
\hline$i$ & Current density & {$\left[\mathrm{A} / \mathrm{cm}^{2}\right]$} \\
\hline$i_{0}$ & Exchange current density & {$\left[\mathrm{A} / \mathrm{cm}^{2}\right]$} \\
\hline$J_{k}$ & Molar flux of gas species $\mathrm{k}$ & {$\left[\mathrm{mol} / \mathrm{m}^{2} \cdot \mathrm{sec}\right]$} \\
\hline$k_{B}$ & Boltzmann constant & {$[\mathrm{J} / \mathrm{K}]$} \\
\hline$k$ & Reaction rate constant & {$[\mathrm{mol}, \mathrm{m}, \mathrm{sec}]$} \\
\hline$k_{i, f}$ & Forward reaction constant of reaction $\mathrm{i}$ & Dimensionless \\
\hline$k_{i, b}$ & Bckward reaction constant of reaction $i$ & Dimensionless \\
\hline$k_{i, a}$ & Anodic thermal reaction rate constants of reaction $i$ & {$[\mathrm{~mol}, \mathrm{~m}, \mathrm{sec}]$} \\
\hline$k_{i, c}$ & Cathodic thermal reaction rate constants of reaction $i$ & {$[\mathrm{~mol}, \mathrm{~m}, \mathrm{sec}]$} \\
\hline$K_{g}$ & Number of gas species & Dimensionless \\
\hline$K_{s}$ & Number of surface species & Dimensionless \\
\hline$K_{n}$ & Knudsen number & Dimensionless \\
\hline$l$ & Distance between two points in a straight line. & {$[\mathrm{m}]$} \\
\hline$l^{e}$ & Effective length between two points & [m] \\
\hline$M_{i}$ & Molar mass of species i & {$[\mathrm{kg} / \mathrm{mol}]$} \\
\hline$n$ & Number of molecules per unit volume & {$\left[1 / \mathrm{m}^{3}\right]$} \\
\hline$p$ & Pressure & {$\left[\mathrm{N} / \mathrm{m}^{2}\right]$} \\
\hline$P$ & Pressure & {$[$ Atm $]$} \\
\hline$R_{g a s, i}$ & Rate of homogeneous reaction $\mathrm{i}$ & {$\left[\mathrm{mol} / \mathrm{m}^{3}\right]$} \\
\hline
\end{tabular}




\begin{tabular}{|lll|}
\hline$R_{\text {surface, } i}$ & Rate of heterogeneous reaction i & {$\left[\mathrm{mol} / \mathrm{m}^{2}\right]$} \\
$\mathfrak{R}$ & Universal gas constant & $8.314[\mathrm{~J} / \mathrm{mol} \cdot \mathrm{K}]$ \\
$\hat{s}$ & Molar entropy & {$[\mathrm{J} / \mathrm{mol} \cdot \mathrm{K}]$} \\
$\dot{s}_{\text {gas }, k}$ & Production rates of the species i by homogeneous reactions & {$\left[\mathrm{mol} / \mathrm{m}^{3} \cdot \mathrm{sec}\right]$} \\
$\dot{S}_{\text {surface }, k}$ & Production rates of the species i by heterogeneous reactions & {$\left[\mathrm{mol} / \mathrm{m}^{2} \cdot \mathrm{sec}\right]$} \\
$S_{i}^{e}$ & Local adsorption probability of gas species i & Dimensionless \\
$S_{i}^{0}$ & Sticking coefficient & Dimensionless \\
$T$ & Temperature & {$[\mathrm{K}]$} \\
$V$ & Convection velocity & {$[\mathrm{m} / \mathrm{sec}]$} \\
$V^{D}$ & Diffusion velocity & {$[\mathrm{m} / \mathrm{sec}]$} \\
$\forall_{i}$ & Partial molar volume of species i & {$\left[\mathrm{m}^{3} / \mathrm{mol}\right]$} \\
$\forall_{\text {void }}$ & Void volume & {$\left[\mathrm{m}^{3}\right]$} \\
$\forall_{\text {material }}$ & Superficial volume of a material & {$\left[\mathrm{m}^{3}\right]$} \\
$W_{\text {rev }}$ & Maximum reversible work & {$[\mathrm{J}]$} \\
$X_{i}$ & Mole fraction of species i & Dimensionless \\
\hline
\end{tabular}

\begin{tabular}{|lll|}
\hline Greek & Meaning & Common Units \\
Symbol & & \\
$\beta_{i, a}$ & Anodic charge transfer coefficient & Dimensionless \\
$\beta_{i, c}$ & Cathodic charge transfer coefficient & Dimensionless \\
$\varepsilon$ & Porosity & Dimensionless \\
$\mathcal{E}_{r e v}$ & Equilibrium reversible potential & {$[\mathrm{V}]$} \\
$\mathcal{E}_{a}$ & Electric potential & {$[\mathrm{V}]$} \\
$\mathcal{E}_{a, e q}$ & Electric potential at equilibrium & {$[\mathrm{V}]$} \\
$\varepsilon_{C O(s)}$ & CO(s) coverage dependent activation energy & {$[\mathrm{kJ} / \mathrm{mol}]$} \\
$\varepsilon_{i j}$ & Characteristic Lennard-Jones energy & {$[\mathrm{J}]$} \\
$\zeta$ & Friction coefficient & {$\left[\mathrm{J} \cdot \mathrm{sec} / \mathrm{m}^{2} \cdot \mathrm{mol}\right]$} \\
$\eta_{a}$ & Activation overpotential & {$[\mathrm{V}]$} \\
$\eta_{a, a}$ & Activation overpotential at the anode & {$[\mathrm{V}]$} \\
$\eta_{a, c}$ & Activation overpotential at the cathode & {$[\mathrm{V}]$} \\
$\eta_{c o n c, a}$ & Concentration overpotential at the anode & {$[\mathrm{V}]$} \\
$\eta_{c o n c, c}$ & Concentrattion overpotential at the cathode & {$[\mathrm{V}]$} \\
$\eta_{\text {ohm }}$ & Ohmic overpotential & {$[\mathrm{V}]$} \\
$\theta_{i}$ & Coverage of species i & Dimensionless \\
$\theta_{v}$ & Vacancy coverage & Dimensionless \\
$\lambda$ & Mean free path & {$[\mathrm{m}]$} \\
$\mu$ & Electrochemical potential & {$[\mathrm{J} / \mathrm{mol}]$} \\
$\mu^{v}$ & Viscosity & {$[\mathrm{kg} \cdot \mathrm{m} / \mathrm{sec}]$} \\
$\mu_{m i x}^{v}$ & Mixture viscosity & {$[\mathrm{kg} \cdot \mathrm{m} / \mathrm{sec}]$} \\
\hline & &
\end{tabular}




\begin{tabular}{|c|c|c|}
\hline$v_{i}$ & Stoichiometric coefficient of species i & Dimensionless \\
\hline$v_{i, k}$ & Stoichiometric coefficient of the species $k$ in reaction $i$ & Dimensionless \\
\hline$v_{v}$ & Stoichiometric coefficient of vacancies & Dimensionless \\
\hline$\sigma$ & Zero-energy collision diameter & {$[\stackrel{0}{A}]$} \\
\hline$\tau$ & Tortuosity & Dimensionless \\
\hline$\Omega_{D, i j}$ & Dimensionless collision integral function & Dimensionless \\
\hline
\end{tabular}

\begin{tabular}{|ll|}
\hline Subscript & Meaning \\
$a$ & Activation or anode \\
$b$ & Backward \\
$B$ & Bulk \\
$c$ & Cathode \\
$c o n c$ & Concentration \\
$e q$ & Equilibrium \\
$f$ & Forward \\
$g$ & Gas species \\
$i, j, k$ & Species \\
$m$ & Molecule \\
$M$ & Matrix \\
$o h m$ & Ohmic \\
$p$ & Particle \\
$s$ & Surface species \\
$t$ & Total \\
$v$ & Vacancy \\
\hline
\end{tabular}

\begin{tabular}{|ll|}
\hline Superscript & Meaning \\
$e$ & Effective \\
$D$ & Diffusion \\
$v$ & Viscosity \\
\hline
\end{tabular}




\section{Chapter 1 Introduction}

\subsection{Motivation}

Global energy consumption has been on a growth trajectory, with a positive second derivative. As the world population grows and the energy use of developing countries expands to level closer to those observed in developed countries, this trend is expected to continue. Developed countries consume energy at multiple rates of those of developing countries and a quarter of the world's populations have no access to electricity, where one third rely on traditional biomass for most of their energy needs. Currently, fossil fuels constitute more than $85 \%$ of the total energy consumption worldwide. However, the amount of recoverable fossil fuels is finite and is likely to get more expensive as resources are depleted. Furthermore, evidence suggests that the rise of atmospheric $\mathrm{CO}_{2}$ due to the combustion of fossil fuels is correlated with the global warming. Thus, considerable effort should be made to develop efficient energy conversion devices with minimal negative environmental impact. The fuel cell is considered an attractive alternative to combustion engines because of its silent operation, high efficiency and low emission.

Our dependence of hydrocarbon fuels as the primary energy source will continue for several decades given the current infrastructure and its dominance in the current source options. Thus, the improvement in hydrocarbon-based conversion technology should have a strong near-term impact. The Solid Oxide Fuel Cell is a promising technology because it can use hydrocarbons directly, and it shows the highest energy-efficiency among fuel cells. 
It can also be hybridized with a gas turbine to increase the overall efficiency further.

Quantitative models of SOFC are valuable in the interpretation of experimental observations and in the development and optimization of fuel cell based systems. The models can be used to evaluate the effect of the design and operating conditions on the cell performance. Mathematical fuel cell models can help explain the governing physics and chemistry, focus experimental development effort, support system design and optimization, support or form the basis of control algorithm, and evaluate the technical and economic suitability of fuel cells in different applications

\subsection{Introduction to Fuel Cells}

\subsubsection{Definition}

Fuel cells are electrochemical devices that convert chemical energy in the fuel to electrical energy directly, promising power generation with high efficiency and low environmental impact. Fuel cells operate isothermally and hence are not limited by thermodynamic limitations of heat engines such as the Carnot efficiency. Therefore, the theoretical conversion efficiency of a fuel cell is very high. In addition, because combustion is avoided, fuel cells produce power with minimal pollutants.

The basic physical structure of a fuel cell is the membrane-electrode assembly (MEA), which consists of an electrolyte layer sandwiched between an anode and a cathode. A schematic presentation of MEA with the reactant/product gases at both sides and the ion conduction flow direction through the cell is show in Figure 1-1. 


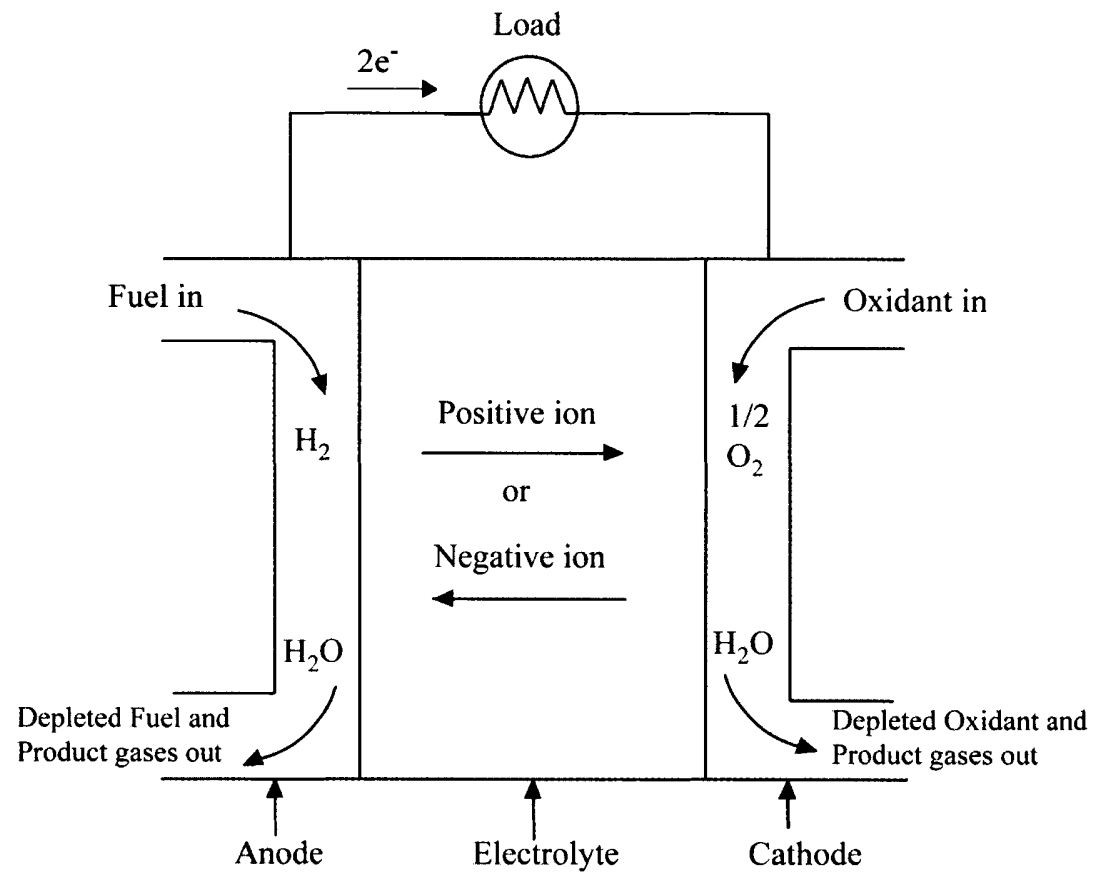

Figure 1-1 The Schematics of Fuel Cells

In a typical fuel cell, the fuel is fed continuously to the anode and the oxidant is fed continuously to the cathode. Electrochemical reactions occur at the interface between both electrodes and electrolyte to produce ionic current through the electrolyte, while driving a complementary electronic current on the external circuit to perform work on the load.

\subsubsection{Components}

The electrodes conduct electrons away from or into the triple phase boundary (TPB) interface once they are formed. Moreover, they provide current collection, and connection with either other cells or the load. They ensure that reactant gases are well distributed over the cell area, and that reaction products are efficiently led away to the bulk 
gas phase. As a consequence, the electrodes are typically porous and made of an electrically conductive material.

The electrolytes are ionic conductor but are impervious to neutral gases in order to prevent the fuel and oxidant streams from directly mixing and reacting. Furthermore, they have negligible electronic conductivity.

The regions in which the actual electrochemical reactions occur are found where either electrode meets the electrolyte. It is referred to as triple-phase-boundary (TPB) because it is exposed to the reactant, in electrical contact with the electrode, and in ionic contact with the electrolyte. The TPB contains sufficient electro-catalyst for the reaction to proceed at the desired rate even at the lower temperature of fuel cell operation.

\subsubsection{Stacks}

The voltage of an individual cell ranges from about one volt at open circuit to around one-half volt at maximum power density. The system voltage can be increased by stacking a number of cells connected electrically in series. A fuel-cell stack is composed of layers of cell. Figure 1-2 illustrates a section of a planar stack architecture where the flow channels are formed in the interconnect material. Planar stacks can be characterized according to the gas flow: 1) Cross-flow where air and fuel flow perpendicular to each other, 2) Co-flow where air and fuel parallel and in the same direction, 3) Counter-flow where air and fuel flow parallel but in opposite directions, 4) Serpentine flow where air or flow follow a zig-zag path, and 5) Spiral flow where the cell is circular 


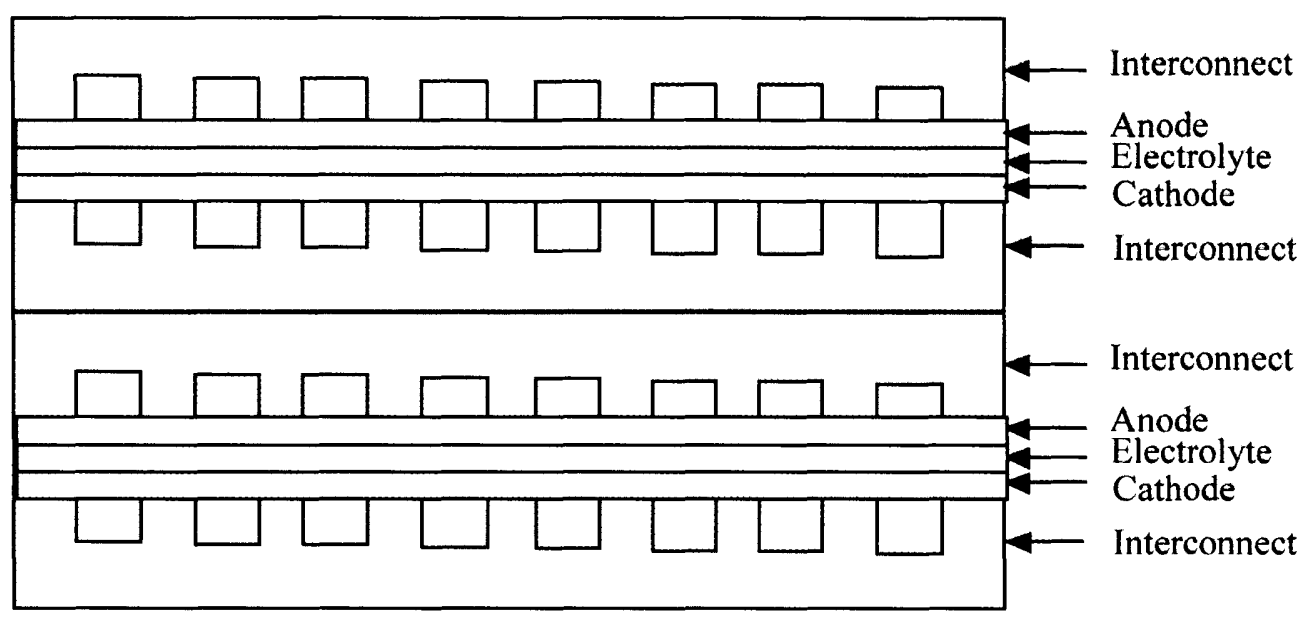

Figure 1-2 Fuel Cell Stacks

\subsubsection{Types}

Fuel cells are classified according to the electrolyte employed. The choice of electrolyte determines the electrode reactions, the type of ions that carry the current across the electrolyte, and the operating temperature range of the fuel cell. Moreover, the operating temperature dictates the degree of fuel pre-processing required and the physicochemical and thermo-mechanical properties of materials used in cell components. There are five types of fuel cell: 1) polymer electrolyte membrane fuel cell (PEMFC), 2) alkaline fuel cell (AFC), 3) phosphoric acid fuel cell (PAFC), 4)molten carbonate fuel cell (MCFC), and 5) solid oxide fuel cell (SOFC). The materials used in these cells, typical operating temperature and the charge carrier are shown next.

\begin{tabular}{|l|l|l|l|l|l|}
\hline & PEFC & AFC & PAFC & MCFC & SOFC \\
\hline Electrolyte & $\begin{array}{l}\text { Hydrated } \\
\text { polymeric } \\
\text { ion } \\
\text { exchange }\end{array}$ & $\begin{array}{l}\text { Potassium } \\
\text { Hydroxide } \\
\text { in asbestos } \\
\text { matrix }\end{array}$ & $\begin{array}{l}\text { Liquid } \\
\text { phosphoric } \\
\text { acid in SiC }\end{array}$ & $\begin{array}{l}\text { Liquid } \\
\text { molten } \\
\text { carbonate } \\
\text { in LiAlO }\end{array}$ & $\begin{array}{l}\text { Perovskites } \\
\text { (Ceramics) }\end{array}$ \\
\hline
\end{tabular}




\begin{tabular}{|l|l|l|l|l|l|}
\hline & membranes & & & & \\
\hline Catalyst & Platinum & Platinum & Platinum & $\begin{array}{l}\text { Electrode } \\
\text { material }\end{array}$ & $\begin{array}{l}\text { Electrode } \\
\text { material }\end{array}$ \\
\hline $\begin{array}{l}\text { Operating } \\
\text { Temperature }\end{array}$ & $40 \sim 80^{\circ} \mathrm{C}$ & $65 \sim 250^{\circ} \mathrm{C}$ & $205^{\circ} \mathrm{C}$ & $650{ }^{\circ} \mathrm{C}$ & $600 \sim 1000^{\circ} \mathrm{C}$ \\
\hline $\begin{array}{l}\text { Charge } \\
\text { carrier }\end{array}$ & $H^{+}$ & $\mathrm{OH}$ & $H^{+}$ & $\mathrm{CO}_{3}{ }^{2-}$ & $\mathrm{O}^{2-}$ \\
\hline
\end{tabular}

Table 1.1. Fuel Cell Types

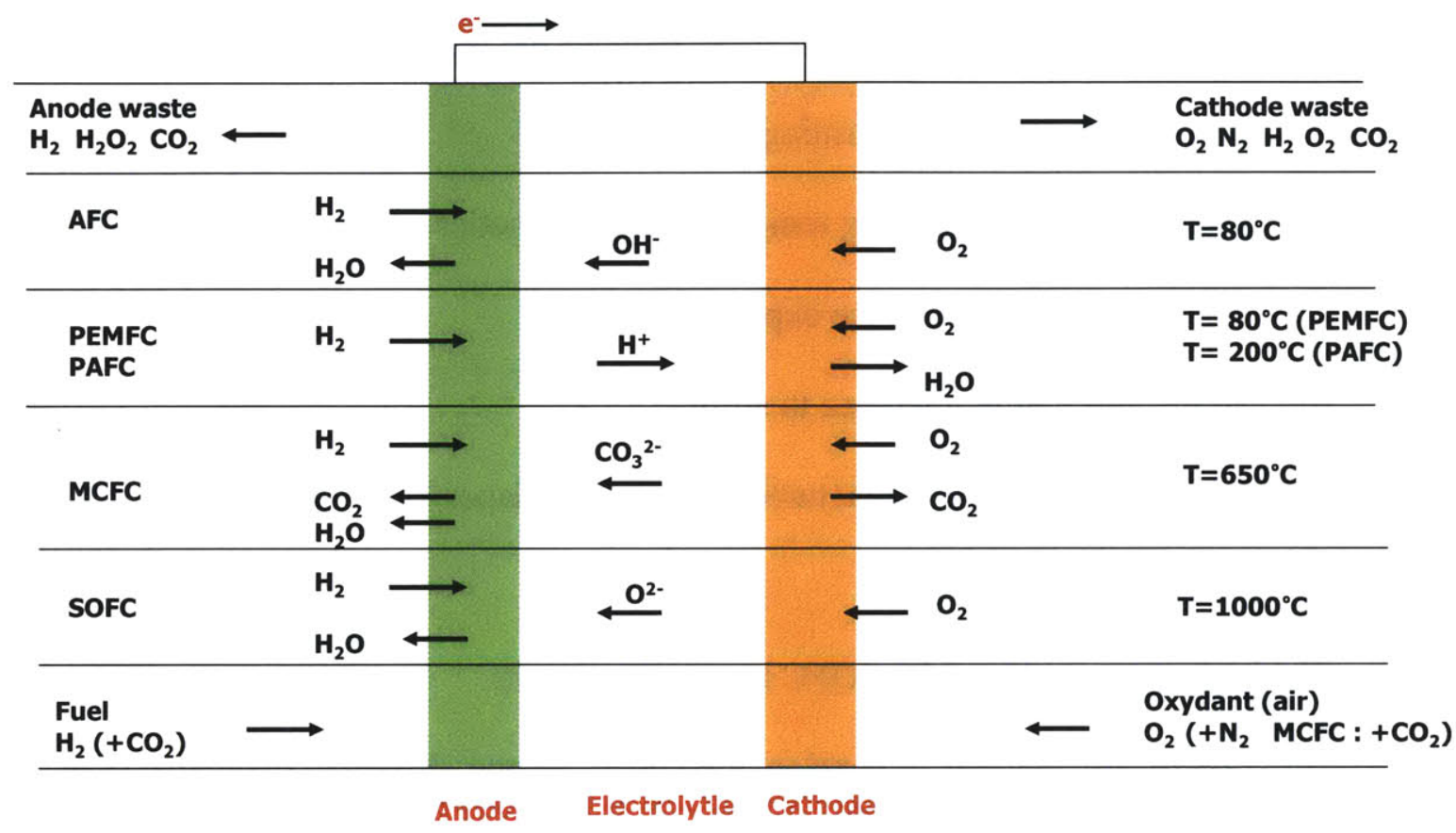

Figure 1-3 Fuel Cell Types

\subsection{Solid Oxide Fuel Cell}

\subsubsection{Advantages and Disadvantage of SOFC}

(1) Efficiencies of SOFC's ranging from around 40 to over 50 percent have been demonstrated.

(2) The high operating temperature of the SOFC allows us to use most of the 
waste heat for cogeneration or in bottoming cycles.

(3) Hybrid fuel cell/reheat gas turbine cycles that reach efficiencies greater than 70 percent based on LHV, using demonstrated cell performance, have been proposed [2].

(4) SOFC can be operated with a variety of fuels, including hydrogen, CO, hydrocarbons or mixtures of these without the requirement for upstream fuel preparation, such as reforming.

(5) Due to its high operating temperature, the kinetics of a cell is relatively fast, alleviating the need to use expensive catalyst.

(6) SOFC has a high tolerance to sulfur.

(7) The cell can be manufactured in various shapes because the electrolyte is solid.

The high temperature of the SOFC has its drawbacks.

(1) There are thermal expansion mismatch among different materials used to construct the cell, and sealing between cells is difficult in the flat configuration.

(2) The operating temperature places sever constraints on materials selection and results in difficult fabrication process.

(3) Corrosion of metal stack components (such as the interconnects in some designs) is a challenge.

\subsubsection{Physics}


Figure 1-4 illustrates the essential components in an SOFC. The MEA consists of an electrolyte layer in contact with an anode and a cathode on either side.

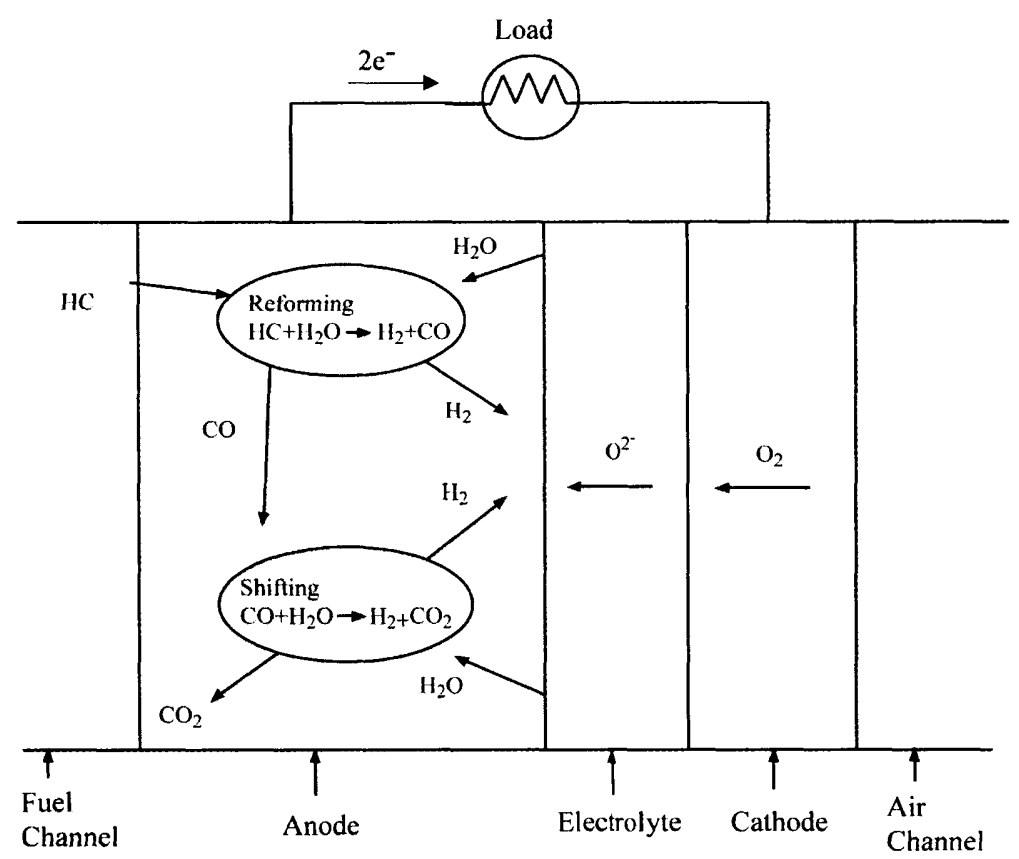

Figure 1-4 The Schematics of Solid Oxide Fuel Cell

SOFCs involve complex physicochemical processes. Oxygen is electrochemically reduced at the cathode-electrolyte-air triple phase boundary (TPB). In global terms, electrons from the cathode react with oxygen molecules in the air to deliver oxygen ions into the electrolyte via a charge-transfer reaction

$$
O_{2}(g)+4 e^{-}(c) \leftrightarrow 2 O^{2-}(e)
$$

The triple phases are denoted as (g) for the gas, (c) for the cathode, and (e) for the electrolyte.

Oxygen ions migrated through the electrolyte via a vacancy-hopping mechanism 
toward the anode-electrolyte-fuel TPB, whereupon they participate in the electrochemical oxidation of fuels. For example, a global $H_{2}$ oxidation may be written as

$$
\mathrm{H}_{2}(g)+\mathrm{O}^{2-}(e) \leftrightarrow \mathrm{H}_{2} \mathrm{O}(\mathrm{g})+2 e^{-}(a)
$$

The triple phases are denoted as (g) for the gas, (a) for the anode, and (e) for the electrolyte. The gas-phase $\mathrm{H}_{2}$ reaction with the $\mathrm{O}^{2-}$ from the electrolyte to produce steam in the gas phase and deliver electrons in the anode.

As long as a load is connected between the anode and cathode, the electrons from the anode will flow through the load back to the cathode, therefore, an electric current $\mathrm{i}$ will flow through the circuit.

\subsubsection{Materials}

The electrolyte should not only be highly ionically conducting, but should also be impermeable to gases, electronically resistive and chemically stable under a wide range of condition. Moreover, the electrolyte must exhibit sufficient mechanical and chemical integrity so as not to develop cracks or pores either during manufacture or in the course of long-term operation.

The ideal electrode must transport gaseous species, and electrons; and at TPB, the electro-catalysts must rapidly catalyze electro-oxidation (anode) or electro-reduction (cathode) reactions. Thus, the electrodes must be porous, electronically conducting, electrochemically active at the interface, and have high surface areas.

To extend the effective triple-phase regions and to facilitate the charge-transfer

processes, SOFC electrodes are fabricated as mixed ionic and electronic conducting 
(MIEC) porous ceramics or ceramic-metallic composites (cermets), which provide interpenetrating, continuous, three-dimensional electron, ion, and gas-transport network.

The interconnect in the SOFC stack not only provides the electrical conductor between adjacent unit cells but can also serve to distribute fuel and air flows. Interconnect materials for SOFC fall into two categories: conductive ceramic materials for operation at high temperature $\left(900 \sim 1000^{\circ} \mathrm{C}\right)$ and metallic alloys for lower temperature operation. One problem with ceramic interconnects is that they are rigid and weak. Metallic interconnects have higher electronic and thermal conductivity and can also substantially reduce cost. The following table shows the typical material, characteristic and problems of each component.

\begin{tabular}{|c|c|c|c|}
\hline Components & Material & Characteristics & Problems \\
\hline Electrolyte & $\begin{array}{l}\mathrm{YSZ} \\
\left(\mathrm{Y}_{2} \mathrm{O}_{3^{-}}\right. \\
\text {stabilized } \\
\left.\mathrm{ZrO}_{2}\right)\end{array}$ & $\begin{array}{l}\text { - Ion conductor } \\
\text { - } 10 \text { Ohm-cm (Resistivity) }\end{array}$ & - Very high resistance \\
\hline Anode & $\mathrm{Ni} / \mathrm{YSZ}$ & $\begin{array}{l}\text { - Electric conductor } \\
\text { - Ion conductor } \\
\text { - High activity for electrochemical } \\
\text { reaction and reforming } \\
-3-6 \text { Ohm-cm (Resistivity) }\end{array}$ & $\begin{array}{l}\text { - Sensitive to sulfur } \\
\text { - Ni reoxidizes readily } \\
\text { - Poor activity for direct } \\
\text { oxidation } \\
\text { - Propensity for carbon } \\
\text { formation when exposed } \\
\text { hydrocarbons }\end{array}$ \\
\hline Cathode & $\begin{array}{l}\text { LSM } \\
(\mathrm{Sr}-\text { doped } \\
\left.\text { LaMnO }_{3}\right)\end{array}$ & $\begin{array}{l}\text { - Electron conducgtor } \\
\text { - Ion conductor } \\
\text { - } 0.01 \mathrm{Ohm}-\mathrm{cm} \text { (Resistivity) }\end{array}$ & $\begin{array}{l}\text { - Conductivity is inadequate for } \\
\text { lower-temperature cells. }\end{array}$ \\
\hline Interconnect & $\begin{array}{l}\text { Ceramic } \\
\text { Metallic alloy }\end{array}$ & $\begin{array}{l}\text { - Ceramic for high temperature } \\
\left(900 \sim 1000^{\circ} \mathrm{C}\right) \\
\text { - Metallic alloy for lower } \\
\text { temperature operation } \\
\text { - } 1 \text { Ohm-cm (Resistivity) } \\
\end{array}$ & - Ceramic is rigid and weak \\
\hline
\end{tabular}

Table 1.2 Typical Materials of SOFC 


\subsubsection{Current SOFC Research foci}

Current efforts in SOFC research are aimed at

(1) reducing operating temperatures to $500 \sim 800^{\circ} \mathrm{C}$ to permit the use of low-cost ferric alloys for the interconnect component of the fuel cell stack

(2) enabling the direct utilization of hydrocarbon fuels [3].

Achieving these goals will require the development of highly active cathode materials and highly selective anode materials that do not catalyze carbon deposition.

\section{1) Lowering the temperature}

Reducing the operating temperature allows the use of metals, which typically have lower fabrication costs than ceramics and reduces the likelihood of cracks developing upon thermal cycling, which extends the cell life-time. Lowering the operating temperature below $1000{ }^{\circ} \mathrm{C}$ allows the use of higher-performance and lower-cost materials for the cell and balance-of-plant, reduces stack thermal insulation requirements, and increases cell life because of reduced thermal degradation and thermal cycling stress[4]. By lowering the operating temperature further below $700{ }^{\circ} \mathrm{C}$, low-cost ferric stainless steels could be used for stack components such as interconnects and gas manifolds. Also, direct oxidation of methane without carbon deposition is possible at $<650^{\circ} \mathrm{C}$. However, it accompanies some problems that electrolyte ohmic resistance increases and the activity of the traditional cathode materials for electrochemical reduction of oxygen becomes poor. As for the cathode poor activity, significant research effort is focused on the development of new material. In order to minimize the electrolyte ohmic resistance, SOFC is manufactured by 
reducing the thickness of the electrolyte such as the case in the planar-type electrodesupported structure. However, it has been reported that cathode-supported SOFC has some manufacturing challenges such as difficulty to achieve full density in a $\mathrm{YSZ}\left(\mathrm{Y}_{2} \mathrm{O}_{3}\right.$-stabilized $\mathrm{ZrO}_{2}$ ) electrolyte without over-sintering an $\operatorname{LSM}\left(\mathrm{Sr}\right.$-doped $\left.\mathrm{LaMnO}_{3}\right)$ cathode[2]. Hence, anode-supported planar SOFC is more promising and is adopted for our MEA model simulation.

\section{(2) Direct use of hydrocarbon}

The great advantage of SOFC systems for highly efficient electric power generation lies in its potential for direct use of hydrocarbon fuels, without the requirement for upstream fuel preparation, such as reforming. Direct oxidation of direct-oxidation fuel cells is theoretically possible in SOFCs because $O^{2-}$ anions, not protons, are the species that are transported through the electrolyte membrane[5]. The primary difficulty encountered during direct oxidation of hydrocarbons is rapid deactivation due to carbon deposition on the anode. Nickel(Ni) in the anode catalyses formation of graphite from hydrocarbons The conventional approach to avoid carbon deposition is to simply add steam or oxygen with the fuel. By adding steam, the system becomes complex and the fuel is diluted. Partial oxidation by the added oxygen leads to a loss of fuel efficiency. A less conventional approach is to run SOFC within a narrow range of operating temperature where carbon formation is not favored [6]. For the hydrocarbons except methane, there is no thermodynamic window of stability at practical temperatures [5]. As a new approach, research has progressed to develop new anode materials that do not catalyze the carbon 
formation.

\subsubsection{Models}

Mathematical models are more important for fuel cell development because of the complexity of fuel cells and fuel cell systems, and because of the difficulty in experimentally characterizing the inner workings of fuel cells such as physical access limitations. While fundamentally the constitutive equations underlie all models, their level of detail, level of aggregations, and numerical implementation method vary widely. A useful categorization of fuel cell models is made by level of aggregation.

\section{(1) $3-\mathrm{D}$ cell/stack model}

Fuel cell stack models are used to evaluate different cell and stack geometries and help understand the impact of stack operating conditions on fuel cell stack performance. A model that represents the key physico-chemical characteristics of stacks is indispensable for the optimization of stack design. Usually, the models must represent electrochemical reactions, ionic and electronic conduction, and heat and mass transfer within the cell. Most of these models rely on existing modeling platforms such as commercial Computational Fluid Dynamics (CFD) codes and structural analysis codes.

(2) 1-D MEA models

1-D MEA models are critical for constructing 3-D models, but they are also highly useful in interpreting and planning button cell experiments. Generally, they include 
transport and thermo-chemical reactions in the electrodes, ion transport in the electrolyte and electrochemical reactions at or near the TPB. Some models are based on numerical discretization methods, while others are using analytical approach.

\section{(3) Electrode kinetic Models}

Since the essential part of fuel cells is the electrochemical reactions at the TPB, the electrode model is critical in the development of all fuel cell models. The individual reaction steps at or near the TPB are considered. Although analytical solutions such as in Butler-Volmer form can be found if a single rate-determining step is considered, generally a numerical solution is necessary for multi-step reactions. This approach can give insight into the rate-determining electrochemical processes. When optimizing electro-catalysis or studying direct oxidation of hydrocarbon, the models can be very enlightening.

\subsection{Conclusion}

A Fuel cell is considered an attractive alternative to combustion engines due to its high efficiency and minimal environmental impact. Among fuel cells, SOFC stands out because of its high energy conversion efficiency and the potential to use hydrocarbons directly, hence exploiting the current infrastructure and leading to a strong near-term impact on energy consumption. The current SOFC research foci are to reduce the operating temperature and to directly utilize hydrocarbon fuels. In order to achieve these two objectives, further improve the efficiency and optimize the design of SOFC, the mathematical models are indispensable. In the next chapters, we shall review the 
methodology of modeling one dimensional MEA in Chapter 2 and construct and simulate one dimensional MEA model in Chapter 3. 


\section{Chapter 2 Modeling of SOFC MEA}

We present a framework for the simulation of the MEA of SOFC. This is a physically based, predictive, quantitative model that can be used for SOFC design and optimization.

We adopt a one-dimensional approach that is critical for constructing 3-D model and useful in interpreting and planning button cell experiments where the conditions in the channel can be assumed to be uniform. In addition, it is assumed that temperature is constant and uniform through the MEA.

The objective of the model is to calculate the polarization curve of the cell, that is, the dependence of the voltage across the cell on the current density. The measured/actual voltage or potential is the equilibrium thermodynamic potential reduced by the losses across the different components due to the finite rate transport, reaction kinetics of the thermo- and electro-chemical reactions, and the ohmic resistance.

\subsection{Equilibrium potential}

The equilibrium potential, $E_{r e v}$, can be calculated from the thermodynamics of the reaction, between the fuel and oxidizer, by combining the first and the second laws. The maximum work produced by a reversible process is given by

$$
W_{\text {rev }}=\sum_{\text {react }}\left(v_{i} \hat{g}_{i}\right)-\sum_{\text {prod }}\left(v_{i} \hat{g}_{i}\right)
$$

where $v_{i}$ is the stoichiometric coefficient of a constituent, $\hat{g}_{i}\left(T, P_{i}\right)=\hat{h}_{i}(T)-T \hat{s}_{i}\left(T, P_{i}\right)$ 
or $\hat{g}_{i}\left(T, P_{i}\right)=\hat{g}_{i}^{0}(T)+\Re T \ln \left(P_{i} / P_{0}\right)$ for an ideal gas

in which $\Re$ is universal gas constant $[\mathrm{J} / \mathrm{mol} \cdot \mathrm{K}], T$ is temperature $[\mathrm{K}], P_{i}$ is the partial pressure of gas species i $[\mathrm{Atm}]$, and the Gibbs free energy, $\hat{g}_{i}^{0}[\mathrm{~J} / \mathrm{mol}]$, is evaluated at atmospheric pressure.

The reversible work is the electrical work done by the fuel cell. That is

$$
\begin{gathered}
W_{\text {rev }}=z F E_{\text {rev }}=\sum_{\text {react }}\left(v_{i} \hat{g}_{i}\right)-\sum_{\text {prod }}\left(v_{i} \hat{g}_{i}\right) \\
z F E_{\text {rev }}=-\Delta G^{0}-\left[\sum_{\text {prod }}\left(v_{i} \Re T \ln \frac{P_{i}}{P_{0}}\right)-\sum_{\text {react }}\left(v_{i} \mathfrak{R} T \ln \frac{P_{i}}{P_{0}}\right)\right]
\end{gathered}
$$

where $z$ is the number of electrons participating in the reaction, $F$ is the Faraday constant $[\mathrm{C} / \mathrm{mol}]$, and $\Delta G^{0}=\sum_{\text {prod }}\left(v_{i} \hat{g}_{i}^{0}\right)-\sum_{\text {react }}\left(v_{i} \hat{g}_{i}^{0}\right)$.

Thus, the potential developed by a reversible cell at zero current is

$$
E_{r e v}=-\frac{\Delta G^{0}}{z F}-\frac{\Re T}{z F} \ln \frac{\prod_{\text {prod }} P_{i}^{v_{i}}}{\prod_{\text {react }} P_{i}^{v_{i}}}
$$

For a hydrogen fuel cell, $\mathrm{H}_{2}+\frac{1}{2} \mathrm{O}_{2} \leftrightarrow \mathrm{H}_{2} \mathrm{O}, \mathrm{z}=2$. Therefore,

$$
E_{\text {rev }}=-\frac{\Delta G^{0}}{2 F}-\frac{\Re T}{2 F} \ln \frac{\left(P_{\mathrm{H}_{2} \mathrm{O}}\right)^{1}}{\left(P_{\mathrm{H}_{2}}\right)\left(P_{\mathrm{O}_{2}}\right)^{1 / 2}}
$$

where $\Delta G^{0}=\hat{g}_{H_{2} O}^{0}-\hat{g}_{H_{2}}^{0}-\frac{1}{2} \hat{g}_{O_{2}}^{0}$

The first term on the right-hand side of Eq. 2-4 shows the effect of the temperature on the fuel cell while the second term shows the effect of the pressures and the temperature of the reactants and products on the cell voltage. 


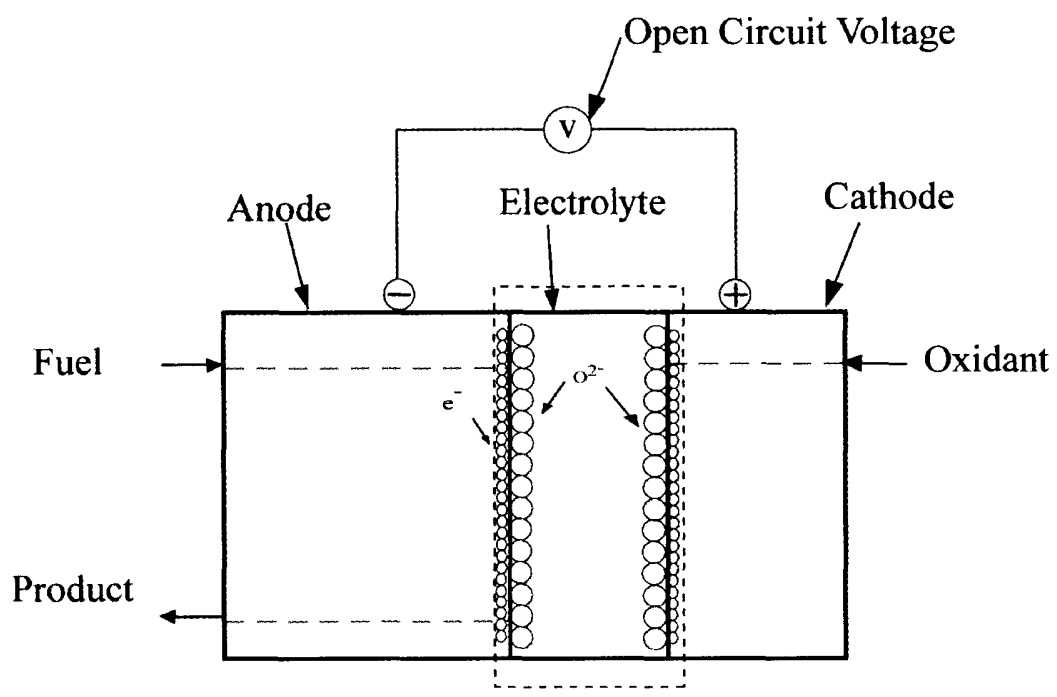

Figure 2-1 The Schematics of Fuel Cell in the Equilibrium State

Achieving a potential close to this limiting value requires that all internal irreversibilities be small. Many irreversibilities in a fuel cell scale with current density, and therefore are negligible near open circuit.

\subsection{Overpotentials}

In many cases, the measured open-circuit potential (OCV) will equal the potential developed by a reversible cell, known also as the Nernst potential. As the current flow increases, internal losses grow, and the cell potential drops. In other words, at finite current part of the available chemical potential is used to overcome internal losses, often called overpotentials. These losses include ohmic overpotential associated with ion transport through the electrolyte and electron transfer through the electrodes, activation overpotentials associated with the energy barriers of the charge-transfer reactions, and the 
concentration overpotentials associated with gas-phase species transport resistance through the electrodes.

The performance of an SOFC is often described by its voltage-current relationship, shown in Figure 2-2. At low and midrange currents, the response is mostly dominated by the charge transfer reaction kinetics, and is often described by the well-known ButlerVolmer equation. A linear central region is often attributed to Ohmic resistance. The high current region is dominated by a precipitous drop in the voltage (and power output) at a limiting, or maximum, current capacity. This phenomenon is often referred to as 'concentration overpotential'. Concentration overpotential is important because it defines the maximum current attainable from the device.

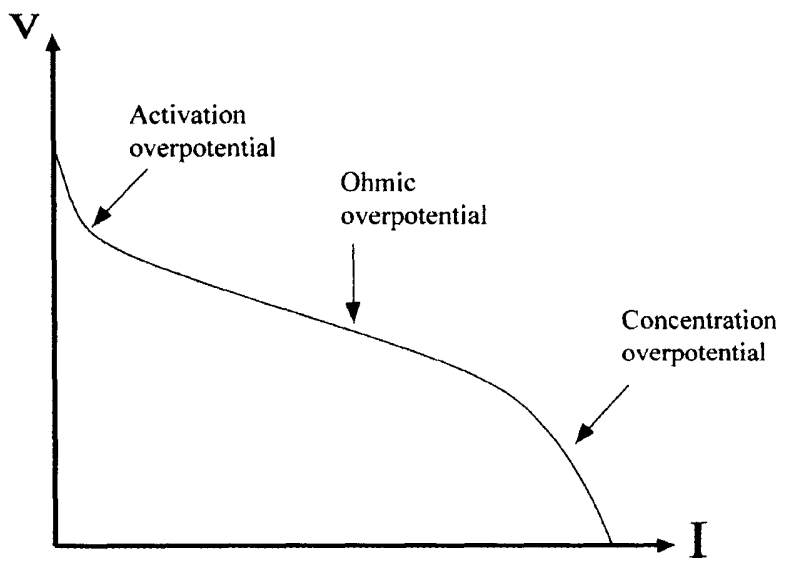

Figure 2-2 Typical Current-Voltage(I-V) Performance Curve

Thus, the operating cell voltage, $E$, can be written as

$$
E_{\text {cell }}=E_{\text {rev }}-\eta_{\text {conc }, a}-\eta_{a, a}-\eta_{\text {ohm }}-\eta_{\text {conc }, c}-\eta_{a, c}
$$

where $\eta_{c o n c, c}$ and $\eta_{c o n c, a}$ are the concentration overpotentials at the anode and the cathode, $\eta_{a, a}$ and $\eta_{a, c}$ the corresponding activation overpotentials, and $\eta_{o h m}$ the ohmic 
overpotential.

Next sections in this thesis develop models for each of these oeverpotentials, all of which are functions of the current density.

\subsubsection{Concentration Overpotential}

For open-circuit conditions, i.e. zero current flow, the species concentrations at the electrolyte interface, which is the triple-phase boundary, are the same as those in the bulk channel flow. However, when the current is flowing species concentrations at the triple phase boundaries are different from the bulk concentrations in the gas channel. This is because the reactants are transported across the electrodes while the products are transported back to the flow channels. Therefore, in evaluating the actual electrochemical potential of the fuel cell, the relevant reactants and products concentrations are those at the anode-electrolyte TPB, which are different from those in the fuel channel. The potential difference associated with the concentration variation is a concentration overpotential.

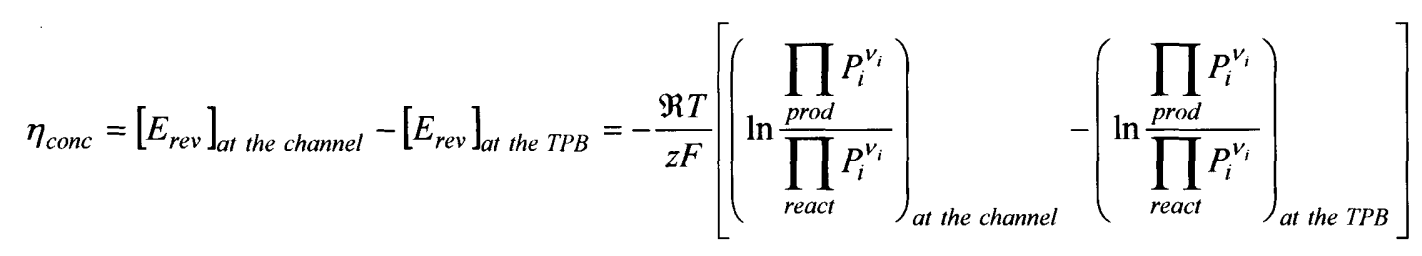

The dashed-line in the Figure 2-3 shows the concentration variation in the electrodes. 


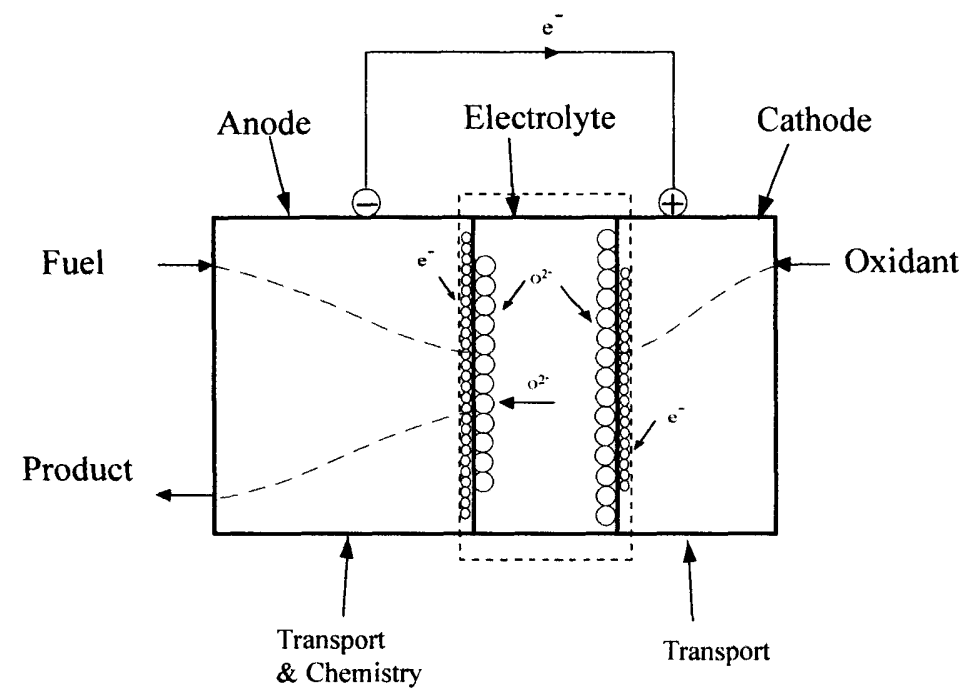

Figure 2-3 The Schematics of Fuel Cell in the Non-equilibrium state

Although these overpotentials have the unit of volts, it should be noticed that there is no voltage difference across the electrode that can be measured with a voltmeter. The concentration difference represents a loss of the potential to produce electric energy due to the drop in the reactants concentration across the electrode. It is a useful concept, especially when comparing the effects of transport and thermo-chemistry with those of other overpotentials.

To compute the concentration overpotentail, the concentrations of gas species at the TPB should be known. Next we develop a model for computing the concentrations of gas species at the TPB.

\section{(1) Conservation equation}

Consider reactive porous-media transport in an electrode such as those illustrated in Figure 2-4. 


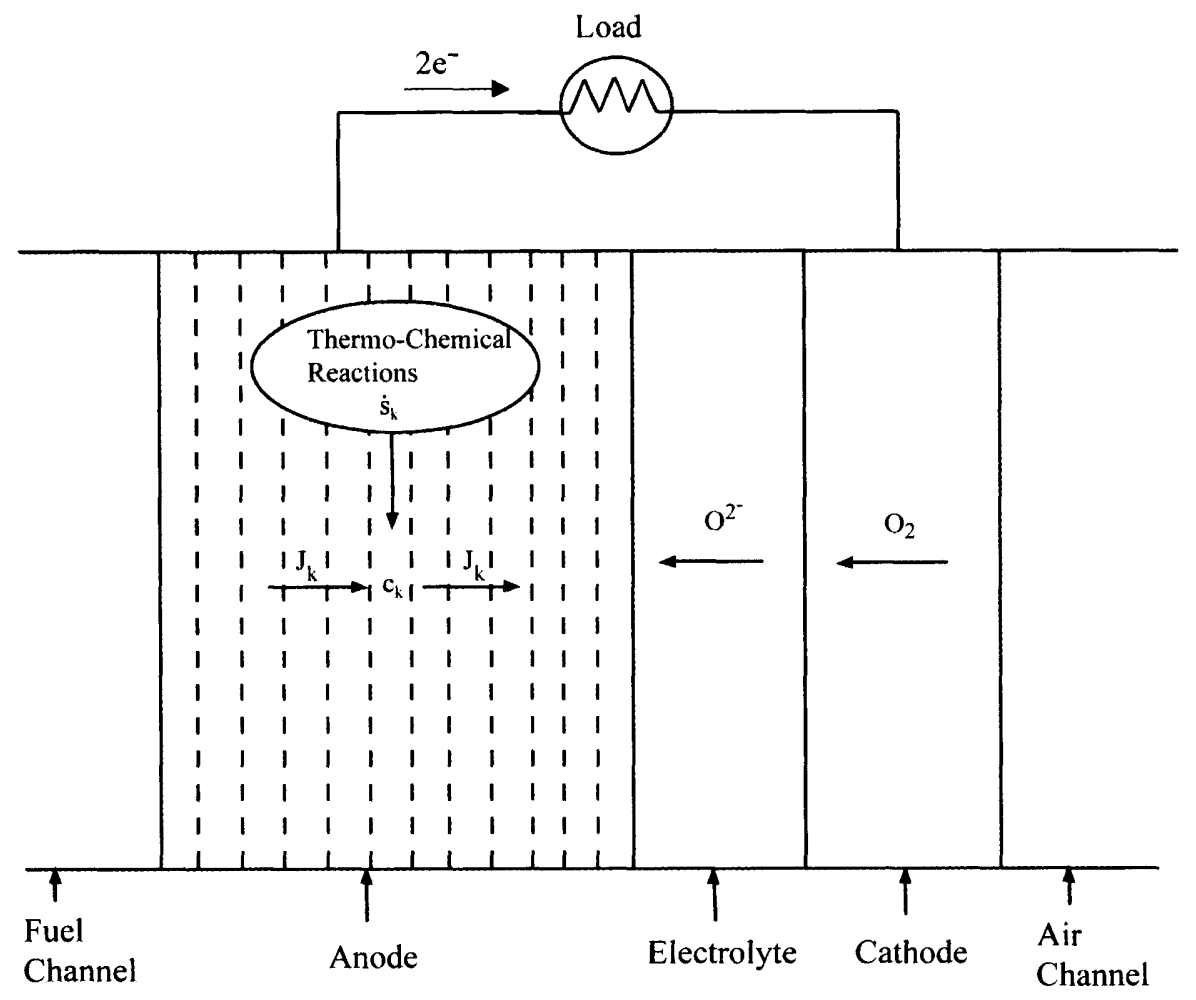

Figure 2-4 Mass Conservation in the Anode

The conservation equation of gas-phase species is

$$
\frac{\partial c_{k}}{\partial t}=A_{s} \dot{s}_{s u r f, k}+\dot{s}_{g a s, k}-\nabla \cdot J_{k} \quad\left(k=1, \ldots, K_{g}\right)
$$

where $c_{k}$ is the concentration of gas species $\mathrm{k}\left[\mathrm{mol} / \mathrm{m}^{3}\right], J_{k}$ is the molar flux of gas species $\mathrm{k}\left[\mathrm{mol} / \mathrm{m}^{2} \cdot \mathrm{sec}\right], \dot{s}_{\text {surf }, k}$ is the production rates of the gas species $\mathrm{k}$ on the surface by heterogeneous reactions $\left[\mathrm{mol} / \mathrm{m}^{2} \cdot \mathrm{sec}\right]$, the $A_{S}$ is the specific catalyst area per unit volume of electrode $[1 / \mathrm{m}], \dot{s}_{g a s, k}$ is production rates of the gas species $\mathrm{k}$ by homogenous reactions $\left[\mathrm{mol} / \mathrm{m}^{3} \cdot \mathrm{sec}\right]$, and $K_{g}$ is the total number of gas species. The molar flux will be determined by the Fick's Model(FM) or the Dusty Gas Model (DGM). The production rates of the gas 
species are obtained from the thermo-chemistry model.

The surface species conservation equation is as follows.

$$
\frac{\partial c_{\text {surf }, k}}{\partial t}=\dot{s}_{\text {surf }, k} \quad\left(k=1, \ldots, K_{s}\right)
$$

where $c_{s u r f, k}$ is the concentration of surface species $\mathrm{k}\left[\mathrm{mol} / \mathrm{m}^{2}\right], \dot{s}_{k}$ is the production rates of the surface species $\mathrm{k}$ by heterogeneous reactions $\left[\mathrm{mol} / \mathrm{m}^{2} \cdot \mathrm{sec}\right]$, and $K_{s}$ is the total number of surface species.

Unlike the gaseous species, the surface species are effectively immobile on length scales larger than an individual catalyst particle. Hence, the surface species transport over macroscopic distance is assumed negligible [7].

\section{(2) Transport}

\section{- Fick's Model (FM)}

FM is the simplest form used to describe the transport of components through the gas phase and within porous media. The general extended form of this model takes into account diffusion and convection transport and is given by [8]

$$
J_{i}=-D_{i}^{e} \nabla c_{i}+c_{i} V=-D_{i}^{e} \nabla c_{i}+c_{i} \frac{B_{0}}{\mu_{m i x}^{v}} \nabla p
$$

where $D_{i}^{e}$ is the effective diffusion coefficient of species i $\left[\mathrm{m}^{2} / \mathrm{s}\right], \mu_{m i x}^{v}$ is the mixture viscosity $[\mathrm{kg} \cdot \mathrm{m} / \mathrm{sec}], V$ is the convection velocity $[\mathrm{m} / \mathrm{sec}], B_{o}$ is the permeability $\left[\mathrm{m}^{2}\right]$, and $p$ is the pressure $[\mathrm{Pa}]$. The first and second terms on the right-hand side account for diffusion and convection transport, respectively.

The diffusion process within a pore typically consists of bulk diffusion and 
Knudsen diffusion. The relative importance of bulk diffusion and Knudsen diffusion is characterized by the Knudsen number $K_{n}=\frac{\lambda}{d_{0}}$, where $\lambda$ is the mean free path in the gas [m] and $d_{0}$ is a characteristic pore diameter [m]. From an order of magnitude analysis, and for $K_{n}<0.01$, bulk diffusion dominates, and when $K_{n}>10$, Knudsen diffusion dominates [9].

The mean free path is

$$
\lambda=\frac{1}{\sqrt{2} \pi d_{m}^{2} n}
$$

Eq. $2-11$

where $d_{m}$ is diameter of molecules [m] and $n$ is number of molecules per unit volume $\left[1 / \mathrm{m}^{3}\right]$, which is determined by ideal gas law. When the gases are hydrogen and water, the diameter of molecules are $0.5654 \times 10^{-9} \mathrm{~m}$ and $0.5282 \times 10^{-9} \mathrm{~m}$, respectively. Since the diameters are almost same, the calculated mean free paths are comparable, $1.04 \times 10^{-7} \mathrm{~m}$ and $1.19 \times 10^{-7} \mathrm{~m}$, respectively, based on hydrogen and water molecule diameter at $800^{\circ} \mathrm{C}$ and $1 \mathrm{~atm}$. For the average pore radius of electrodes, $5 \times 10^{-7} \mathrm{~m}$, Knudsen number $\left(=\lambda d_{0}\right)$ is about 0.1 .

Since the Knudsen number is 0.1 , both bulk diffusion and Knudsen diffusion are comparable and must be considered together.

The effective diffusion coefficient $D_{i}^{e}$ can be written by combining the effective bulk diffusion coefficient $D_{i B}^{e}$ and the effective Knudsen diffusion coefficient $D_{i M}^{e}$ as follows (Bosanquet formula) [10] 


$$
D_{i}^{e}=\left(\frac{1}{D_{i B}^{e}}+\frac{1}{D_{i M}^{e}}\right)^{-1}
$$

The effective Knudsen diffusion coefficient for the component $\mathrm{i}, D_{i M}^{e}$ in the multicomopnent mixture gas can be expressed as [11]

$$
D_{i M}^{e}=\frac{d_{o}}{3} \frac{\varepsilon}{\tau} \sqrt{\frac{8 R T}{\pi M_{i}}}
$$

Eq. $2-13$

where $M_{i}$ is molar mass of species $\mathrm{i}[\mathrm{kg} / \mathrm{mol}]$

In a multi-component gas system, the effective bulk diffusion coefficient of the species $i$ is given by [12]

$$
D_{i B}^{e}=\frac{1-X_{i}}{\sum_{k \neq i} \frac{X_{k}}{D_{i k}^{e}}}
$$

where $X_{i}$ is the mole fraction of species $\mathrm{i}$.

The $D_{i j}^{e}$ represents the effective binary diffusion coefficient in the porous medium. The $D_{i j}^{e}$ is related to the corresponding ordinary binary diffusion coefficient $D_{i j}$ as [13]

$$
D_{i j}^{e}=\frac{\varepsilon}{\tau} D_{i j}
$$

in which $\varepsilon$ is the porosity and $\tau$ is the tortuosity.

Porosity is defined as

$$
\varepsilon=\frac{\forall_{\text {void }}}{\forall_{\text {material }}}
$$

in which $\forall_{\text {void }}$ is a void volume and $\forall_{\text {material }}$ is the superficial volume of a material. 
Tortuosity is defined as

$$
\tau=\left(\frac{l^{e}}{l}\right)^{2}
$$

where $l^{e}$ is the effective length between two points through pores and $l$ is the distance between two points in a straight line.

According to Champan-Enskog kinetic theory, the binary diffusion coefficient $D_{i j}$ is derived as follows [14]

$$
D_{i j}=5.8765 \times 10^{-9} \frac{\sqrt{T^{3}\left(\frac{1}{M_{i}}+\frac{1}{M_{j}}\right)}}{P \sigma_{i j}^{2} \Omega_{D, i j}}
$$

where $\Omega_{D, i j}$ is a dimensionless collision integral function of the temperature and the intermolecular potential field for one molecule of $i$ and one of $j[14]$

$$
\Omega_{D, i j}=f c n\left(\frac{k_{B} T}{\varepsilon_{i j}}\right)
$$

where $k_{B}$ is the Boltzmann constant $[\mathrm{J} / \mathrm{K}]$ and $\varepsilon_{i j}$ is the characteristic LennardJones energy[J]. Here, $\sigma_{i j}$ and $\varepsilon_{i j}$ are calculated from the individual parameters using the approximate equations [14].

$$
\begin{array}{r}
\sigma_{i j}=\frac{\left(\sigma_{i}+\sigma_{j}\right)}{2} \\
\varepsilon_{i j}=\sqrt{\varepsilon_{i} \varepsilon_{j}}
\end{array}
$$

The mixture viscosity, $\mu_{m i x}^{v}$, is given as [14] 


$$
\mu_{m i x}^{v}=\sum_{i=1}^{n} \frac{X_{i} \mu_{i}^{v}}{\sum_{j=1}^{n} X_{j} \Phi_{i j}}
$$

in which

$$
\Phi_{i j}=\frac{1}{\sqrt{8}}\left(1+\frac{M_{i}}{M_{j}}\right)^{-1 / 2}\left[1+\left(\frac{\mu_{i}^{v}}{\mu_{j}^{v}}\right)^{1 / 2}\left(\frac{M_{j}}{M_{i}}\right)^{1 / 4}\right]^{2}
$$

The viscosity of each species is determined by [14]

$$
\mu^{v}=8.4411 \times 10^{-5} \frac{\sqrt{M T}}{\sigma^{2} \Omega_{\mu}}
$$

in which

$$
\Omega_{\mu}=f c n\left(\frac{k_{B} T}{\varepsilon}\right)
$$

The permeability $B_{0}$ is characteristic of the porous matrix structure and has to be determined experimentally, along with the porosity and tortuosity factors. If the porous electrodes is assumed to be an aggregated bed of spherical particles with diameter $d_{p}[\mathrm{~m}]$, the permeability can be expressed by the Kozeny-Carman relationship [15]

$$
B_{0}=\frac{d_{p}^{2}}{180} \frac{\varepsilon^{3}}{(1-\varepsilon)^{2}}
$$

\section{- The Dusty Gas model}

In a more accurate representation, the fluxes $\mathrm{J}_{\mathrm{k}}$ are computed using the dusty gas model (DGM) [11], which is a straight-forward application of the Maxwell-Stefan diffusion equations, considering the pore wall as consisting of giant molecules ('dust') uniformly distributed in space. It is generally agreed that DGM is the most convenient approach to 
modeling combined bulk and Knudsen diffusion. Using Maxwell-Stefan description of multi-component diffusion is more fundamental. Also, DGM can explain physical phenomena which are beyond description by Fick's Model: such as osmotic diffusion (diffusion that occurs in the absence of the concentration gradient), reverse diffusion (diffusion that occurs counter to the concentration gradient), and diffusion barrier (there is no flux when there is a large concentration gradient) [13].
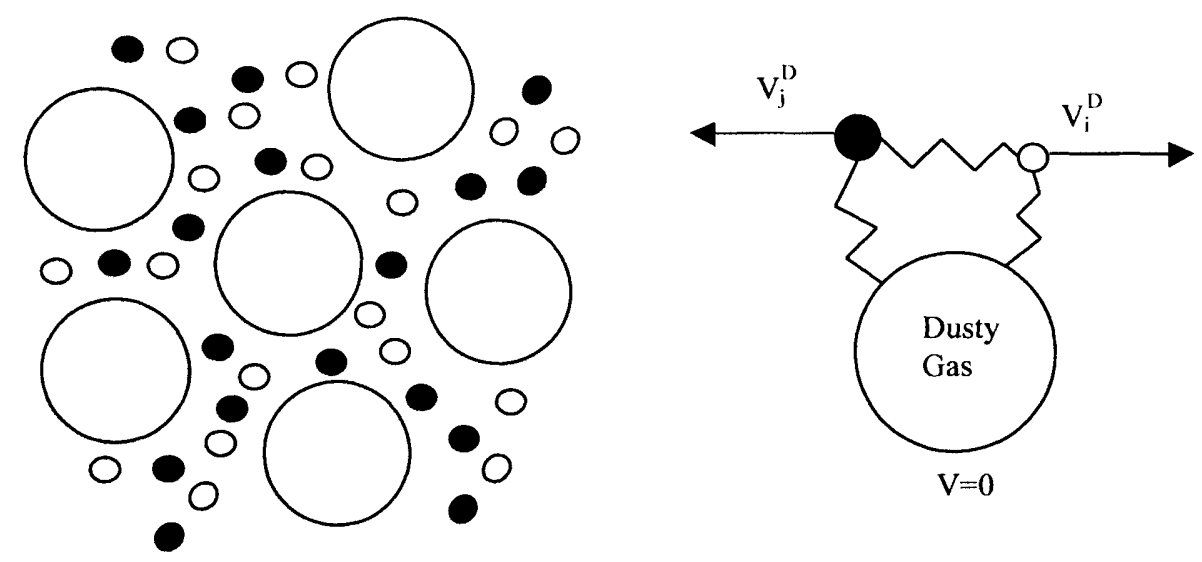

Figure 2-5 Dusty Gas Model

The DGM can be regarded as a force balance equation between driving forces and friction forces as follows [16]

$$
-\nabla_{T} \mu_{i}=\sum_{j \neq i} \zeta_{i j} x_{j}\left(V_{i}^{D}-V_{j}^{D}\right)+\zeta_{i M} V_{i}^{D}
$$

where $\mu$ is a electrochemical potential $[\mathrm{J} / \mathrm{mol}], \zeta$ is a friction coefficient $\left[\mathrm{J} \cdot \mathrm{sec} / \mathrm{m}^{2} \cdot \mathrm{mol}\right], V^{D}$ is a diffusion velocity $[\mathrm{m} / \mathrm{sec}]$, and $\nabla_{T}$ is the gradient at constant temperature.

The left hand side(LHS) is the driving force acting per mole of species $i$ and the first term and the second term of the right hand side are the friction forces between species $i$ 
and other gas species and between species i and matrix, respectively.

Comparing Eq. 2-27 with the Maxwell-Stefan equation, $-\nabla_{T} \mu_{i}=\sum_{j \neq i} \zeta_{i j} x_{j}\left(V_{i}^{D}-V_{j}^{D}\right)$, shows that DGM includes the interaction between the gas species and the porous matrix.

Expressing Eq. 2-27 in terms of diffusion coefficients using the relation between friction coefficients and diffusion coefficients $[13,16]$

$$
\zeta_{i j}=\frac{\Re T}{D_{i j}} \& \zeta_{i M}=\frac{\Re T}{D_{i M}}
$$

and multiplying $c_{i}$ to convert Eq. 2-27 in terms of forces acting on species i per unit volume, we get $[13,17]$

$$
-\frac{c_{i}}{R T} \nabla_{T} \mu_{i}=\sum_{j \neq i} \frac{c_{i} c_{j}}{c_{\imath} D_{i j}}\left(V_{i}^{D}-V_{j}^{D}\right)+\frac{c_{i}}{D_{i M}} V_{i}^{D}
$$

In equation Eq. 2-29, the electrochemical potential gradient at constant temperature is described as

$$
\nabla_{T} \mu_{i}=\frac{R T}{c_{i}} \nabla c_{i}
$$

Substituting $J_{i}$, the molar flux of species i, for the diffusion velocity $V^{D}$ in equation Eq. 2-29 using following relationships,

$$
\begin{aligned}
& J_{i}=c_{i} V_{i} \\
& V_{i}=V+V_{i}^{D}
\end{aligned}
$$

in which $V$ is the convection velocity 


$$
V=-\frac{B_{o}}{\mu_{m i x}^{v}} \nabla p
$$

we obtain [13]

$$
-\nabla c_{i}=\sum_{j(\neq i)} \frac{1}{c_{t} D_{i j}^{e}}\left(c_{j} J_{i}-c_{i} J_{j}\right)+\frac{J_{i}}{D_{i M}^{e}}+\frac{B_{0}}{\mu_{m i x}^{v}} \frac{c_{i}}{D_{i M}^{e}} \nabla p
$$

where $c_{t}=\frac{p}{\Re T}$ is total molar concentration $\left[\mathrm{mol} / \mathrm{m}^{3}\right]$.

The transport of gaseous species through porous electrodes is affected by the microstructure of the electrodes, particularly, the porosity, permeability, pore size, and tortuosity factor.

\section{(3) Thermo-chemistry}

Because of the relatively high operating temperatures and the catalytic surfaces in the anode structure, various thermo-chemical reactions occur within the anode, such as steam reforming, water-gas shift, partial oxidation, and carbon formation. A substantial impediment to the direct use of hydrocarbon fuels in SOFC is carbon formation in the anodes [5, 18-20]. Thermo-chemistry has usually been handled using significant simplifying assumptions, such as local equilibration of reforming and water-gas-shift chemistry [21, 22], or global reaction kinetics[23]. Recently, detailed kinetics models based on the knowledge of the elementary reactions have been established and validated over a wide range of conditions [1]. Because nickel is the most common anode metal, being a cost-effective catalyst, the reactions of methane on $\mathrm{Ni}$ have been extensively studied.

\section{- Equilibration of reforming and water-gas-shirt chemistry}


When a nickel surface is present, the catalytic reactions are fast, causing the gasphase compositions to approach equilibrium in the anode. As a first attempt to include the thermo-chemistry within the anode, it was assumed that water-gas shift reaction reached equilibrium with the fuel of $H$ and $C O$ [21]. This shift reaction was used only to adjust the composition at the channel. Also, the equilibrium assumption of water-gas shift reaction was used only to explain the experimental results with the fuel of $H_{2}$ and $C O$ [22]. In both cases, the thermo-chemistry was not coupled with the transport equation.

\section{- Global reaction kinetics}

A simulation study of gas transport with steam-reforming and gas shift reactions was conducted with the global reaction kinetics as follows [23]

(i) steam reforming of the methane

$\mathrm{CH}_{4}+\mathrm{H}_{2} \mathrm{O} \leftrightarrow \mathrm{CO}+3 \mathrm{H}_{2}$

(ii) water-gas-shift processes

$\mathrm{H}_{2} \mathrm{O}+\mathrm{CO} \leftrightarrow \mathrm{H}_{2}+\mathrm{CO}_{2}$

The reaction rates can be formulated as

$$
\begin{aligned}
& R_{g a s,(i)}=k_{(i), f} p_{C_{4}} p_{\mathrm{H}_{2} \mathrm{O}}-k_{(i), b} p_{C O}\left(p_{\mathrm{H}_{2}}\right)^{3} \\
& R_{g a s,(i i)}=k_{(i i), f} p_{C O} p_{\mathrm{H}_{2} \mathrm{O}}-k_{(i i), b} p_{\mathrm{CO}_{2}} p_{\mathrm{H}_{2}}
\end{aligned}
$$

where $R_{\text {gas }}$ is the reaction rate $\left[\mathrm{mole} / \mathrm{m}^{3} \cdot \mathrm{sec}\right]$ and the reaction rate constants were determined experimentally.

\section{- Detailed kinetic model of elementary reactions}

- Homogeneous thermo-chemistry 
Gas-phase chemistry may be neglected because the heterogeneous thermochemical reactions are considerably faster than homogeneous thermo-chemistry and the probability for gas-gas collisions is low when the pore space comparable to the mean freepath length [1].

$$
\dot{s}_{g a s, k}=0 \quad\left(k=1, \ldots, K_{g}\right)
$$

\section{- Heterogeneous thermo-chemistry}

The surface mechanism of the methane reforming and oxidation over the nickel has been suggested [24]. The mechanism was initially developed and validated using Ni-coated honeycomb monoliths for the temperature range from 700 to $1300 \mathrm{~K}$. The reaction mechanism consists of 6 pairs of the adsorption and the desorption for 6 gas species and 15 pairs of surface reactions among 12 adsorbed species. The use of microkinetic mechanisms for reforming and/or catalytic partial oxidation, given the difficulty of obtaining accurate thermodynamic data for surface species, have a potential problem that the individual reactions might not satisfy microscopic reversibility. Moreover, the predicted gas-phase concentrations might not be consistent with equilibrium values. To avoid this problem, The kinetic data of the backward reactions are calculated from thermodynamics using Massaction kinetics. 


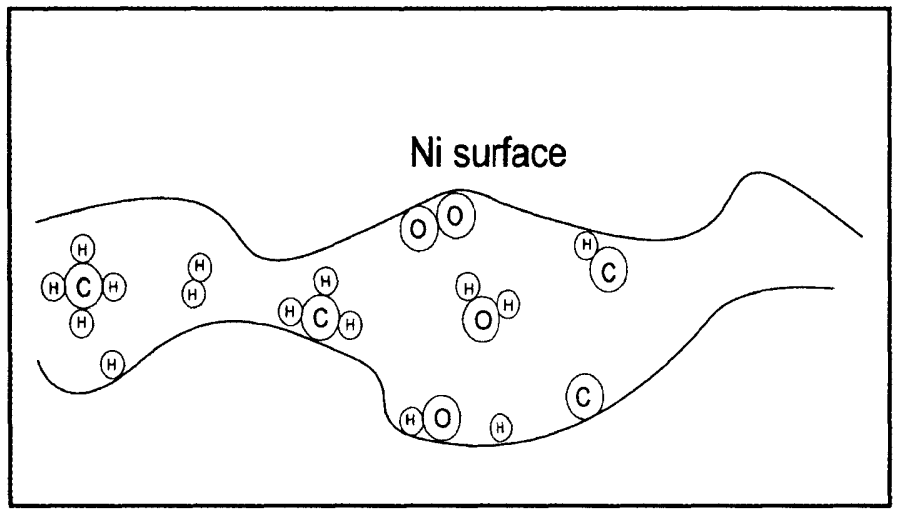

Figure 2-6 The Schematics of Elementary Heterogeneous Chemistry

Since this mechanism is formulated in terms of elementary reactions on the catalyst surface, the reaction rates depend both on the concentrations of the gaseous reactants and on the coverages of the surface species. The coverage of surface species is defined as

$$
\theta_{i}=\frac{\text { number of adsorption sites occupied by surface species } \mathrm{i}}{\text { number of adsorption sites available }}
$$

The net production rate of any gas or surface species $\mathrm{k}$ on the surface by heterogeneous reactions is given by

$$
\dot{s}_{\text {surf }, k}=\sum_{i} R_{\text {surf }, i} v_{i, k}
$$

where $R_{\text {surf }, i}$ is the rate of heterogeneous reaction i $\left[\mathrm{mol} /\left(\mathrm{m}^{2} \mathrm{sec}\right)\right]$ and $v_{i, k}$ is the stoichiometric coefficient of the species $\mathrm{k}$ in rea ction $\mathrm{i}$, which is positive for products and negative for reactants.

For the adsorption reactions such as reactions $1,3,5,7,9$ and 11 , the reaction rate can be computed using the kinetic theory of gases by [25] 


$$
R_{\text {surf }, k}=S_{i}^{e} \sqrt{\frac{\Re T}{2 \pi M_{i}}} c_{i} \quad(\mathrm{k}=1,3,5,7,9 \text { and 11) }
$$

where $S_{i}^{e}$ is a local adsorption probability of gas species $\mathrm{i}$

This equation assumes a Boltzmann distribution of molecular velocities near the surface.

The local adsorption probability is defined as [25]

$$
S_{i}^{e}=S_{i}^{0} \theta_{v}^{v_{v}}
$$

where $S_{i}^{0}$ is a sticking coefficient, which determines the probability that a particle hitting the surface is adsorbed, $\theta_{v}$ is a vacancy coverage, and $v_{v}$ is the stoichiometric coefficient of vacancies.

For example, the local adsorption probability of hydrogen during the dissociative adsorption reaction, $\mathrm{H}_{2}+2(\mathrm{Ni}) \rightarrow 2 \mathrm{H}(\mathrm{Ni})$,

$$
S_{i}^{e}=10^{-2} \theta_{v}^{2}
$$

Hence, the reaction rate of reaction 1 , adsorption of hydrogen, is

$$
R_{1}=10^{-2} \sqrt{\frac{\Re T}{2 \pi M_{H_{2}}}} c_{H_{2}} \theta_{v}^{2}
$$

For the desorption and surface reactions between surface species, where only surface species are involved, the reaction rate can be expressed using Mass-action kinetics such as

$$
R_{\text {surf }, k}=k_{k}(T) \prod_{\text {react }} c_{\text {surf }, i}^{v_{i}}
$$

where $k_{i}$ is the reaction rate constant of the reaction $i$. 
The reaction rate constants are represented in the Arrhenius form

$$
k=A T^{n} \exp \left(-\frac{E_{a}}{\Re T}\right)
$$

where $A$ is a pre-exponential factor and $E_{a}$ is the activation energy.

In principle, the activation energy can vary with coverage because of multiple binding states and attractive and repulsive lateral interactions between adsorbed particles. The activation energy for desorption usually decline with increasing the coverage because a repulsive adsorbate-adsorbate interaction results in a weakening of the bonding of the molecules to the surface $[26,27]$. The CO-metal systems show a delicate interplay between the repulsive inter-adsorbate forces and structural changes within the adsorbed layer. This interplay results in modifications in the CO-substrate bonding strength and geometry. Therefore, the activation energy dependency on CO coverage is included in the reactions of 12, 20, 21 and 23. The net activation energies depend on the adsorbed $\mathrm{CO}(\mathrm{s})$ coverage, $\theta_{C O(s)}$, in the form of

$$
k=A T^{n} \exp \left(-\frac{E_{a}}{\mathfrak{R} T}\right) \exp \left(-\frac{\varepsilon_{C O(s)} \theta_{C O(s)}}{\mathfrak{R} T}\right)
$$

in which $\varepsilon_{C O(s)}$ is the $C O(s)$ coverage dependent activation energy.

\begin{tabular}{|lllll|}
\hline & Reaction & $A^{a}$ & $n$ & $E_{a}$ \\
\hline \multicolumn{1}{c}{ Adsorption/Desorption } & & & \\
1 & $\mathrm{H}_{2}+(\mathrm{Ni})+(\mathrm{Ni}) \rightarrow \mathrm{H}(\mathrm{Ni})+\mathrm{H}(\mathrm{Ni})$ & $1.000 \cdot 10^{-02 \mathrm{~b}}$ & 0.0 & 0.00 \\
2 & $\mathrm{H}(\mathrm{Ni})+\mathrm{H}(\mathrm{Ni}) \rightarrow \mathrm{H}_{2}+(\mathrm{Ni})+(\mathrm{Ni})$ & $5.593 \cdot 10^{+19}$ & 0.0 & 88.12 \\
3 & $\mathrm{O}_{2}+(\mathrm{Ni})+(\mathrm{Ni}) \rightarrow \mathrm{O}(\mathrm{Ni})+\mathrm{O}(\mathrm{Ni})$ & $1.000 \cdot 10^{-02 \mathrm{~b}}$ & 0.0 & 0.00 \\
4 & $\mathrm{O}(\mathrm{Ni})+\mathrm{O}(\mathrm{Ni}) \rightarrow \mathrm{O}_{2}+(\mathrm{Ni})+(\mathrm{Ni})$ & $2.508 \cdot 10^{+23}$ & 0.0 & 470.39 \\
5 & $\mathrm{CH}+\left(\mathrm{Ni} \rightarrow \mathrm{CH}_{4}(\mathrm{Ni})\right.$ & $8.000 \cdot 10^{-03 \mathrm{~b}}$ & 0.0 & 0.00 \\
6 & $\mathrm{CH}_{4}\left(\mathrm{Ni} \rightarrow \mathrm{CH}_{4}+(\mathrm{Ni})\right.$ & $5.302 \cdot 10^{+15}$ & 0.0 & 33.15 \\
7 & $\mathrm{H}_{2} \mathrm{O}+(\mathrm{Ni}) \rightarrow \mathrm{H}_{2} \mathrm{O}(\mathrm{Ni})$ & $1.000 \cdot 10^{-01 \mathrm{~b}}$ & 0.0 & 0.00 \\
8 & $\mathrm{H}_{2} \mathrm{O}\left(\mathrm{Ni} \rightarrow \mathrm{H}_{2} \mathrm{O}+(\mathrm{Ni})\right.$ & $4.579 \cdot 10^{+12}$ & 0.0 & 62.68 \\
\hline
\end{tabular}




\begin{tabular}{|c|c|c|c|c|}
\hline 9 & $\mathrm{CO}_{2}+(\mathrm{Ni}) \rightarrow \mathrm{CO}_{2}(\mathrm{Ni})$ & $1.000 \cdot 10^{-050}$ & 0.0 & 0.00 \\
\hline 10 & $\mathrm{CO}_{2}(\mathrm{Ni}) \rightarrow \mathrm{CO}_{2}+(\mathrm{Ni})$ & $9.334 \cdot 10^{+07}$ & 0.0 & 28.80 \\
\hline 11 & $\mathrm{CO}+(\mathrm{Ni}) \rightarrow \mathrm{CO}(\mathrm{Ni})$ & $5.000 \cdot 10^{-01 b}$ & 0.0 & 0.00 \\
\hline \multirow[t]{2}{*}{12} & $\mathrm{CO}(\mathrm{Ni}) \rightarrow \mathrm{CO}+(\mathrm{Ni})$ & $4.041 \cdot 10^{+11}$ & 0.0 & 112.85 \\
\hline & & $\varepsilon_{\mathrm{CO}(\mathrm{s})}$ & & $-50.0_{c}$ \\
\hline 13 & $\mathrm{O}(\mathrm{Ni})+\mathrm{H}(\mathrm{Ni}) \rightarrow \mathrm{OH}(\mathrm{Ni})+(\mathrm{Ni})$ & $5.000 \cdot 10^{+22}$ & 0.0 & 97.90 \\
\hline 14 & $\mathrm{OH}(\mathrm{Ni})+(\mathrm{Ni}) \rightarrow \mathrm{O}(\mathrm{Ni})+\mathrm{H}(\mathrm{Ni})$ & $2.005 \cdot 10^{+21}$ & 0.0 & 37.19 \\
\hline 15 & $\mathrm{OH}(\mathrm{Ni})+\mathrm{H}(\mathrm{Ni}) \rightarrow \mathrm{H}_{2} \mathrm{O}(\mathrm{Ni})+(\mathrm{Ni})$ & $3.000 \cdot 10^{+20}$ & 0.0 & 42.70 \\
\hline 16 & $\mathrm{H}_{2} \mathrm{O}(\mathrm{Ni})+(\mathrm{Ni}) \rightarrow \mathrm{OH}(\mathrm{Ni})+\mathrm{H}(\mathrm{Ni})$ & $2.175 \cdot 10^{+21}$ & 0.0 & 91.36 \\
\hline 17 & $\mathrm{OH}(\mathrm{Ni})+\mathrm{OH}(\mathrm{Ni}) \rightarrow \mathrm{H}_{2} \mathrm{O}(\mathrm{Ni})+\mathrm{O}(\mathrm{Ni})$ & $3.000 \cdot 10^{+21}$ & 0.0 & 100.00 \\
\hline 18 & $\mathrm{H}_{2} \mathrm{O}(\mathrm{Ni})+\mathrm{O}(\mathrm{Ni}) \rightarrow \mathrm{OH}(\mathrm{Ni})+\mathrm{OH}(\mathrm{Ni})$ & $5.423 \cdot 10^{+23}$ & 0.0 & 209.37 \\
\hline 19 & $O(N i)+C(N i) \rightarrow C O(N i)+(N i)$ & $5.200 \cdot 10^{+23}$ & 0.0 & 148.10 \\
\hline \multirow[t]{2}{*}{20} & $\mathrm{CO}(\mathrm{Ni})+(\mathrm{Ni}) \rightarrow \mathrm{O}(\mathrm{Ni})+\mathrm{C}(\mathrm{Ni})$ & $1.418 \cdot 10^{+22}$ & -3.0 & 115.97 \\
\hline & $\mathrm{O}(\mathrm{Ni})+\mathrm{CO}(\mathrm{Ni}) \rightarrow \mathrm{CO}_{2}(\mathrm{Ni})+(\mathrm{Ni})$ & $\begin{array}{l}\varepsilon_{\mathrm{CO}(\mathrm{s})} \\
2.000 \cdot 10^{+19}\end{array}$ & 0.0 & $\begin{array}{l}-50.0_{c} \\
123.60\end{array}$ \\
\hline 21 & & $\varepsilon_{\mathrm{CO}(\mathrm{s})}+23$ & & $-50.0_{c}$ \\
\hline 22 & $\mathrm{CO}_{2}(\mathrm{Ni})+(\mathrm{Ni}) \rightarrow \mathrm{O}(\mathrm{Ni})+\mathrm{CO}(\mathrm{Ni})$ & $3.214 \cdot 10^{+20}$ & -1.0 & 86.50 \\
\hline 23 & $H C O(N i)+(N i) \rightarrow C O(N i)+H(N i)$ & $3.700 \cdot 10^{+21}$ & 0.0 & 0.0 \\
\hline 24 & $\mathrm{CO}(\mathrm{Ni})+\mathrm{H}(\mathrm{Ni}) \rightarrow \mathrm{HCO}(\mathrm{Ni})+(\mathrm{Ni})$ & $\begin{array}{l}\varepsilon_{\mathrm{CO}(\mathrm{s})} \\
2.338 \cdot 10^{+20}\end{array}$ & -1.0 & $\begin{array}{l}50.0_{c} \\
127.98\end{array}$ \\
\hline 25 & $\mathrm{HCO}(\mathrm{Ni})+(\mathrm{Ni}) \rightarrow \mathrm{O}(\mathrm{Ni})+\mathrm{CH}(\mathrm{Ni})$ & $3.700 \cdot 10^{+24}$ & -3.0 & 95.80 \\
\hline 26 & $\mathrm{O}(\mathrm{Ni})+\mathrm{CH}(\mathrm{Ni}) \rightarrow \mathrm{HCO}(\mathrm{Ni})+(\mathrm{Ni})$ & $7.914 \cdot 10^{+20}$ & 0.0 & 114.22 \\
\hline 27 & $\mathrm{CH}_{4}(\mathrm{Ni})+(\mathrm{Ni}) \rightarrow \mathrm{CH}_{3}(\mathrm{Ni})+\mathrm{H}(\mathrm{Ni})$ & $3.700 \cdot 10^{+21}$ & 0.0 & 57.70 \\
\hline 28 & $\mathrm{CH}_{3}(\mathrm{Ni})+\mathrm{H}(\mathrm{Ni}) \rightarrow \mathrm{CH}_{4}(\mathrm{Ni})+(\mathrm{Ni})$ & $4.438 \cdot 10^{+21}$ & 0.0 & 58.83 \\
\hline 29 & $\mathrm{CH}_{3}(\mathrm{Ni})+(\mathrm{Ni}) \rightarrow \mathrm{CH}_{2}(\mathrm{Ni})+\mathrm{H}(\mathrm{Ni})$ & $3.700 \cdot 10^{+24}$ & 0.0 & 100.00 \\
\hline 30 & $\mathrm{CH}_{2}(\mathrm{Ni})+\mathrm{H}(\mathrm{Ni}) \rightarrow \mathrm{CH}_{3}(\mathrm{Ni})+(\mathrm{Ni})$ & $9.513 \cdot 10^{+22}$ & 0.0 & 52.58 \\
\hline 31 & $\mathrm{CH}_{2}(\mathrm{Ni})+(\mathrm{Ni}) \rightarrow \mathrm{CH}(\mathrm{Ni})+\mathrm{H}(\mathrm{Ni})$ & $3.700 \cdot 10^{+24}$ & 0.0 & 97.10 \\
\hline 32 & $\mathrm{CH}(\mathrm{Ni})+\mathrm{H}(\mathrm{Ni}) \rightarrow \mathrm{CH}_{2}(\mathrm{Ni})+(\mathrm{Ni})$ & $3.008 \cdot 10^{+24}$ & 0.0 & 76.43 \\
\hline 33 & $\mathrm{CH}(\mathrm{Ni})+(\mathrm{Ni}) \rightarrow \mathrm{C}(\mathrm{Ni})+\mathrm{H}(\mathrm{Ni})$ & $3.700 \cdot 10^{+21}$ & 0.0 & 18.80 \\
\hline 34 & $\mathrm{C}(\mathrm{Ni})+\mathrm{H}(\mathrm{Ni}) \rightarrow \mathrm{CH}(\mathrm{Ni})+(\mathrm{Ni})$ & $4.400 \cdot 10^{+22}$ & 0.0 & 160.49 \\
\hline 35 & $\mathrm{O}(\mathrm{Ni})+\mathrm{CH}_{4}(\mathrm{Ni}) \rightarrow \mathrm{CH}_{3}(\mathrm{Ni})+\mathrm{OH}(\mathrm{Ni})$ & $1.700 \cdot 10^{+24}$ & 0.0 & 88.30 \\
\hline 36 & $\mathrm{CH}_{3}(\mathrm{Ni})+\mathrm{OH}(\mathrm{Ni}) \rightarrow \mathrm{O}(\mathrm{Ni})+\mathrm{CH}_{4}(\mathrm{Ni})$ & $8.178 \cdot 10^{+22}$ & 0.0 & 28.72 \\
\hline 37 & $\mathrm{O}(\mathrm{Ni})+\mathrm{CH}_{3}(\mathrm{Ni}) \rightarrow \mathrm{CH}_{2}(\mathrm{Ni})+\mathrm{OH}(\mathrm{Ni})$ & $3.700 \cdot 10^{+24}$ & 00 & 130.10 \\
\hline 38 & $\mathrm{CH}_{2}(\mathrm{Ni})+\mathrm{OH}(\mathrm{Ni}) \rightarrow \mathrm{O}(\mathrm{Ni})+\mathrm{CH}_{3}(\mathrm{Ni})$ & $3.815 \cdot 10^{+21}$ & 0.0 & 21.97 \\
\hline 39 & $\mathrm{O}(\mathrm{Ni})+\mathrm{CH}_{2}(\mathrm{Ni}) \rightarrow \mathrm{CH}(\mathrm{Ni})+\mathrm{OH}(\mathrm{Ni})$ & $3.700 \cdot 10^{+24}$ & 0.0 & 126.80 \\
\hline 40 & $\mathrm{CH}(\mathrm{Ni})+\mathrm{OH}(\mathrm{Ni}) \rightarrow \mathrm{O}(\mathrm{Ni})+\mathrm{CH}_{2}(\mathrm{Ni})$ & $1.206 \cdot 10^{+23}$ & 0.0 & 45.42 \\
\hline 41 & $\mathrm{O}(\mathrm{Ni})+\mathrm{CH}(\mathrm{Ni}) \rightarrow \mathrm{C}(\mathrm{Ni})+\mathrm{OH}(\mathrm{Ni})$ & $3.700 \cdot 10^{+21}$ & 0.0 & 48.10 \\
\hline 42 & $\mathrm{C}(\mathrm{Ni})+\mathrm{OH}(\mathrm{Ni}) \rightarrow \mathrm{O}(\mathrm{Ni})+\mathrm{CH}(\mathrm{Ni})$ & $1.764 \cdot 10^{+21}$ & 0.0 & 129.08 \\
\hline \multicolumn{5}{|c|}{$\begin{array}{l}\text { a The units of A are given in terms of moles, centimeters, and seconds. } \mathrm{E} \text { is } \mathrm{kJ} / \mathrm{mol} \text {. } \\
\text { b Sticking coefficient. }\end{array}$} \\
\hline
\end{tabular}

Table 2.1 Detailed Heterogeneous Elementary Chemical Reactions

Because the reaction mechanism is based on elementary molecular processes, it represents all the global processes in an SOFC anode, including 
(i) Steam reforming of the methane

$\mathrm{CH}_{4}+\mathrm{H}_{2} \mathrm{O} \leftrightarrow \mathrm{CO}+3 \mathrm{H}_{2}$

(ii) Water-gas-shift processes

$\mathrm{H}_{2} \mathrm{O}+\mathrm{CO} \leftrightarrow \mathrm{H}_{2}+\mathrm{CO}_{2}$

(iii) Oxidation of the methane

$\mathrm{CH}_{4}+2 \mathrm{O}_{2} \leftrightarrow \mathrm{CO}_{2}+2 \mathrm{H}_{2} \mathrm{O}$

However, the mechanism for carbon formation and bulk phase nickel oxidation haven't been specified. Thus, the example discussed in this thesis use operating conditions where coking and $\mathrm{NiO}$ formation are not of primary concerns.

\subsubsection{Activation overpotential}

Because the electrodes are electronic conductors and the electrolyte is an ionic conductor, the charge cannot cross directly between the electrode and the electrolyte. Rather, an electrochemical charge-transfer reaction is needed. Since the electrodes and the electrolyte all have free-charge carriers, each one is, to a good approximation, internally charge-neutral, with any excess charge being distributed on its surface. The interface behaves as a capacitor, with excess charge on one side and equal but opposite charge on the other side. The very thin (nanometer scale) region at the interface where the charge is stored is called the electric double layer. The electric potential varies sharply though the double layer. As the electrons cross the double layer, the charge-transfer reactions must overcome the potential difference across the double layer. This potential difference less the equilibrium potential difference is defined as an activation overpotential. 
Charge-transfer processes are among the least understood aspects of fuel-cell chemistry. To calculate the activation overpotential, an experimental approach was explored using the concept of an effective charge-transfer resistance, which is defined in terms of micro-structural parameters of the electrode, intrinsic charge-transfer resistance, ionic conductivity of the electrolyte, and the electrode thickness [28]. As an alternative analytical approach, a single global charge-transfer reaction was often used to describe the electrochemical kinetics, leading to the Butler-Volmer equation. [21, 29, 30]. Since the two approaches above are semi-empirical approaches, there have been some efforts to develop the detailed charge-transfer kinetics in terms of elementary reactions step, in a manner that resembles the treatment of thermal heterogeneous thermo-chemistry.

\section{(a) A single Global Charge-Transfer Reaction}

The assumption of a single global charge-transfer reaction provides a relationship between the current density and the activation overpotential, known as the Butler-Volmer equation, as follows

$$
i=i_{0}\left[\exp \left(\beta_{a} \frac{F \eta_{a}}{\mathfrak{R} T}\right)-\exp \left(-\beta_{c} \frac{F \eta_{a}}{\mathfrak{R} T}\right)\right]
$$

where $i$ is the current density, $i_{0}$ is the exchange current density, $\beta_{a}$ is the anodic charge-transfer coefficient, $\beta_{c}$ is the cathodic charge-transfer coefficient, and $\eta_{a}$ is the activation overpotential. This Butler-Volmer equation represents the net anodic and cathodic current due to a single global charge-transfer reaction. The exchange current density $i_{0}$ is the current density of the charge-transfer reaction at the dynamic equilibrium when the forward and backward current densities are equal at $i_{0}$. 
Other than the charge-transfer reaction, additional reactions are required that describe the rate of adsorption and desorption of the species that participate in chargetransfer reaction. Applying the Buler-Volumer equation for the electrochemical reactions at TPB is a semi-empirical method, in which parameters such as the exchange current density $i_{0}$ must be measured from experiments. The exchange current density $i_{0}$ is a measure of the electocatalytic activity of the electrode-electrolyte interface for a given electrochemical reaction. It is not a simple constant parameter, but its value may depend on the operating conditions such as concentrations of reactants and products at TPB, temperature, and pressure and material properties, microstructure and electrocatalytic activity of the electrode. However, this single global charge-transfer reaction approach couldn't estimate the dependency of the exchange current density on the product and reactant concentrations. Determining the dependence of the exchange current density on the products and reactants, that is, the reaction order with respect to the reactants and products, based on a global reaction might result in unreasonable overpotential profiles.

\section{(b) Detailed elementary reactions of electrochemistry at TPB}

The state-of-the-art approach is to apply a model that includes all elementary reactions. However, a clear understanding of the electrode kinetics does not exist yet. Regarding the anode, for example, according to the literature, adsorption/desorption, surface diffusion, the formation of hydroxyl, and a charge transfer reaction are feasible ratelimiting reaction steps in a simplified SOFC anode. Furthermore, it is not even evident whether the chemical and the electrochemical reactions take place only on the surfaces of 
$N i$ and of YSZ, or whether the bulk material is also active.

Zhu et. al. [1] applied the detailed electrode kinetics model and obtained a ButlerVolmer formalism. This approach provides qualitative information about important functional dependencies such as the reaction orders in the exchange current density, and enables comparison with experimental results that have been interpreted using the parameters in the Butler-Volmer equation.

\section{(1) Anode}

In developing an expression for the anode activation overpotential in the ButlerVolmer form, it is useful to begin by considering the elementary steps by which hydrogen is electrochemically oxidized. Global electrochemical oxidation of hydrogen can be written in Kroger-Vink notation as [31]

$$
H_{2}(g)+O_{O}^{\times}(e l) \leftrightarrow H_{2} O(g)+V_{O}^{\prime \prime}(e l)+2 e^{-}(a)
$$

where $(\mathrm{g})$ means gas phases, $\mathrm{e}^{-}(\mathrm{a})$ is an electron on the anode, and the species in the electrolyte follows Kroger-Vink notation in which the subscript describes the relevant lattice site and the superscript describes the charge. For example, $V_{O}^{*}$ is the vacancy on the oxygen site, hence the charge is positive 2 relatively to the oxygen site, which should have negative 2 ions. This electrochemical reaction involves species in the gas, electrolyte, and anode(metal) phases.

The five elementary reaction mechanism proposed by De Boer[32] is assumed. In this model, hydrogen could be adsorbed only on the nickel surface $(N i)$ and other surface species reside on the electrolyte surface (YSZ). Or, there exist an adsorbed atomic hydrogen, $H(\mathrm{Ni})$, an empty surface site, $(\mathrm{Ni})$, and an electron within the $\mathrm{Ni}$ anode, $e^{-}(\mathrm{Ni})$, on the $\mathrm{Ni}$ 
anode surface. Within the YSZ electrolyte, there is a lattice oxygen, $O_{O}^{\times}$(YSZ), and an oxygen vacancy, $V_{O}^{*}(\mathrm{YSZ})$. On the YSZ surface there are three species, $O H(Y S Z)$, $\mathrm{H}_{2} \mathrm{O}(Y S Z), \mathrm{O}^{2-}(Y S Z)$, and empty sites (YSZ).

- Adsorption on the Ni surface

$$
\mathrm{H}_{2}(\mathrm{~g})+2(\mathrm{Ni}) \Leftrightarrow 2 \mathrm{H}(\mathrm{Ni})
$$

- Charge-transfer reactions at the TPB region

$$
\begin{gathered}
H(\mathrm{Ni})+\mathrm{O}^{2-}(\mathrm{YSZ}) \Leftrightarrow(\mathrm{Ni})+\mathrm{OH}^{-}(\mathrm{YSZ})+e^{-}(\mathrm{Ni}) \\
H(\mathrm{Ni})+\mathrm{OH}^{-}(\mathrm{YSZ}) \Leftrightarrow(\mathrm{Ni})+\mathrm{H}_{2} \mathrm{O}(\mathrm{YSZ})+e^{-}(\mathrm{Ni})
\end{gathered}
$$

- Adsorption/desorption on the YSZ surface

$$
\mathrm{H}_{2} \mathrm{O}(Y S Z) \Leftrightarrow \mathrm{H}_{2} \mathrm{O}(\mathrm{g})+(\mathrm{YSZ})
$$

- Transfer of oxygen ion between the surface and the bulk YSZ

$$
O_{o}^{X}(Y S Z)+(Y S Z) \Leftrightarrow O^{2-}(Y S Z)+V_{o}^{* \bullet}(Y S Z)
$$

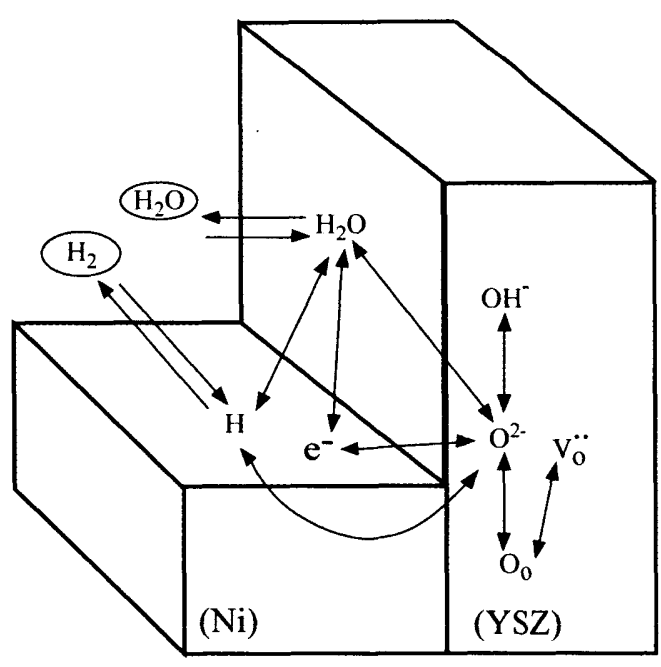

Figure 2-7 The Schematics of the Detailed Anode Kinetics 
The residence time of adsorbed hydrogen is several nanoseconds and the corresponding diffusion length is several nanometers $[33,34]$. Therefore, it might not be a problem that this model doesn't include surface diffusion of hydrogen.

The surface species can be related through five chemical reaction rate equations. With the assumption that one reaction is rate-limiting, relatively simple analytical expression may be derived through the forward and the backward reaction coefficient of the rate-limiting reaction and the equilibrium constants of other reactions.

\section{- Derivation of Butler-Volmer Form Using the Detailed Kinetics}

It is claimed that the current density becomes several order of magnitude higher if all the adsorbed hydrogen reacts [33, 35]. First, we will assume that reaction (1) could not the rate-limiting. Later, this assumption will be discussed in the Chapter 3.2. Also, it is generally assumed that the oxygen ion is abundant on the electrolyte. Reaction (5) might be fast enough. We examine the other possible cases when either reaction (2), reaction (3) or reaction (4) is the rate-limiting.

The detailed anode kinetic model involve six surface species, $H(N i),(N i)$, $\mathrm{OH}^{-}(\mathrm{YSZ}), \mathrm{O}^{2-}(\mathrm{YSZ}), \mathrm{H}_{2} \mathrm{O}(\mathrm{YSZ})$, and $(\mathrm{YSZ})$ and two gas-phase species, $\mathrm{H}_{2}(\mathrm{~g})$ and $\mathrm{H}_{2} \mathrm{O}(\mathrm{g})$. By definition coverages of each species on the Ni and on the YSZ must sum to unity;

$$
\begin{gathered}
\theta_{H}+\theta_{N i}=1 \\
\theta_{O}+\theta_{O H}+\theta_{H_{2} O}+\theta_{Y S Z}=1
\end{gathered}
$$


where $\theta_{H}$ is the coverage of $H(N i) ; \theta_{N i}$ represents a vacancy on the $N i ; \theta_{O}$ represents

$\mathrm{O}^{2-}(Y S Z) ; \theta_{O H}$ represents $\mathrm{OH}(Y S Z) ; \theta_{\mathrm{H}_{2} \mathrm{O}}$ represents $\mathrm{H}_{2} \mathrm{O}(\mathrm{YSZ})$; and $\theta_{Y S Z}$ represents a vacancy on the YSZ.

There are six unknown surface species and two conservation equations, Eq. 2-48 and Eq. 2-49. By assuming rate-limiting one among the five reactions, (1)-(5), we can get four relations between the coverages of surface species through equilibrium constants $K_{i}$ of the remaining fast four reactions.

\section{Assuming reaction (2) to be rate-limiting}

When the reaction (2) is assumed to be rate-limiting, the species partial pressures and surface coverages can be related through equilibrium constants $K_{i}$ for the reactions (1), (4) and (5) as

$$
\begin{gathered}
\frac{\theta_{H}^{2}}{\theta_{N_{i}}^{2} p_{H_{2}}}=K_{1} \\
\frac{\theta_{Y S Z} p_{H_{2} O}}{\theta_{H_{2} O}}=K_{4} \\
\frac{\theta_{Y S Z}}{\theta_{O}}=K_{5}
\end{gathered}
$$

For the charge-transfer reaction (3), the anodic and cathodic current densities, $i_{a}$ and $i_{c}$, can be expressed using the electric potential difference between anode and electrolyte, $\varepsilon_{a}[V]$, as [36] 


$$
\begin{aligned}
& i_{a}=l_{T P B} F k_{3, a} \theta_{H} \theta_{O H} \exp \left(\frac{\beta_{3, a} F \varepsilon_{a}}{\mathfrak{R} T}\right) \\
& i_{c}=l_{T P B} F k_{3, c} \theta_{H_{2} O} \theta_{N i} \exp \left(-\frac{\beta_{3, c} F \varepsilon_{a}}{\mathfrak{R} T}\right)
\end{aligned}
$$

where $l_{T P B}=\frac{A_{T P B}}{A_{\text {electrode }}}$ is the ratio of TPB area to the electrode-electrolyte interface area, $k_{i, a}$ and $k_{i, c}$ are the anodic and cathodic thermal reaction rate constants of the reaction $\mathrm{i}$, and $\beta_{i, a}$ and $\beta_{i, c}$ are the anodic and cathodic charge transfer coefficient with $\beta_{i, a}+\beta_{i, c}=1$ for the reaction $i$.

When in equilibrium, the net current density vanishes $\left(i_{a}=i_{c}\right)$, with $K_{3}=k_{3, a} / k_{3, c}$

$$
\frac{\theta_{N_{i}} \theta_{H_{2} O}}{\theta_{H} \theta_{O H}}=K_{3} \exp \left(\frac{F \varepsilon_{a}}{R T}\right)
$$

Using six equations, Eq. 2-48 Eq. 2-52 and Eq. 2-55 , all six surface coverages can be expressed using the gaseous partial pressures and the equilibrium constants.

The current density is determined by the rate-limiting reaction (2) and can be expressed as follows

$$
i=i_{a}-i_{c}=l_{T P B} F\left[k_{2, a} \theta_{H} \theta_{O} \exp \left(\frac{\beta_{2, a} F \varepsilon_{a}}{\mathfrak{R} T}\right)-k_{2, c} \theta_{O H} \theta_{N i} \exp \left(-\frac{\beta_{2, c} F \varepsilon_{a}}{\mathfrak{R} T}\right)\right]
$$

The equation above can be expressed in terms of partial pressures, the equilibrium constants, and the thermal reaction rate constants of reaction (2) as follows.

$$
i=\frac{F l_{T P B}\left(e^{\frac{\left(1+\beta_{2, a}\right) \varepsilon_{a} F}{\mathfrak{R} T}} K_{1} k_{2, a} K_{3} K_{4} p_{H_{2}}-e^{\frac{-\beta_{2,} \varepsilon_{a} F}{\mathfrak{R} T}} k_{2, c} K_{5} p_{H_{2} O}\right)}{\left(1+\sqrt{K_{1}} \sqrt{p_{H_{2}}}\right)\left(K_{5} p_{H_{2} O}+e^{\frac{\varepsilon_{\alpha} F}{\mathfrak{R} T}} \sqrt{K_{1}} K_{3} \sqrt{p_{H_{2}}}\left(K_{4}+K_{4} K_{5}+K_{5} p_{H_{2} O} O\right)\right)}
$$


When the overall reactions are at equilibrium, or when $\mathrm{i}$ is zero, the electricpotential is

$$
\varepsilon_{a, e q}=\frac{\Re T}{\left(1+\beta_{2, a}+\beta_{2, c}\right)} \ln \frac{k_{2, c} K_{5} p_{H_{2} O}}{K_{1} k_{2, a} K_{3} K_{4} p_{H_{2}}}
$$

Combining Eq. 2-57 and Eq. 2-58 with the assumption that the YSZ surface is nearly covered with $O^{2-}(Y S Z), \theta_{O} \approx 1[1,37]$, the current density can be expressed in terms of the activation overpotential, $\eta_{a}=\varepsilon_{\alpha}-\varepsilon_{a, e q}$ as follows

$$
i=i_{0}\left(\exp \left(\frac{\beta_{2, a} F \eta_{a}}{\mathfrak{R} T}\right)-\exp \left(\frac{-\left(1+\beta_{2, c}\right) F \eta_{a}}{\mathfrak{R} T}\right)\right)
$$

where

$$
i_{0}=\frac{l_{T P B} F k_{2, c} K_{5} p_{H_{2} O}}{\left(\sqrt{K_{1}} K_{3} K_{4} \sqrt{p_{H_{2}}}+K_{1} K_{3} K_{4} p_{H_{2}}\left(\frac{k_{2, c} K_{5} p_{H_{2} O}}{K_{1} k_{2, a} K_{3} K_{4} p_{H_{2}}}\right)^{\left(1+\beta_{2, c}\right) /\left(1+\beta_{2, a}+\beta_{2, c}\right)}\right.}
$$

Since the charge-transfer coefficients are usually assumed as $0.5[36,38]$, it simplifies to

$$
\begin{gathered}
i=i_{0}\left(\exp \left(\frac{F \eta_{a}}{2 \Re T}\right)-\exp \left(-\frac{3 F \eta_{a}}{2 \Re T}\right)\right) \\
i_{0}=\frac{l_{T P B} F K_{1}^{1 / 4} K_{5}^{1 / 4} k_{2, a}^{3 / 4} k_{2, c}^{1 / 4}}{\left(K_{3} K_{4}\right)^{1 / 4}} \frac{p_{H_{2} O}^{1 / 4} p_{H 2}^{1 / 4}}{\left(1+K_{1}^{1 / 2} p_{H_{2}}^{1 / 2}\right)}
\end{gathered}
$$

There are two charge-transfer reactions (2) and (3), with reaction (2) assumed to be rate-limiting and reaction (3) assumed to be in equilibrium. Thus, the overall current density is twice the current density resulting from reaction (2). 
Since reasonable estimate of the hydrogen adsorption-desorption rates are available, $K_{l}$ can be computed as follows.

$$
K_{1}=\frac{\frac{S_{i}^{0}}{\sqrt{2 \pi R T M_{H_{2}}}}}{A_{d e s} \Gamma^{2} \exp \left(-\frac{E_{\text {des }}}{\Re T}\right)}
$$

where $E_{\text {des }}$ is the activation energy for hydrogen desorption.

The notation is simplified by collecting the terms in the leading coefficients of Eq. $2-62$ and defining

$$
i_{H_{2}}^{*}=\frac{2 l_{T P B} F K_{5}^{1 / 4} k_{2, a}^{3 / 4} k_{2, c}^{1 / 4}}{\left(K_{3} K_{4}\right)^{1 / 4}}
$$

The exchange current density can be rewritten as

$$
i_{0}=i_{H_{2}}^{*} \frac{p_{H_{2} O}^{1 / 4}\left(K_{1} p_{H_{2}}\right)^{1 / 4}}{\left(1+\left(K_{1} p_{H_{2}}\right)^{1 / 2}\right)}
$$

However, the variables that appear in the expression of $i_{H_{2}}^{*}$, which depend only on temperature, are not known. Therefore, $i_{H_{2}}^{*}$ is used as an empirical parameter that can be adjusted to fit measured data.

\section{Assuming reaction (3) to be rate-limiting}

When the reaction (3) is assumed to be rate-limiting, the relations between gaseous partial pressures and surface species coverages are

$$
\frac{\theta_{H}^{2}}{\theta_{N i}^{2} p_{H_{2}}}=K_{1}
$$




$$
\begin{gathered}
\frac{\theta_{Y S Z} p_{H_{2} O}}{\theta_{H_{2} O}}=K_{4} \\
\frac{\theta_{Y S Z}}{\theta_{O}}=K_{5} \\
\frac{\theta_{N i} \theta_{O H}}{\theta_{O} \theta_{H}}=K_{2} \exp \left(\frac{F \varepsilon_{a}}{R T}\right) \\
i=k_{3, a} \theta_{H} \theta_{O H} \exp \left(\frac{\beta_{3, a} \varepsilon_{a}}{\Re T}\right)-k_{3, c} \theta_{H_{2} O} \theta_{N i} \exp \left(-\frac{\beta_{3, c} F \varepsilon_{a}}{\Re T}\right)
\end{gathered}
$$

Following the same approach, we can get

$$
i=i_{0}\left(\exp \left(\frac{\left(1+\beta_{3, a}\right) F \eta_{a}}{\mathfrak{R} T}\right)-\exp \left(\frac{-\beta_{3, c} F \eta_{a}}{\mathfrak{R} T}\right)\right)
$$

where

$$
i_{0}=\frac{2 l_{T P B} F k_{3, c} K_{5} p_{H_{2} O}}{K_{4}\left(1+\sqrt{K_{1}} \sqrt{p_{H_{2}}}\left(\frac{k_{3, K_{5}} K_{5} p_{H_{2} O} O}{K_{1} K_{2} k_{3, a} K_{4} p_{H_{2}}}\right)^{\beta_{3, c}\left(1+\beta_{3, a}+\beta_{3, c}\right)}\right.}
$$

Assuming the charge-transfer coefficients as 0.5 , it simplifies to

$$
\begin{gathered}
i=i_{0}\left[\exp \left(\frac{3 F \eta_{a}}{2 \Re T}\right)-\exp \left(-\frac{F \eta_{a}}{2 \Re T}\right)\right] \\
i_{0}=i_{H_{2}}^{*} \frac{\left(K_{1} p_{H_{2}}\right)^{1 / 4}\left(p_{H_{2} O}\right)^{3 / 4}}{1+\left(K_{1} p_{H_{2}}\right)^{1 / 2}} \\
i_{H_{2}}^{*}=2 l_{T P B} F k_{3, c}\left(K_{3} K_{2}\right)^{1 / 4}\left(K_{5} / K_{4}\right)^{3 / 4}
\end{gathered}
$$

\section{Assuming reaction (4) to be rate-limiting}

When the reaction (4) is assumed to be rate-limiting, we should be careful in formulating the equilibrium equations. When the equilibrium equations for both chargetransfer reactions are formulated using the equilibrium constants, the relation between 
current density and activation overpotential cannot be obtained. In this case, the expression showing that the rates of reaction (3) and (4) are same can be used as Eq. 2-79. Then, the relation between current density and activation overpotential can be obtained from the rate of reaction (3).

$$
\begin{gathered}
\frac{\theta_{H}^{2}}{\theta_{N i}^{2} p_{H_{2}}}=K_{1} \\
\frac{\theta_{Y S Z}}{\theta_{O}}=K_{5} \\
\frac{\theta_{N i} \theta_{O H}}{\theta_{O} \theta_{H}}=K_{2} \exp \left(\frac{F \varepsilon_{a}}{R T}\right) \\
k_{3, a} \theta_{H} \theta_{O H} \exp \left(\frac{\beta_{3, a} F \varepsilon_{a}}{\mathfrak{R} T}\right)-k_{3, c} \theta_{H, 0} \theta_{N i} \exp \left(-\frac{\beta_{3, c} F \varepsilon_{a}}{\mathfrak{R} T}\right)=k_{4,} \theta_{H_{2} O}-k_{4 b} \theta_{Y S Z} p_{H_{2} O}
\end{gathered}
$$

Following the same approach, we can show that

$$
\begin{gathered}
i=i_{0}\left[\exp \left(\frac{\left(1+\beta_{3, a}+\beta_{3, c}\right) F \eta_{a}}{R T}\right)-\exp \left(-\frac{0 F \eta_{a}}{R T}\right)\right] \\
i_{0}=i_{H_{2}}^{*}\left(p_{H_{2} O}\right) \\
i_{H_{2}}^{*}=2 F l_{T P B} k_{4 b} K_{5}
\end{gathered}
$$

Note the expressions for the exchange current density and their dependence on the partial pressure of the reactants and product, and the charge-transfer coefficients in the Butler-Volmer form.

\begin{tabular}{|c|c|c|c|}
\hline $\begin{array}{c}\text { Rate-limiting } \\
\text { reaction }\end{array}$ & Exchange Current density & $\begin{array}{c}\text { Anodic charge } \\
\text { transfer coefficient }\end{array}$ & $\begin{array}{c}\text { Cathodic charge } \\
\text { transfer coefficient }\end{array}$ \\
\hline 2 & $i_{0}=i_{\mathrm{H}_{2}}^{*} \frac{p_{\mathrm{H}_{2} \mathrm{O}}^{1 / 4}\left(K_{1} p_{\mathrm{H}_{2}}\right)^{1 / 4}}{\left(1+\left(K_{1} p_{\mathrm{H}_{2}}\right)^{1 / 2}\right)}$ & 0.5 & 1.5 \\
\hline 3 & $i_{0}=i_{\mathrm{H}_{2}}^{*} \frac{\left(K_{1} p_{\mathrm{H}_{2}}\right)^{1 / 4}\left(p_{\mathrm{H}_{2} \mathrm{O}}\right)^{3 / 4}}{1+\left(K_{1} p_{\mathrm{H}_{2}}\right)^{1 / 2}}$ & 1.5 & 0.5 \\
\hline
\end{tabular}




\begin{tabular}{|l|l|l|l|}
\hline 4 & $i_{0}=i_{H_{2}}\left(p_{H_{2}}\right)$ & 2 & 0 \\
\hline
\end{tabular}

Table 2.2 Butler-Volmer Form for Each Rate-limiting Reaction

\section{- Experimental Basis to determine the rate-limiting reaction}

Even though experimental results are sometimes contradictory about the ratelimiting reaction, similar qualitative trends have been observed for the anode charge transfer reaction. First, the anodic charge-transfer coefficient, $\beta_{a}$, is greater than the value, usually assumed by a single-rate limiting charge-transfer reaction, that is 0.5 .

$$
i=i_{0}\left[\exp \left(\underline{\beta_{a}} \frac{F \eta_{a}}{\Re T}\right)-\exp \left(-\beta_{c} \frac{F \eta_{a}}{\Re T}\right)\right]
$$

At the anode for a hydrogen fuel cell, $\mathrm{H}_{2}+\mathrm{O}^{2-} \leftrightarrow \mathrm{H}_{2} \mathrm{O}$, we can construct the global reaction rate using electric potential difference between the anode and the electrolyte, $\varepsilon_{a}$ as follows.

$$
i=i_{a}-i_{c}=l_{T P B} F\left(k p_{H_{2}}^{m} \exp \left(\frac{p F \varepsilon_{a}}{\Re T}\right)-k^{\prime} p_{H_{2} O}^{n} \exp \left(\frac{-q F \varepsilon_{a}}{\Re T}\right)\right)
$$

where $l_{T P B}$ is the length of the TPB, and $k$ and $k^{\prime}$ are forward and backward reaction rate constants.

The unknowns $\mathrm{m}, \mathrm{n}, \mathrm{p}$ and $\mathrm{q}$ in Eq. 2-83 are determined based on experimental results as follows[35]

$$
i=l_{T P B} F\left(k p_{H_{2}} \exp \left(\frac{2 F \varepsilon_{a}}{\Re T}\right)-k^{\prime} p_{H_{2} O}^{1 / 2} \exp \left(\frac{-F \varepsilon_{a}}{\Re T}\right)\right)
$$

The exchange current density can be calculated when the current density is zero as follows 


$$
i_{0}=l_{T P B} F k p_{H_{2}} \exp \left(\frac{2 F \varepsilon_{a, e q}}{\Re T}\right)=l_{T P B} F k^{\prime} p_{H_{2} O}^{1 / 2} \exp \left(\frac{-F \varepsilon_{a, e q}}{\Re T}\right)
$$

in which $\varepsilon_{a, e q}$ is the electrical potential at equilibrium.

Then, Eq. 2-84 can be expressed in terms of the activation overpotential as

$$
i=i_{0}\left(\exp \left(\frac{2 F \eta_{a}}{\mathfrak{R} T}\right)-\exp \left(\frac{-F \eta_{a}}{\mathfrak{R} T}\right)\right)
$$

In Eq. 2-86, the anodic charge transfer coefficient is 2 and the cathodic charge transfer coefficient is -1 . These reported values of them vary between different groups. However, they all share the same qualitative trend.

Secondly, it has been reported that small amounts of water added to the fuel gas accelerates the electrochemical charge-transfer reaction, which is known as the catalytic effect of water $[32,35,37]$. Considering the global reaction, the partial pressure of hydrogen, a reactant, should have a positive reaction order and the partial pressure of water should have a negative reaction order. Contrarily, the water promotes the electrochemical reactions.

\section{- Determination of the rate-limiting reaction}

If the reaction (3) or (4) is assumed to be a rate-limiting process, the anodic charge transfer coefficients are 1.5 and 2, respectively, when anodic and cathodic charge transfer coefficients are assumed to be 0.5 . Also, water has positive reaction order in the exchange current density. However, when the reaction (4) is assumed to be rate-limiting, there is no dependence of the exchange current density on hydrogen and the cathodic charge transfer reaction reduces to zero. According to Boer, it is reported that anodic charge transfer 
coefficients in most cases that were close to 1.5 for cermet anode. For the cathodic branch, charge transfer coefficient is approximately $0.5 \sim 1.0$. Furthermore, for $N i$ pattern anodes, a considerable influence of $\mathrm{p}_{\mathrm{H} 2}$ on the polarization resistance was found at a very low partial pressure of hydrogen [37]. Hence, it seems that the analytic expression shows a little better agreement with experiments when (3) is assumed to be rate-liming. Also, it explains the first-order dependence of the anodic branch on $\mathrm{p}_{\mathrm{H} 2}$ qualitatively.

This analysis is expected to help explain the apparent reaction orders, which are different from those that might be anticipated from a single global charge-transfer reaction. In particular, note that the exchange current density has a positive order with respect to $\mathrm{H}_{2} \mathrm{O}$.

In principle, $i_{H_{2}}^{*}$ can be derived from parameters associated with the chargetransfer reactions. However, parameters like specific triple-phase boundary length and the elementary charge-transfer rates are not directly known. Thus, here we take $i_{H_{2}}^{*}$ as an empirical constant.

\section{(2) Cathode}

The overall oxygen reduction and incorporation at the electrode-electrolyte interface can be written as

$$
\frac{1}{2} O_{2}(g)+V_{O}^{\prime \prime}(e l)+2 e^{-}(c) \leftrightarrow O_{O}^{\times}(e l)
$$

Where $V_{O}^{\prime \prime}(e l)$ and $O_{O}^{\times}(e l)$ denote the oxygen vacancies and lattice oxygen ions in the bulk of the electrolyte and $e^{-}(c)$ are the electrons within the cathode. As with oxidation 
at the anode, the global reaction may be the result of elementary steps.

Here, it is generally assumed that oxygen reduction proceeds in two steps [1].

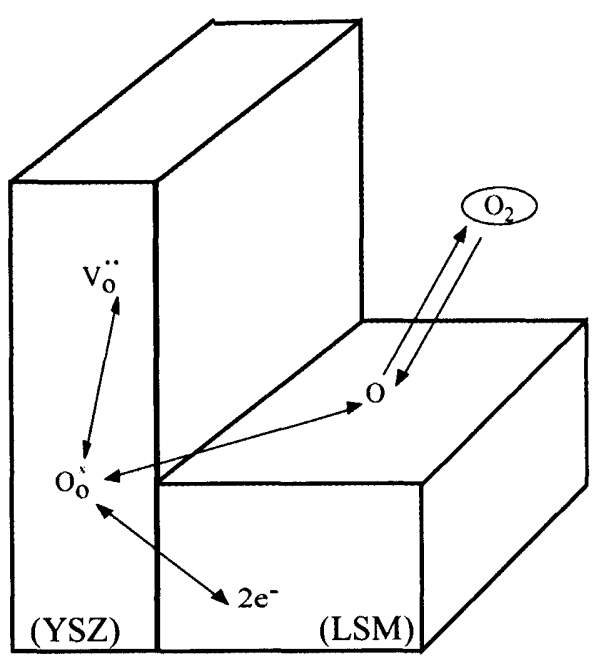

Figure 2-8 The Schematics of the Detailed Cathode Kinetics

- Adsorption/Desorption

$$
O_{2}(g)+2(c) \Leftrightarrow 2 O_{a d}(c)
$$

- Charge transfer and incorporation at the TPB

$$
O_{a d}(c)+V_{o}^{* \bullet}(e l)+2 e^{-}(c) \Leftrightarrow O_{o}^{X}(e l)+(c)
$$

In these reactions $O_{a d}(c)$ is adsorbed atomic oxygen on the cathode surface and (c) is an unoccupied cathode surface site. The charge transfer step is assumed to be ratelimiting since there is no current if it is assumed to be in equilibrium.

$$
\frac{p_{O_{2}} \theta_{v}}{\theta_{O}^{2}}=K_{6}
$$

where $\theta_{v}$ represents the coverage of the vacancy on the cathode surface, and $\theta_{O}$ represents the coverage of adsorbed oxygen on the cathode surface. 
The surface of the cathode is covered with only adsorbed oxygen and vacancies. Hence,

$$
\theta_{v}+\theta_{O}=1
$$

Using two equations, Eq. 2-87 and Eq. 2-88, all two surface coverages can be expressed using the gaseous partial pressures and the equilibrium constants.

The current density is determined by the charge-transfer reaction (7) and can be expressed using the electric potential difference between cathode and electrolyte, $\varepsilon_{a}[\mathrm{~V}]$, as follows

$$
i=2 l_{T P B} F\left[k_{7, a} \theta_{v} \exp \left(\frac{\beta_{7, a} F \varepsilon_{a}}{\mathfrak{R} T}\right)-k_{7, c} \theta_{O} \exp \left(-\frac{\beta_{7, c} F \varepsilon_{a}}{\mathfrak{R} T}\right)\right]
$$

The equation above can be expressed in terms of partial pressures, the equilibrium constants, and the thermal reaction rate constants of reaction (7)

When the overall reaction is at equilibrium, the electric-potential is

$$
E_{a, e q}=\frac{\Re T}{F} \ln \frac{p_{O_{2}}^{1 / 2}}{K_{6}^{1 / 2} K_{7}}
$$

Combining Eq. 2-89 and Eq. 2-90, the current density can be expressed in terms of the activation overpotential, $\eta_{a}=\varepsilon_{a}-\varepsilon_{a, e q}$ as follows

$$
i=i_{0}\left(\exp \left(\frac{\beta_{7, a} F \eta_{a}}{\Re T}\right)-\exp \left(\frac{-\beta_{7, c} F \eta_{a}}{\Re T}\right)\right)
$$

where

$$
i_{0}=\frac{2 l_{T P B} F k_{7, c} p_{O_{2}}^{1 / 2}}{\left(K_{6}^{1 / 2}+p_{O_{2}}^{1 / 2}\left(\frac{p_{O_{2}}^{1 / 2} k_{7, c}}{K_{6}^{1 / 2} k_{7, a}}\right)^{\beta_{7, c}}\right.}
$$


Assuming the charge-transfer coefficients as 0.5 , it simplifies to

$$
\begin{array}{r}
i=i_{0}\left(\exp \left(\frac{F \eta_{a}}{2 \mathfrak{R} T}\right)-\exp \left(-\frac{F \eta_{a}}{2 \Re T}\right)\right) \\
i_{0}=\frac{2 l_{T P B} F k_{7, c}^{1 / 2} k_{7, a}^{1 / 2}\left(p_{O_{2}} K_{6}\right)^{1 / 4}}{\left(K_{6}^{1 / 2}+p_{O_{2}}^{1 / 2}\right)}
\end{array}
$$

By defining

$$
i_{O_{2}}^{*}=2 l_{T P B} F k_{7, c}^{1 / 2} k_{7, a}^{1 / 2}
$$

, the exchange current density can be expressed as

$$
i_{0}=i_{O_{2}}^{*} \frac{\left(\frac{p_{O_{2}}}{K_{6}}\right)^{1 / 4}}{1+\left(\frac{p_{O_{2}}}{K_{6}}\right)^{1 / 2}}
$$

For an LSM-YSZ interface, $\mathrm{K}_{6}$ can be represented in Arrhenius form as [39]

$$
K_{6}=A_{O_{2}} \exp \left(\frac{E_{O_{2}}}{\mathfrak{R} T}\right)
$$

in which $A_{O_{2}}=4.9 \times 10^{8} \mathrm{~atm}$ and $E_{O_{2}}=200 \mathrm{~kJ} / \mathrm{mol}$.

Even though there is a discrepancy in the exponent, Eq. 2-96 well matches with the experimental results given by [39]

$$
i_{0}=i_{O_{2}} \frac{\left(p_{O_{2}}\right)^{1 / 2}}{1+\left(\frac{p_{O_{2}}}{K_{6}}\right)^{1 / 2}}
$$

The parameter $i_{\mathrm{O}_{2}}^{*}$ is taken here an as empirical parameter that is adjusted to represent experimentally observed performance by Jiang and Virkar [22]. For the results 
shown in subsequent sections, $i_{O_{2}}^{*}=2.8\left[\mathrm{~A} / \mathrm{cm}^{2}\right]$

\subsubsection{Ohmic overpotential}

Sources of ohmic losses in a fuel cell are the resistance to the ion flow in the electrolyte and the resistance to the electronic flow in the electrode. According to the Table 1.2 , the electrolyte has several order-of-magnitude higher resistivity than the electrodes and the interconnect. Thus, ohmic polarization in an SOFC system is typically dominated by ion resistance thorough the electrolyte. The ohmic overpotential can be expressed as [40]

$$
\begin{gathered}
\eta_{o h m}=i_{e} R_{e l} \\
R_{e l}=\frac{l_{e l}}{\sigma_{e l}}=\left[\Omega \mathrm{cm}^{2}\right] \\
\sigma_{e l}=\sigma_{0} T^{-1} \exp \left(-\frac{E_{e l}}{R T}\right)=\left[\frac{S}{\mathrm{~cm}}\right]
\end{gathered}
$$

\subsection{Conclusion}

The performance of the cell is determined using the polarization curve, which is constructed from the equilibrium potential reduced by the concentration overpotentials, activation overpotentials, and ohmic overpotentials. The concentration overpotential results from the concentration various which is determined by the transport and thermo-chemistry in the electrodes. While FM and DGM were employed for the transport, thermo-chemistry has been handled using the equilibrium, global reaction kinetics, or detailed heterogeneous kinetics. The activation overpotential represents the energy barrier of the charge-transfer reactions, which can be calculated using a single global charge transfer reaction or detailed 
electrode kinetics. The ohmic overpotential is expressed using the experimental results.

While the reviewing the current methodologies to calculate each overpotential, we corrected some errors in the concentration overpotential and additionally analyzed the possibilities that reactions other than (3) is rate-limiting. In the next chapter, first, we shall compare the current anode models since the anode-supported planar SOFC is the most promising design and the analysis in the anode needs special attention compared with the cathode model. Then, we shall construct and simulate our MEA model. 


\section{Chapter 3 The Simulation of SOFC MEA}

\subsection{The Current Anode Models}

To calculate the concentration at the interface between the electrodes and the electrolyte, several models has been proposed and used. Comparing them provides a basis to evaluate the validity of the assumptions used to construct these models. It should also offer the criteria on which models should be chosen depending on the operating conditions. All of the current models assume steady-state. In the anode-supported planar SOFC, currently the most promising design, the anode concentration overpotential is considerably larger than the cathode concentration overpotential since the thickness of the anode is an order of $1000 \mu \mathrm{m}$ and that of cathode is an order of $10 \mu \mathrm{m}$. Hence, we will focus on the anode in this section. In the next sections, we reconstruct the overall model with most detailed format.

\subsubsection{Model 1}

The first attempt to calculate the concentrations of gas species at the TPB was to apply Fick's Model without considering the thermo-chemistry. Fick's model is used more frequently because it is simpler to implement than the dusty gas model and analytical expressions can be derived more easily. Since there is no chemical reaction in the anode, the flux is constant at the steady state according to Eq. 2-8. Also, when FM is applied it is usually assumed that the total pressure drop across the anode is insignificant, which 
simplifies the analysis significantly $[8,21,41]$. Thus, only the diffusion transport is necessary to determine the rate of mass transport. Eq. 2-10 reduces to

$$
J_{i}=-D_{i}^{e} \nabla c_{i}
$$

where $\mathrm{J}_{\mathrm{i}}$ is determined at the TPB by the current density as follows

$$
J_{i}=v_{i} \frac{i}{z F}
$$

For the hydrogen fuel cell, $\mathrm{H}_{2}+\mathrm{O}^{2-} \leftrightarrow \mathrm{H}_{2} \mathrm{O}+2 e^{-}$,

$$
J_{H_{2}}=\frac{i}{2 F}
$$

Hence,

$$
c_{i, T P B}=c_{i, \text { channel }}-\frac{J_{i} l_{\text {anode }}}{D_{i}^{e}}
$$

where $c_{i, T P B}$ is the concentration of species $\mathrm{i}$ at the TPB, $c_{i, \text { channel }}$ is the concentration of speices $i$ at the channel, $l_{\text {anode }}$ is the length of the anode.

According to this model, only the concentrations of reactants and products are changing because only they have fluxes at the TPB.

\subsubsection{Model 2}

The DGM predictions are more accurate than those obtained from Fick's model [8, 13]. The model using DGM instead of Fick's law without chemistry was proposed and used with some assumptions $[8,22,29]$.

Jiang and Virkar [22] assumed that the pressure is constant through the electrode while Zhu and Kee[29] assumed that the pressure and concentration gradient are constant 
through the electrode. Since Zhu and Kee's model is the more accurate model, it is adopted here as Model 2.

$$
-\nabla c_{i}=\sum_{j(\neq i)} \frac{1}{c_{t} D_{i j}^{e}}\left(c_{j} J_{i}-c_{i} J_{j}\right)+\frac{J_{i}}{D_{i M}^{e}}+\frac{B_{0}}{\mu_{m i x}^{v}} \frac{c_{i}}{D_{i M}^{e}} \nabla p
$$

The summation of the equations above gives [29]

$$
0=\sum_{i=1}^{n} \frac{J_{i}}{D_{i M}^{e}}+\left(\frac{1}{R T}+\frac{B_{o}}{\mu_{m i x}^{v}} \sum_{i=1}^{n} \frac{c_{i}}{D_{i M}^{e}}\right) \nabla P
$$

Therefore, the pressure gradient can be expresses as [29]

$$
-\nabla P=\frac{\sum_{i=1}^{n} \frac{J_{i}}{D_{M M}^{e}}}{\frac{1}{R T}+\frac{B_{o}}{\mu_{m i x}^{v}} \sum_{i=1}^{n} \frac{c_{i}}{D_{i M}^{e}}}
$$

The pressure gradient is calculated based on the concentrations either at the channel or at the TPB using Eq. 3-7, and the molar fluxes, which are assumed constant, are determined at the TPB using the boundary conditions. Hence, the concentration gradients, which are assumed constant, can be computed by Eq. 3-5. The analysis is significantly simplified by assuming the linear profiles of concentration and pressure across the electrode.

\subsubsection{Model 3}

In Model 3, we use the DGM directly, but without thermo-chemistry.

\subsubsection{Model 4}

Model 4 uses DGM with the detailed kinetic model of heterogeneous chemistry 
within the electrode.

\subsubsection{Comparison of Current Anode Models}

All models are summarized at Table 3.1

\begin{tabular}{|l|l|l|l|}
\hline Model \# & Trasnport & Assumptions & Thermo-chemistry \\
\hline 1 & Fick's Model & $\nabla \mathrm{P}=0$ & Not included \\
\hline 2 & DGM & $\nabla \mathrm{P}$ and $\nabla \mathrm{c}_{\mathrm{i}}$ are constant & Not included \\
\hline 3 & DGM & None & Not included \\
\hline 4 & DGM & None & $\begin{array}{l}\text { Detailed kinetics of heterogeneous } \\
\text { chemistry }\end{array}$ \\
\hline
\end{tabular}

Table 3.1 Summary of Anode Models

The following figures show comparisons between simulation results of all the models using the operating conditions described in Table 3.2. These are the same design and operating conditions used by Zhu et al. [1]

\begin{tabular}{|lcc|}
\hline Operating condition & Value & Units \\
\hline Fuel composition at the channel & & \\
$\mathrm{H}_{2}(6 \%), \mathrm{H}_{2} \mathrm{O}(5 \%), \mathrm{CO}(3 \%), \mathrm{CO}_{2}(4 \%), \mathrm{CH}_{4}(12 \%)$ & and $\mathrm{Ar}(70 \%)$ & $\mathrm{A} / \mathrm{cm}^{2}$ \\
Current densitys & 0.6 & $\mathrm{~K}$ \\
Temperature & 1028 & $\mathrm{Units}$ \\
Anode Parameters & Value & $\mu \mathrm{m}$ \\
\hline Anode & & \\
Thinkness $\left(\mathrm{L}_{\mathrm{a}}\right)$ & 1000 & \\
Porosity $(\varepsilon)$ & 0.35 & $\mu \mathrm{m}$ \\
Tortousity $(\tau)$ & 3.50 & $\mu \mathrm{m}^{-1}$ \\
Average pore diameter $\left(\mathrm{d}_{0}\right)$ & 1.00 & $\mathrm{~cm}^{-1}$ \\
Average particle diameter $\left(\mathrm{d}_{\mathrm{p}}\right)$ & 2.50 & 1080 \\
Specific catalyst area $\left(\mathrm{A}_{\mathrm{s}}\right)$ & 1080 & \\
\hline
\end{tabular}

Table 3.2 Operating Conditions and Anode Parameters

Results of Model 1 show that there is no concentration change in gases other than $\mathrm{H}_{2}$ and $\mathrm{H}_{2} \mathrm{O}$. For Argon, an inert gas, all models show relatively similar results. The results of Model 2 and Model 3 are almost same as indicated by the circles in Figure 3-1 to Figure 
3-6. Hence, if there is no chemical reaction within the anode, the previously applied assumption that concentration and pressure profiles are linear is reasonable. If the fuel and oxidant are supplied only with inert gases such as argon or nitrogen, where there is no chemical reaction, linear concentration and pressure assumptions could reduce computational cost without losing much accuracy.

Moreover, thermo-chemical reactions result in substantial changes in gas concentrations such as indicated by arrows in Figure 3-1 to Figure 3-6. Because of the water-gas-shift reaction, $\mathrm{H}_{2} \mathrm{O}+\mathrm{CO} \rightarrow \mathrm{H}_{2}+\mathrm{CO}_{2}$, and steam reforming, $\mathrm{CH}_{4}+\mathrm{H}_{2} \mathrm{O} \rightarrow \mathrm{CO}$ $+3 \mathrm{H}_{2}, \mathrm{H}_{2}$ and $\mathrm{CO}_{2}$ are produced while $\mathrm{H}_{2} \mathrm{O}$ and $\mathrm{CH}_{4}$ are consumed within the anode. Near the channel, steam reforming is dominant, producing $C O$, while water-gas-shift reaction is dominant near the interface, consuming $\mathrm{CO}$. Hence, as the gas species moves toward the interface between the anode and the electrolyte, carbon dioxide and hydrogen increase and methane while carbon monoxide fist increases and then decreases. 


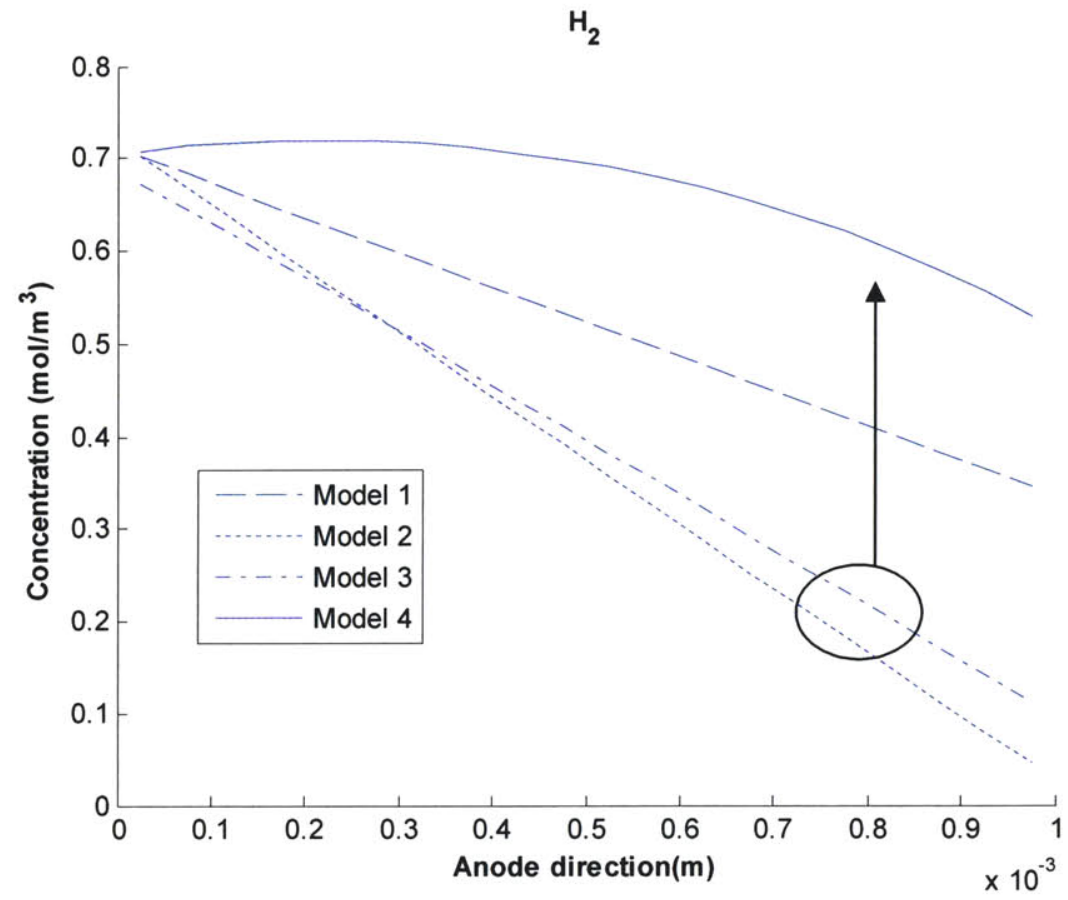

Figure 3-1 Concentration of $\mathrm{H}_{2}$ in the anode

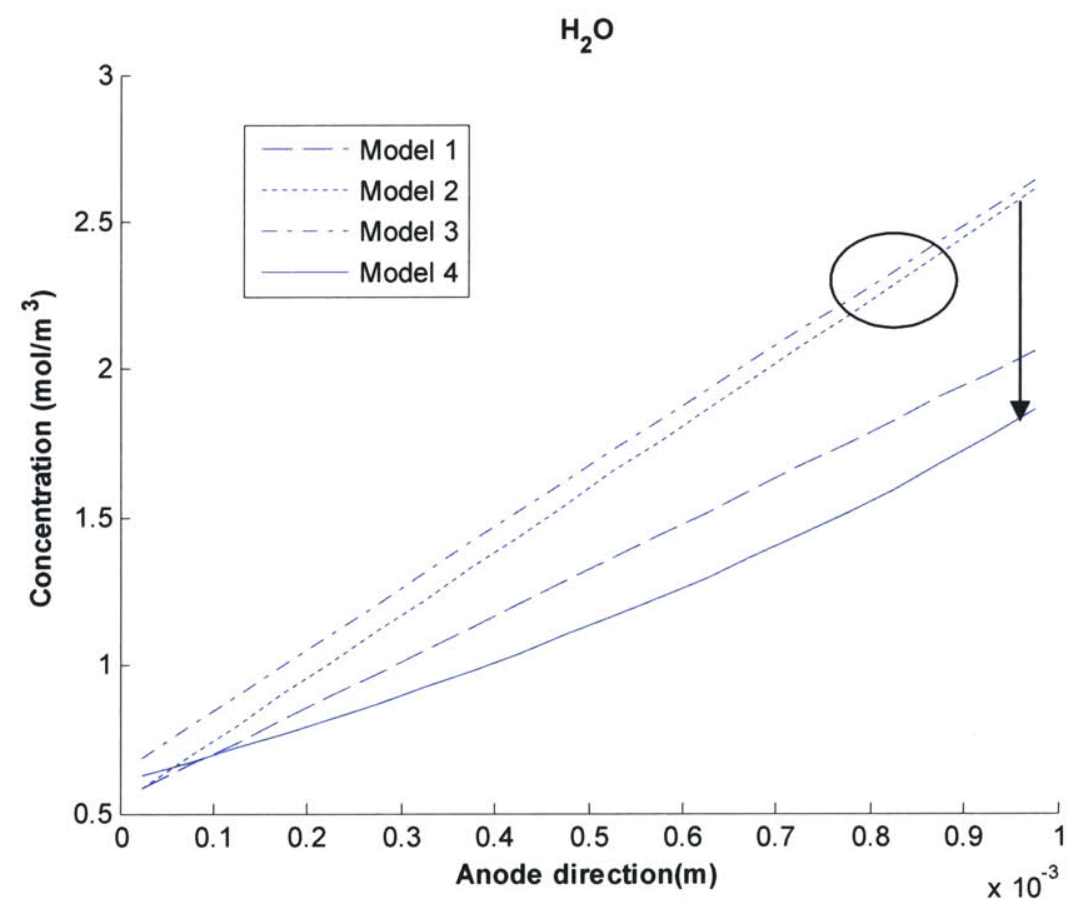

Figure 3-2 Concentration of $\mathrm{H}_{2} \mathrm{O}$ in the anode 


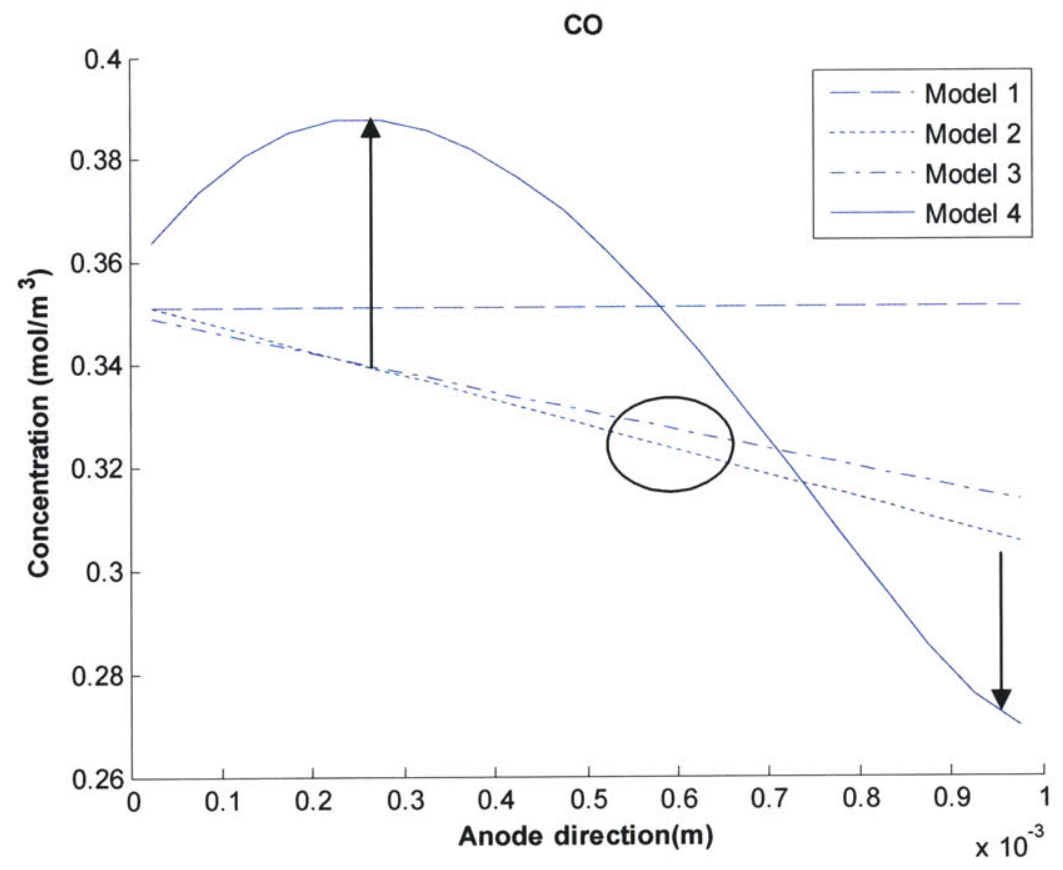

Figure 3-3 Concentration of $\mathrm{CO}$ in the anode

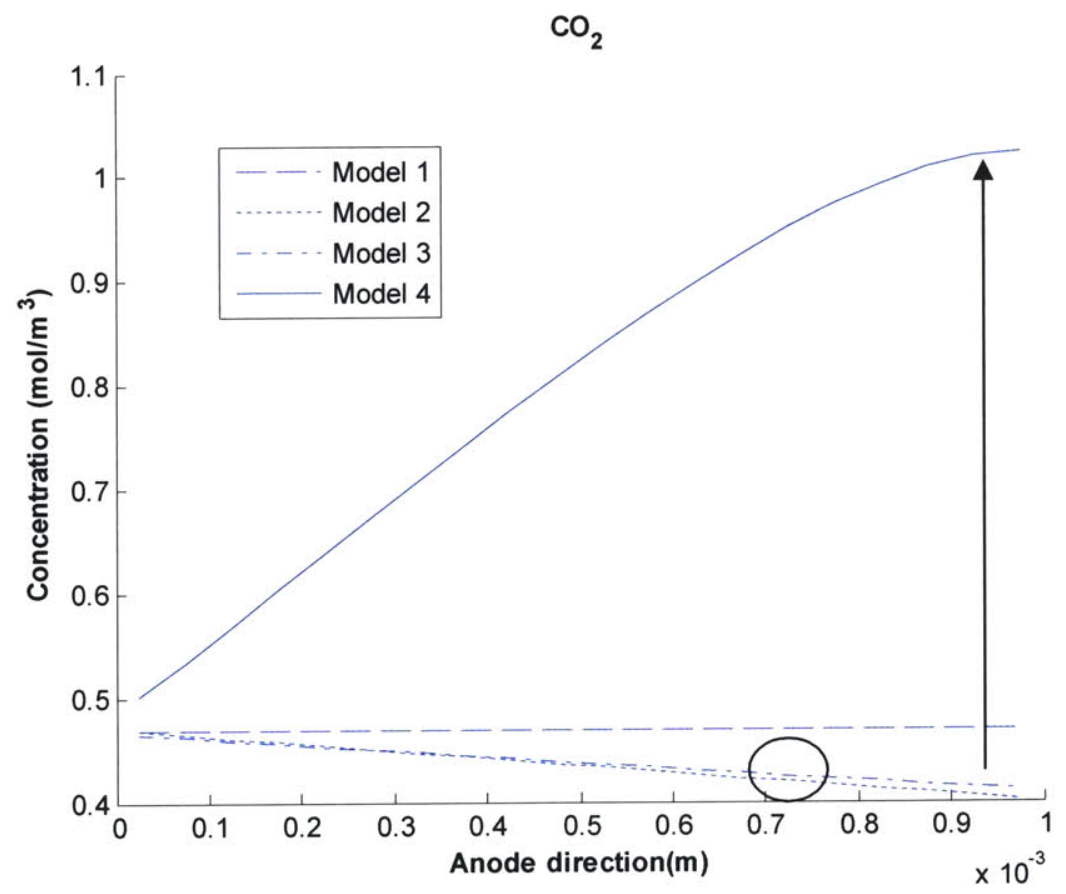

Figure 3-4 Concentration of $\mathrm{CO}_{2}$ in the anode 


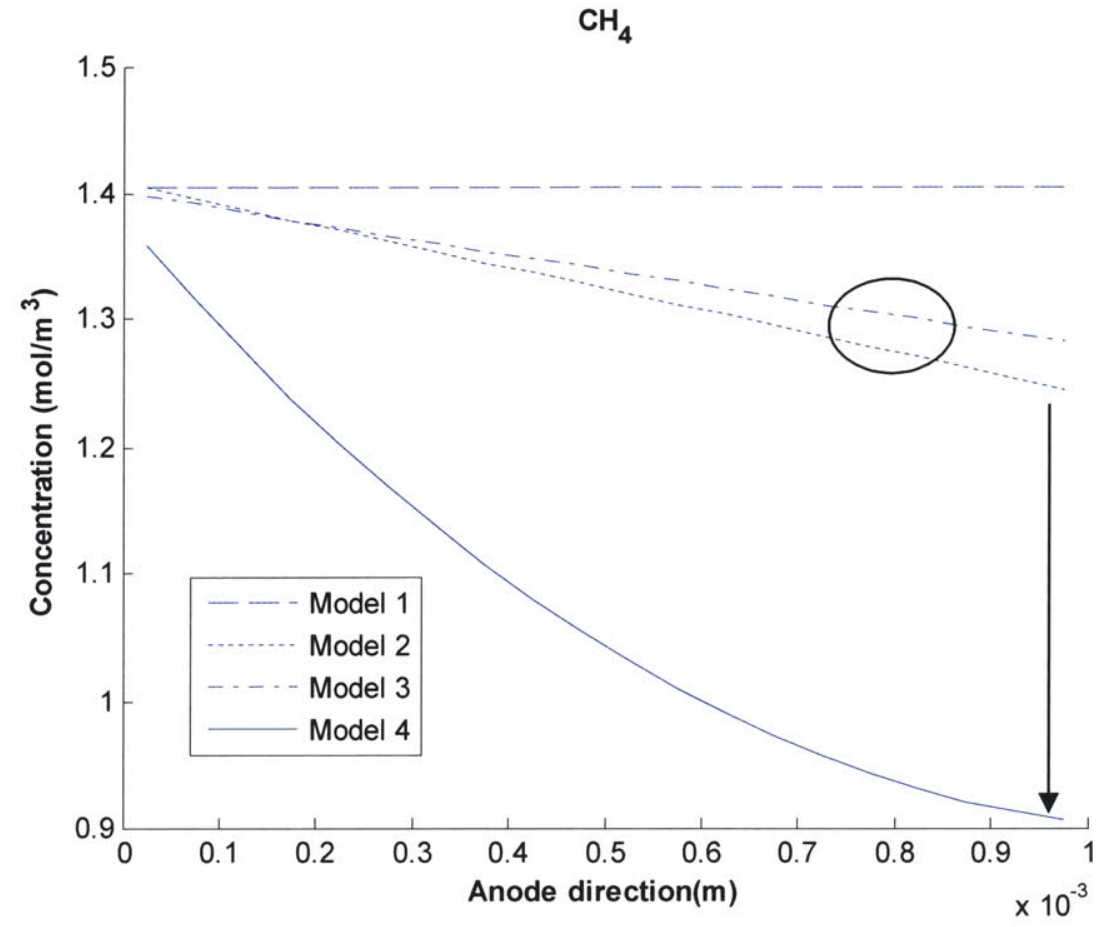

Figure 3-5 Concentration of $\mathrm{CH}_{4}$ in the anode

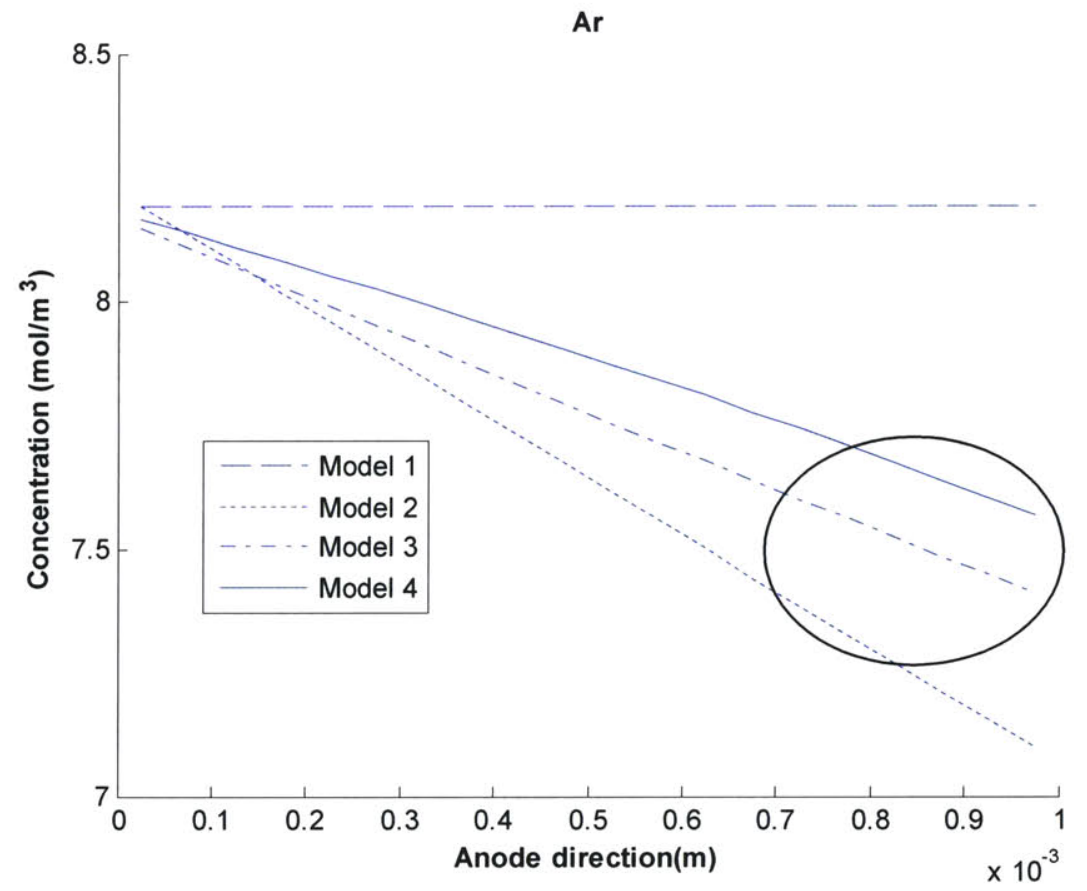

Figure 3-6 Concentration of Ar in the anode 


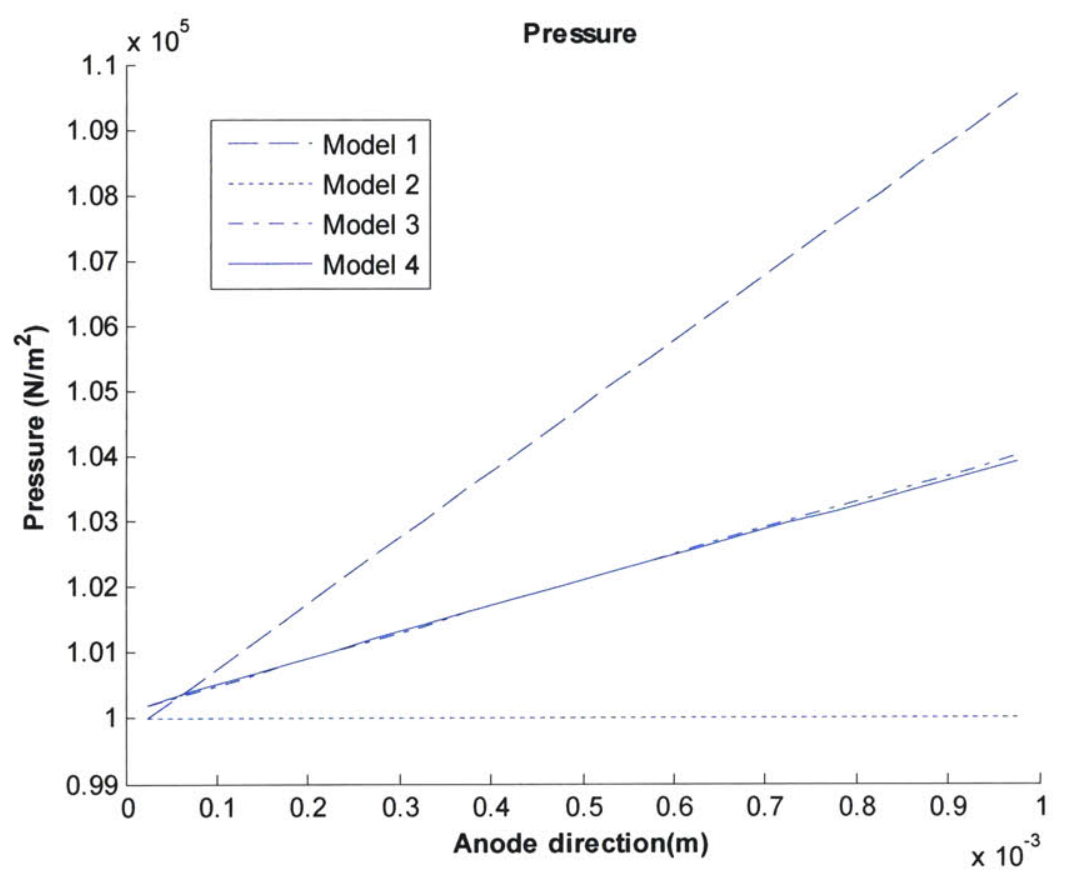

Figure 3-7 Pressure Distribution in the anode

\subsection{An Improved MEA model}

Many MEA models have been suggested during the last several decades. However, different approaches has been adopted to model significantly complex physical, thermochemical and electrochemical mechanisms. As for the transport in the electrode, Fick's law and DGM with some assumptions have been applied. Until recently, thermo-chemistry has been handled with significant simplifying assumptions, such as global reaction kinetics or local equilibration of reforming and water-gas-shift chemistry. Regarding, the electrochemistry at TPB, it was a general approach to assume a single global chargetransfer reaction. Recently, the Multidisciplinary University Research Initiative (MURI) program developed the most detailed model based on DGM, detailed heterogeneous 
thermo-chemistry and detail electrode kinetics. Table 3.3 is the summary of current MEA models. We have improved the MURI model, which is considered the most detailed among current models.

\begin{tabular}{|l|l|l|l|}
\hline & MURI & PNNL[21] & Virkar[22] \\
\hline Transport & $\begin{array}{l}\text { DGM with linear profile } \\
\text { assumptions[29] } \\
\text { DGM[1] }\end{array}$ & $\begin{array}{l}\text { Fick's law adjusted by } \\
\text { surface diffusion }\end{array}$ & $\begin{array}{l}\text { DGM with a zero } \\
\text { pressure gradient } \\
\text { assumption }\end{array}$ \\
\hline Thermo-chemistry & $\begin{array}{l}\text { No chemistry [29] } \\
\text { Detailed heterogeneous } \\
\text { chemistry[1] }\end{array}$ & $\begin{array}{l}\text { Equilibrium } \\
\text { (Partial oxidation, } \\
\text { water-gas shift } \\
\text { reaction) }\end{array}$ & $\begin{array}{l}\text { Equilibrium } \\
\text { (Water-gas shift } \\
\text { reaction) }\end{array}$ \\
\hline Electrochemistry & $\begin{array}{l}\text { Butler-Volmer equation } \\
\text { for each electrode [29] } \\
\text { Detailed kinetics[1] }\end{array}$ & $\begin{array}{l}\text { One Butler-Volmer } \\
\text { equation for both } \\
\text { electrodes }\end{array}$ & $\begin{array}{l}\text { Effective charge } \\
\text { transfer resistance[42] }\end{array}$ \\
\hline Ohmic overpotential & Experimental equation & Experimental equation & Fitting parameter \\
\hline Program & CHEMKIN, DETChem & Excel & DOE \& SECA \\
\hline Project & ONR & SECA & \\
\hline
\end{tabular}

Table 3.3 Current MEA Models

\subsubsection{Concentration Overpotential}

First of all, our Reacting Gas Dynamics Lab model (RGD model) formulates the conservation equations in the unsteady form, allowing for analyzing the response of the MEA to imposed dynamics. There are discrepancies in the effective Knudsen diffusion coefficient and the permeability between our RGD model and the MURI model. The effective Knudsen diffusion coefficient [11,43]

$$
D_{i M}^{e}=\frac{d_{o}}{3} \frac{\varepsilon}{\tau} \sqrt{\frac{8 R T}{\pi M_{i}}}
$$

is mistakenly referred in the MURI model as $[1,29]$ 


$$
D_{i M}^{e}=\frac{2 d_{o}}{3} \frac{\varepsilon}{\tau} \sqrt{\frac{8 R T}{\pi M_{i}}}
$$

The permeability can be expressed by the Kozeny- Carman model when the porous electrode is assumed to be an aggregated bed of spherical particles with diameter $d_{p}$ as [15, 44]

$$
B_{0}=\frac{d_{p}^{2}}{36 k_{0} \tau} \frac{\varepsilon^{3}}{(1-\varepsilon)^{2}}
$$

where $k_{0}$ is a shape factor.

Carman reported that the best value of the combined factor, $k_{0} \tau$ to fit most experimental data on packed beds is equal to 5, which is the so-called Kozeny constant. Then, the permeability can be expressed as

$$
B_{0}=\frac{d_{p}^{2}}{180} \frac{\varepsilon^{3}}{(1-\varepsilon)^{2}}
$$

Wyllie and coworkers found the shape factor, $k_{0}$, lies between 2.0 and $3.0[44]$. The MURI model might use the shape factor of 2 to calculate the permeability as follows [1, 29]

$$
B_{0}=\frac{d_{p}^{2}}{72 \tau} \frac{\varepsilon^{3}}{(1-\varepsilon)^{2}}
$$

Both expressions for the permeability are correct, but we adopt the original Kozeny-Carman relation.

The two terms have two to four times larger values than in the MURI model, based on a tortuosity of 3.5. Each term that has been modified from the MURI model has been underlined and the approximate influences of each term are expressed in Figure 3-8. 


$$
\begin{array}{r}
-\nabla c_{i}=\sum_{j \neq i)} \frac{1}{c_{t} D_{i j}^{e}}\left(c_{j} J_{i}-c_{i} J_{j}\right)+\frac{J_{i}}{\underline{D_{i M}^{e}}}+\frac{B_{0}}{\underline{\underline{\mu_{m i x}^{v}}}} \frac{c_{i}}{D_{i M}^{e}} \nabla p \\
2 \text { times } 4 \text { times }
\end{array}
$$

Figure 3-8 Impact of Correcting Terms

\subsubsection{Activation Overpotential}

As far as the detailed electrochemistry model is concerned, we additionally analyzed the possibilities that reactions other than reaction (3) are rate-limiting and assumed that reaction (3) is rate-limiting because it can explain previous experimental results. We will examine the possibility that hydrogen adsorption reaction (1) is ratelimiting, which was excluded from the possible rate-limiting reaction in Chapter 2 because it is claimed that hydrogen adsorption rate is several order of magnitude higher than the current density $[33,35]$. When the hydrogen adsorption rate is calculated in the previous literature, the electrode area is used instead of TPB area where the electrochemical reactions occur. However, the actual TPB area is much smaller than the electrode area as follows.

(a) Three Phase Boundary(TPB) area

Recently, a 3D reconstruction of the Ni-YSZ composite anode, typical of an anodesupported SOFC, is obtained by stacking the $2 \mathrm{D}$ scanning electron microscopy (SEM) images in 3D space. From the 3D reconstruction, the volume-specific TBP length is directly measured and is found to be $4.28 \times 10^{12} \mathrm{~m} / \mathrm{m}^{3}$. The TPB must be connected to the rest of the structure for the electrochemical reactions to take place. 
That is, the pore must be connected through the surrounding pore network to the fuel stream, the Ni phase to the external electrical circuit, and the YSZ phase to the bulk YSZ electrolyte. It is reported that $63 \%$ of TPBs are interconnected. [45]. It is argued that the TPB width is in the range of $0.1 \sim 1 \mathrm{~nm}$ in [46] and $0.5 \mathrm{~nm}$ in [21]. The active thickness of the anode is about $10 \mu \mathrm{m}$ [47]. Based on these figures, the TPB area per the actual electrode area can be calculated as follows

$$
\frac{A_{T P B}}{A_{\text {electrode }}}=\left(\frac{4.28 \times 10^{12} \mathrm{~m}}{\mathrm{~m}^{3}}\right) \times 63 \% \times(0.5 \mathrm{~nm}) \times(10 \mu \mathrm{m})=0.013 \quad \text { Eq. } 3-13
$$

(b) Hydrogen adsorption rate at TPB

Using Eq. 2-43, the hydrogen adsorption rate can be computed from

$$
R_{1}=10^{-2} \sqrt{\frac{\Re T}{2 \pi M_{H_{2}}}} c_{H_{2}} \theta_{v}^{2}
$$

The concentration of hydrogen in the fuel channel is in the order of several mole $/ \mathrm{m}^{3}$. If all the adsorbed hydrogen reacts, the order of magnitude of the current density is

$$
i=\frac{A_{T P B}}{A_{\text {electrode }}} \times F \times R_{\mathrm{1}} \sim O\left(1 \mathrm{~A} / \mathrm{cm}^{2}\right)
$$

Actually, $A_{T P B}$ is the combined area of nickel and YSZ surfaces. Furthermore, the current model assumes that only hydrogen can be adsorbed on the nickel surfaces. However, $\mathrm{H}_{2}, \mathrm{H}_{2} \mathrm{O}, \mathrm{OH}$, and $\mathrm{O}$ can be competitively adsorbed on the nickel surfaces. Considering the actual TPB area and competitive adsorption, the hydrogen adsorption can be rate-limiting reaction. 
(c) Rate-limiting switch-over

The experimental results supporting that reaction (3) is the rate-limiting are not obtained near the limiting current density. Also, it has been argued based on experimental results that the adsorption of hydrogen might be the rate-limiting process in the anode[35, 37]. Therefore, we propose that the rate-limiting reaction switches from the charge-transfer reaction (3) to hydrogen adsorption reaction (1) near the limiting current density where a vast amount of water molecules are produced and waiting to be desorbed, preventing hydrogen from being adsorbed.

(d) I-V relation for the hydrogen adsorption rate-limiting

The relationship between current density and activation overpotential can be obtained following the same approach when reaction (4) is assumed to be ratelimiting. Assuming that other reactions are in equilibrium and rates of hydrogen adsorption reaction and the previous rate-limiting reaction are same, the relation between current density and activation overpotential can be obtained.

$$
\begin{gathered}
\frac{\theta_{N_{i}} \theta_{O H}}{\theta_{O} \theta_{H}}=K_{2} \exp \left(\frac{F \varepsilon_{a}}{R T}\right) \\
\frac{\theta_{Y S Z} p_{H_{2} O}}{\theta_{H_{2} O}}=K_{4} \\
\frac{\theta_{Y S Z}}{\theta_{O}}=K_{5} \\
k_{3, a} \theta_{H} \theta_{O H} \exp \left(\frac{\beta_{3, a} F \varepsilon_{a}}{\mathfrak{R} T}\right)-k_{3, c} \theta_{H_{2} O} \theta_{N i} \exp \left(-\frac{\beta_{3, c} F \varepsilon_{a}}{\mathfrak{R} T}\right)=k_{1 f} \theta_{N i}^{2} p_{H_{2}}-k_{1 b} \theta_{H}^{2}
\end{gathered}
$$


Following the same approach, we can show that

$$
\begin{gathered}
i=i_{0}\left[\exp \left(\frac{0 F \eta_{a}}{R T}\right)-\exp \left(-\frac{\left(1+\beta_{3, a}+\beta_{3, c}\right) F \eta_{a}}{R T}\right)\right] \\
i_{0}=i_{H_{2}}^{*}\left(p_{H_{2}}\right) \\
i_{H_{2}}^{*}=2 F l_{T P B} k_{1 f}=2 F \frac{A_{T P B}}{A_{\text {electrode }}} \frac{S_{i}^{0}}{\sqrt{2 \pi R T M_{H_{2}}}}
\end{gathered}
$$

In this case, the exchange current density is found to be the adsorption rate of hydrogen on the TPB area.

\subsection{Simulation method}

The model is used to determine the cell voltage for a given current density. The cell potential is expressed as the difference between the equilibrium potential $\mathrm{E}$ and the sum of all the relevant overpotentials, which depend on the current density.

$$
E_{\text {cell }}=E_{\text {rev }}-\eta_{c o n c, a}-\eta_{a, a}-\eta_{\text {ohm }}-\eta_{c o n c, c}-\eta_{a, c}
$$

The solution procedure follows several steps as follows:

(1) Calculate the equilibrium potential based on the global electrochemical reaction

The equilibrium potential depends on the fuel and oxidant compositions in the corresponding channels, temperature and pressure.

(2) Calculate concentration overpotentials

- Set up the boundary conditions

Boundary conditions at the channel-electrode interface are established by requiring 
the gas-phase species concentrations to match those in the gas channel. At the anode/electrolyte interface, the boundary condition of each gas species depends on the charge-transfer chemistry, and hence the current density.

$$
J_{k}=v_{k} \frac{i}{z F}
$$

For the anode of the hydrogen fuel cell, $\mathrm{H}_{2}+\mathrm{O}^{2-} \leftrightarrow \mathrm{H}_{2} \mathrm{O}+2 e^{-}$,

$$
J_{H_{2}}=\frac{i}{2 F}
$$

- calculate the molar flux, $J_{k}$ using the current values of the concentrations by substituting in the DGM.

$$
-\nabla c_{i}-\frac{B_{0}}{\mu_{m i x}^{v}} \frac{c_{i}}{D_{i M}^{e}} \nabla P=\sum_{j(\neq i)} \frac{1}{c_{i} D_{i j}^{e}}\left(c_{j} J_{i}-c_{i} J_{j}\right)+\frac{J_{i}}{D_{i M}^{e}}=[H][J]
$$

$[H]$ is defined as

$$
h_{k l}=\left[\frac{1}{D_{k M}^{e}}+\sum_{j \neq k} \frac{X_{j}}{D_{k j}^{e}}\right] \delta_{k l}+\left(\delta_{k l}-1\right) \frac{X_{k}}{D_{k l}^{e}}
$$

Because the pressure is determined using the ideal gas law, the left hand side(LHS) of Eq. 3-26 can be calculated from the present values of the concentrations of gas species and the concentration boundary conditions at the channel, estimating $\nabla c_{i}$ using forward difference approximation. Also, the $\mathrm{H}$ matrix is expressed in terms of diffusion coefficients and the mole fractions. Hence, the molar flux can be calculated as

$$
[J]=[H]^{-1}[L H S]
$$

substitute $J_{k}$ in the conservation equation of the gas species 


$$
\begin{aligned}
& \frac{\partial c_{k}}{\partial t}=A_{s} \dot{s}_{\text {surf }, k}-\nabla \cdot J_{k} \quad\left(k=1, \ldots, K_{g}\right) \\
& \frac{\partial c_{\text {surf }, k}}{\partial t}=\dot{s}_{\text {surf }, k} \quad\left(k=1, \ldots, K_{s}\right)
\end{aligned}
$$

The conservation equations become a set of ordinary differential equation when equation Eq. 3-28 is cast into the finite-volume form using the flux boundary conditions at the interface. The electrodes are approximated as continuous media, with homogenized, volume averaged properties.

- Calculate $\dot{s}_{k}$ using the heterogeneous model based on the current values of the concentrations of gas and surface species.

The ODEs of gas species and surface species are solved simultaneously using 'ode15s' function in MATLAB® with the Gear's method option on.

- Calculate the concentrations at the interface between the electrodes and the electrolyte when the solution reaches the steady state.

- Calculate the concentration overpotentials for each electrode, $\eta_{c o n, a}$ and $\eta_{c o n, c}$

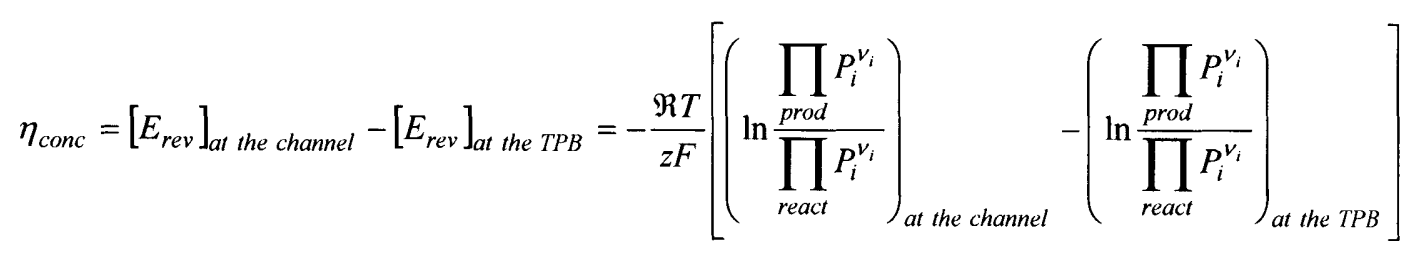

(3) Calculate the activation overpotentials for each electrode

For the anode, the activation overpotentail, $\eta_{a, a}$, can be computed using the following equations

$$
i=i_{H_{2}}^{*} \frac{\left(K_{1} p_{H_{2}}\right)^{1 / 4}\left(p_{H_{2} O}\right)^{3 / 4}}{1+\left(K_{1} p_{H_{2}}\right)^{1 / 2}}\left[\exp \left(\frac{\left(1+\beta_{a}\right) F \eta_{a, a}}{R T}\right)-\exp \left(-\frac{\beta_{c} F \eta_{a, a}}{R T}\right)\right]
$$




$$
i=i_{H_{2}}^{*}\left(p_{H_{2}}\right)\left[\exp \left(\frac{0 F \eta_{a}}{R T}\right)-\exp \left(-\frac{\left(1+\beta_{3, a}+\beta_{3, c}\right) F \eta_{a}}{R T}\right)\right]
$$

For the cathode, the activation overpotentail, $\eta_{a, c}$, can be computed using the following equation

$$
i=i_{O_{2}}^{*} \frac{\left(\frac{p_{O_{2}}}{K_{6}}\right)^{1 / 4}}{1+\left(\frac{p_{O_{2}}}{K_{6}}\right)^{1 / 2}}\left(\exp \left(\frac{F \eta_{a, c}}{2 \Re T}\right)-\exp \left(-\frac{F \eta_{a, c}}{2 \mathfrak{R T}}\right)\right)
$$

$\eta_{a, a}$ and $\eta_{a, c}$ are determined from nonlinear solver function, 'fsolve' function in MATLAB ${ }^{\circledR}$

(4) Calculate ohmic overpotential

$$
\eta_{o h m}=\frac{i l_{e l}}{\sigma_{0} T^{-1} \exp \left(-\frac{E_{e l}}{\Re T}\right)}
$$

(5) Calculate cell voltage

$$
E_{c e l l}=E_{\text {rev }}-\eta_{\text {conc }, a}-\eta_{a, a}-\eta_{\text {ohm }}-\eta_{c o n c, c}-\eta_{a, c}
$$

\subsection{Simulation Results}

Our RGD model is improved in both transport and activation overpotential model. In order to evaluate the effect of each improvement, we simulate I-V curve for the one rate-limting case like the previous models and for our proposing the rate-limiting switch-over mechanism. The button-cell experimental results by Jiang and Virkar[22] were used to establish the empirical parameters, $i_{H_{2}}^{*}$ and $i_{O_{2}}^{*}$, in the electrochemistry model by fitting MEA performance on mixtures of hydrogen and steam. 


\subsubsection{Single rate-limiting}

The structure, operating and fitting parameters are chosen as same with those of MURI model to compare the effect of the corrected Knudsen diffusion coefficient and the permeability the DGM model.

\begin{tabular}{|lll|}
\hline Parameters for an SOFC MEA structure & Value & Units \\
Parameters & & \\
\hline Anode & 1220 & $\mu \mathrm{m}$ \\
Thickness $\left(\mathrm{l}_{\mathrm{a}}\right)$ & 0.35 & \\
Porosity $(\varepsilon)$ & 3.50 & $\mu \mathrm{m}$ \\
Tortuosity $(\tau)$ & 1.00 & $\mu \mathrm{m}$ \\
Average pore diameter $\left(\mathrm{d}_{0}\right)$ & 2.50 & $\mathrm{~cm}^{-1}$ \\
Average particle diameter $\left(\mathrm{d}_{\mathrm{p}}\right)$ & 1080 & $\mathrm{~A} / \mathrm{cm}^{2}$ \\
Specific catalyst area $\left(\mathrm{A}_{\mathrm{s}}\right)$ & 8.5 & \\
$i_{H_{2}}^{*}$ (Fitting parameter) & & $\mu \mathrm{m}$ \\
Cathode & 30 & \\
Thickness $\left(\mathrm{l}_{\mathrm{c}}\right)$ & 0.35 & \\
Porosity $(\varepsilon)$ & 3.50 & $\mu \mathrm{m}$ \\
Tortuosity $(\tau)$ & 1.00 & $\mathrm{Am}$ \\
Average pore diameter $\left(\mathrm{d}_{0}\right)$ & 2.50 & \\
Average particle diameter $\left(\mathrm{d}_{\mathrm{p}}\right)$ & 2.8 & \\
$i_{O_{2}}^{*}$ (Fitting parameter $)$ & & $\mathrm{cm}$ \\
Electrolyte & & $\mathrm{J} / \mathrm{mol}$ \\
Thickness $\left(l_{\mathrm{el}}\right)$ & 25 & $\mathrm{~S} / \mathrm{cm}$ \\
Activation energy of $\mathrm{O}^{2-}\left(\mathrm{E}_{\mathrm{el}}\right)$ & $8.0 \times 10^{4}$ & $\mathrm{Atm}$ \\
Pre-factor of $\mathrm{O}^{2-}\left(\sigma_{0}\right)$ & $3.6 \times 10^{5}$ & $\mathrm{~K}$ \\
& & \\
Operating Conditions & 1 & \\
Pressure & 1073 & \\
Temperature & & \\
\hline
\end{tabular}




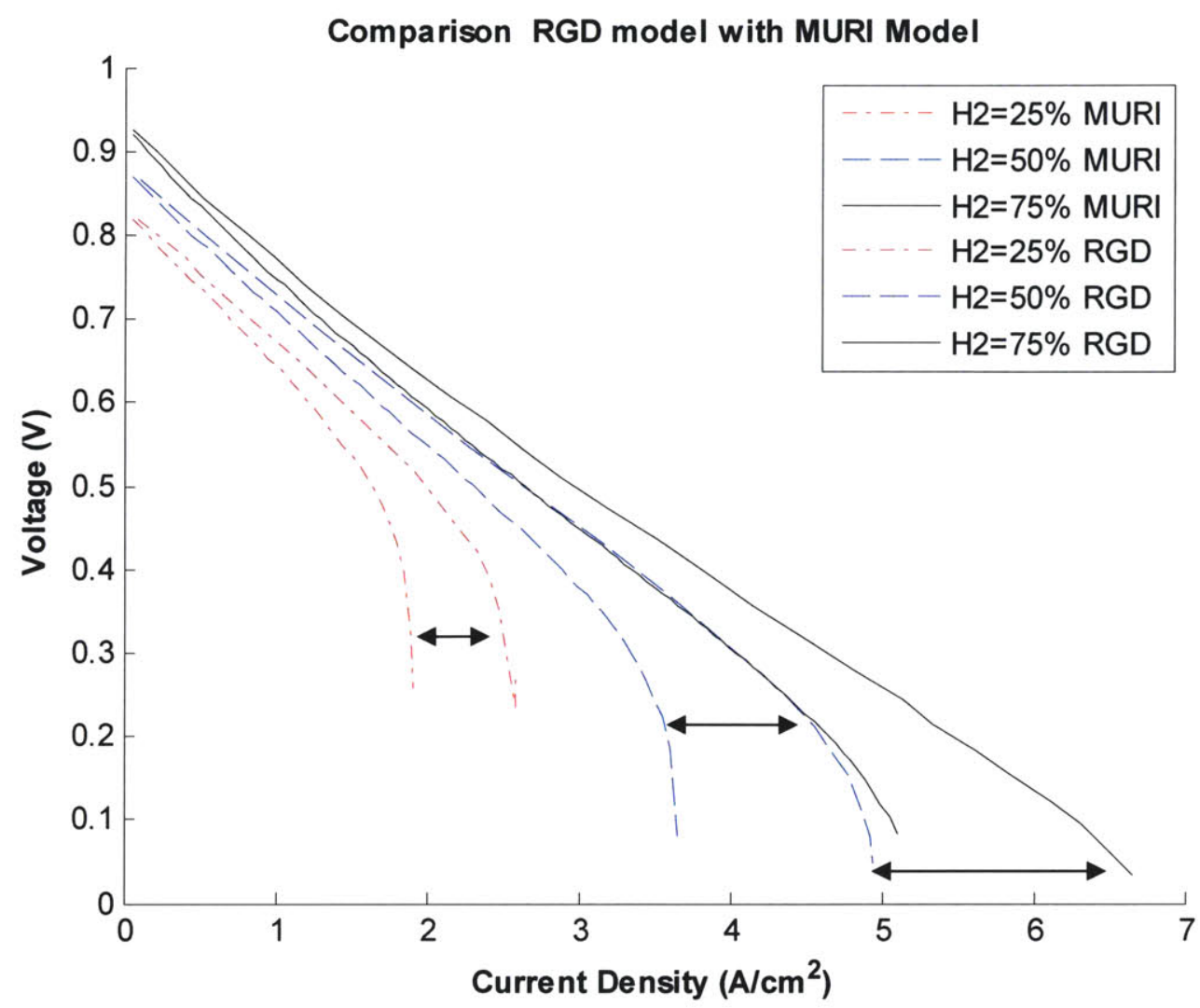

Figure 3-9 Comparison of RGD model with MURI model

Figure 3-9 shows substantial difference between our RGD model and the MURI model. In our RGD model, the corrected terms have larger values than in the MURI model. Accordingly, our model reaches the limiting current density faster.

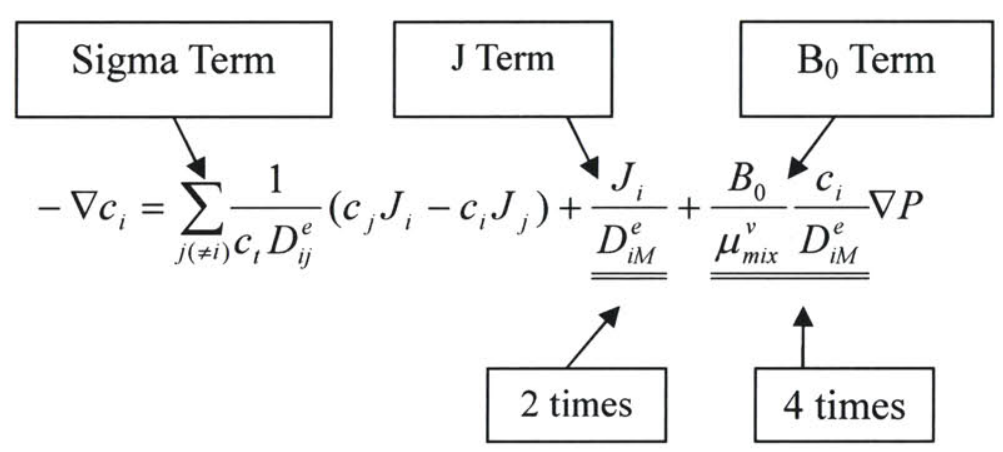


Figure 3-8 Impact of Correcting Terms

Since the current density increase leads to the rise of molar flux and pressure gradient, the magnitude of each term on the RHS of DGM increases. Figure 3-10 Figure 3-15 show an increase of each term by an order of magnitude when the current density changes from 0.2 to $3 \mathrm{~A} / \mathrm{cm}^{2}$ when the hydrogen composition is $50 \%$. .

Hence, the difference between the RGD model and the MURI model becomes considerable as the current density increases. Most of the difference results from the J-term which includes the Knudsen diffusion coefficient.

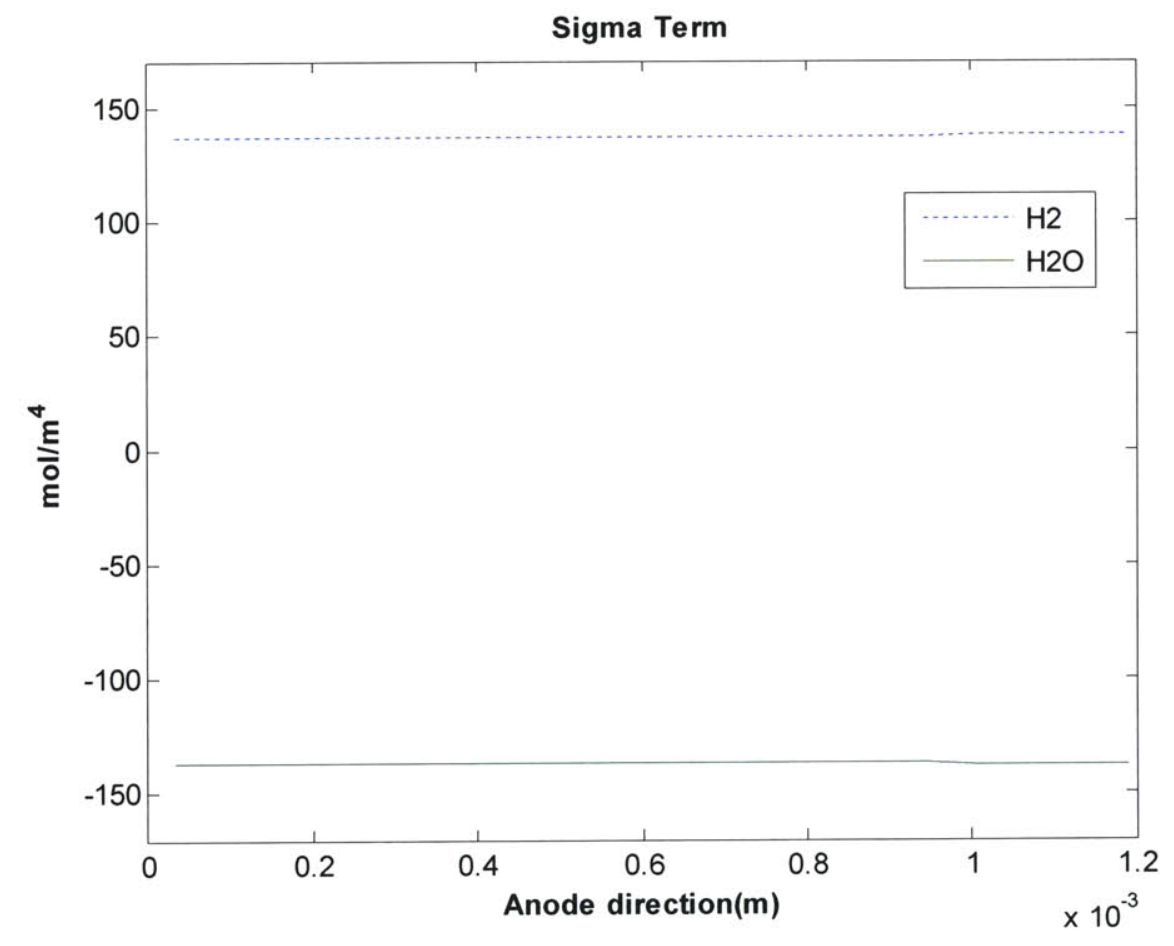

Figure 3-10 Sigma Term in DGM at the current density of $0.2 \mathrm{~A} / \mathrm{cm}^{2}$ 


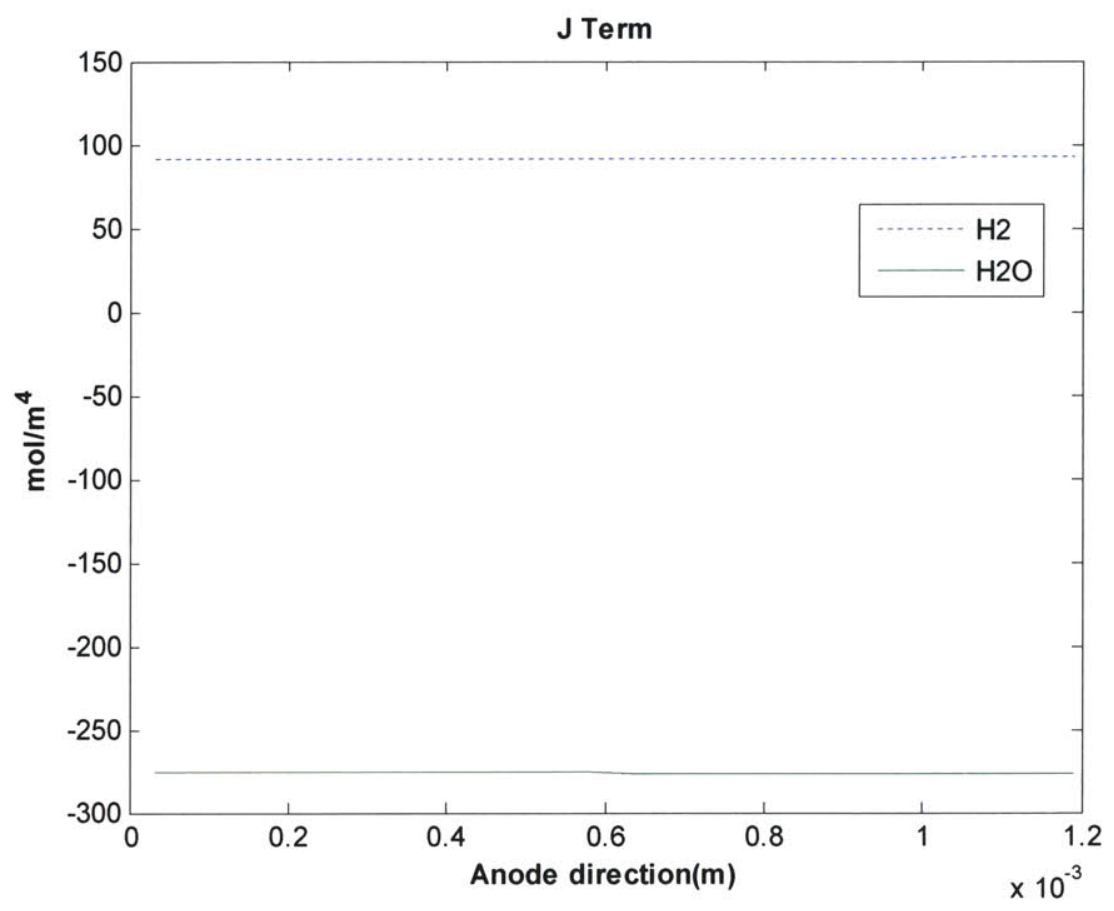

Figure 3-11 $\mathrm{J}$ Term in DGM at the current density of $0.2 \mathrm{~A} / \mathrm{cm}^{2}$

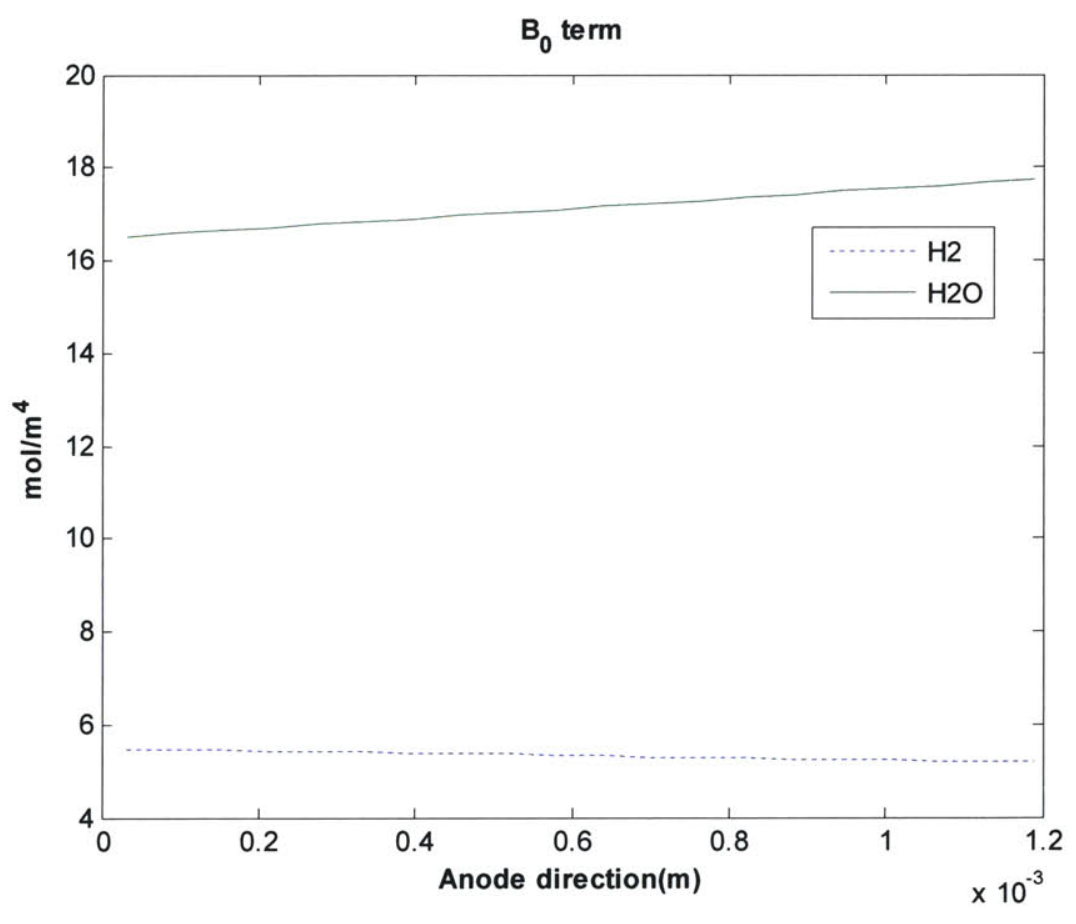

Figure $3-12 \mathrm{~B}_{0}$ Term in DGM at the current density of $0.2 \mathrm{~A} / \mathrm{cm}^{2}$ 


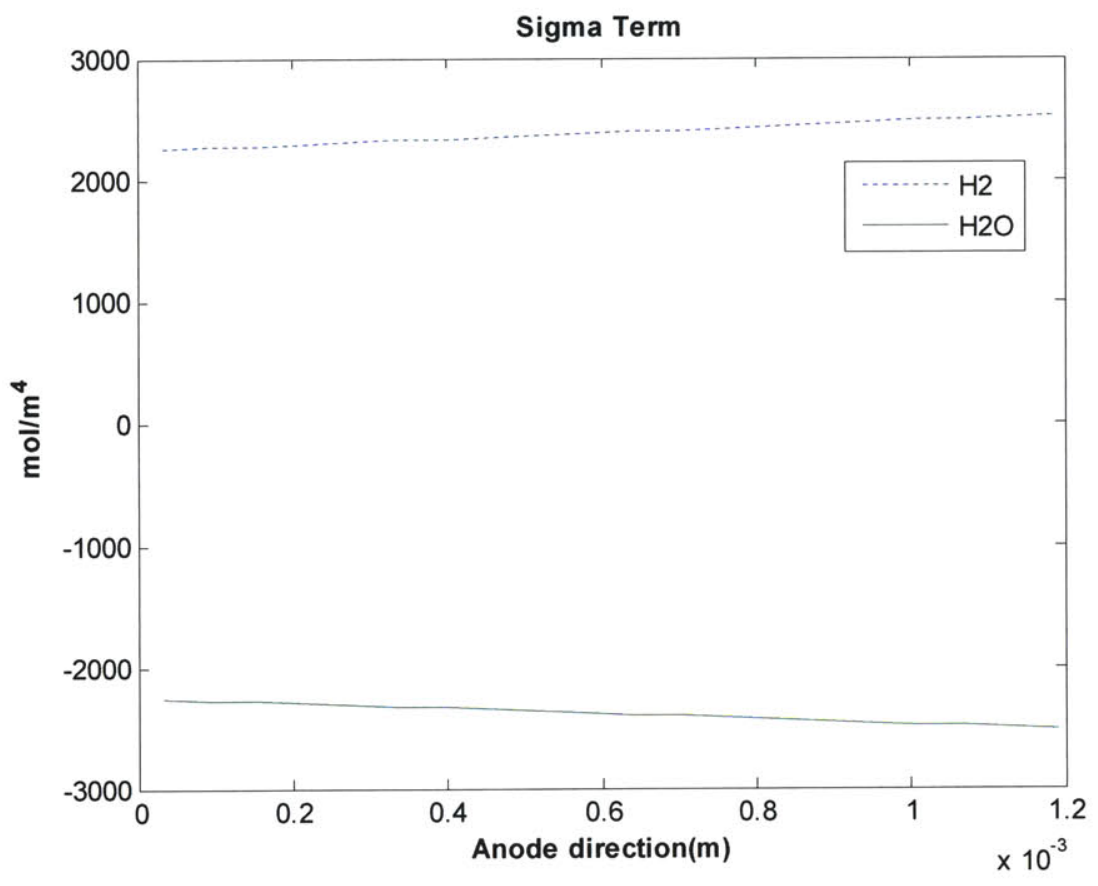

Figure 3-13 Sigma Term in DGM at the current density of $3 \mathrm{~A} / \mathrm{cm}^{2}$

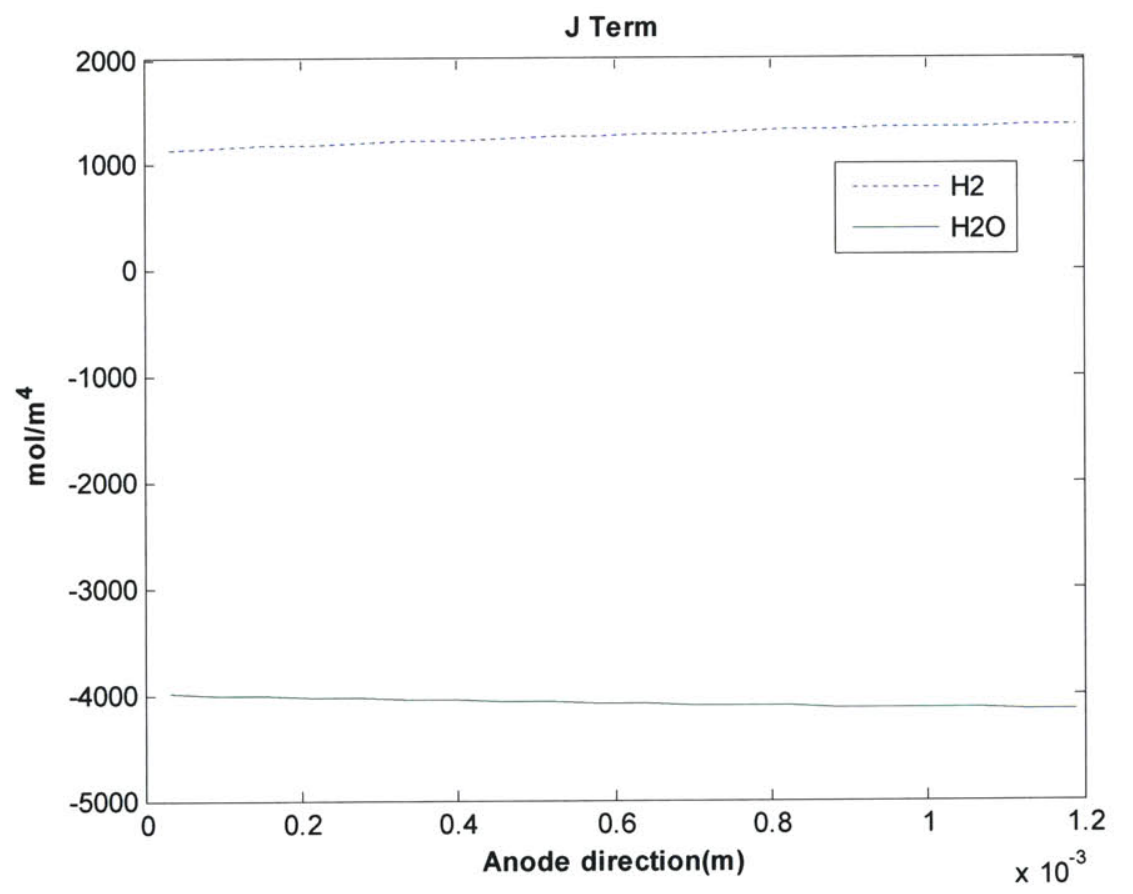

Figure 3-14 J Term in DGM at the current density of $3 \mathrm{~A} / \mathrm{cm}^{2}$ 


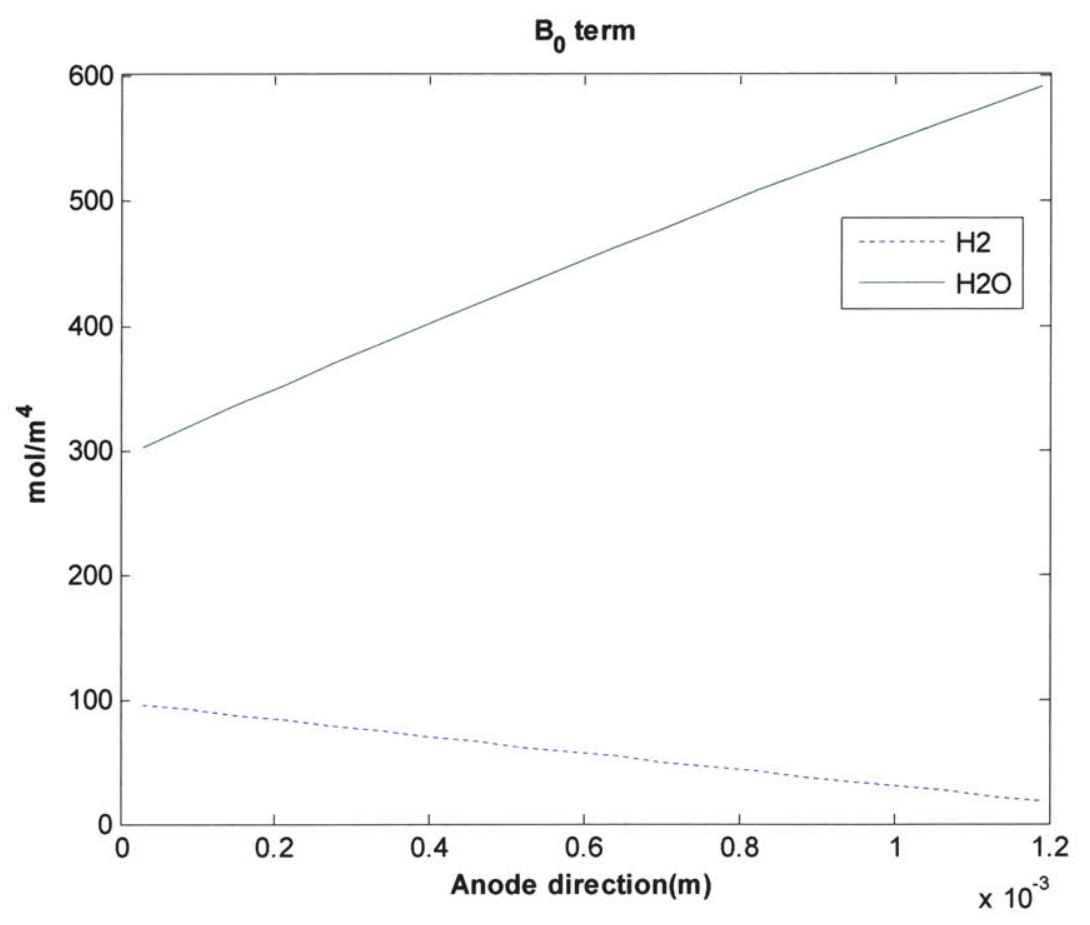

Figure 3-15 $\mathrm{B}_{0}$ Term in DGM at the current density of $3 \mathrm{~A} / \mathrm{cm}^{2}$

Figure 3-16 shows better match between our model and the experimental results by Jiang \& Virkar [22]. However, the current model with the single rate-limiting becomes inaccurate near the limiting current density as in Figure 3-17. Therefore, we will apply the rate-limiting switch-over proposed in Chapter 3.2. 


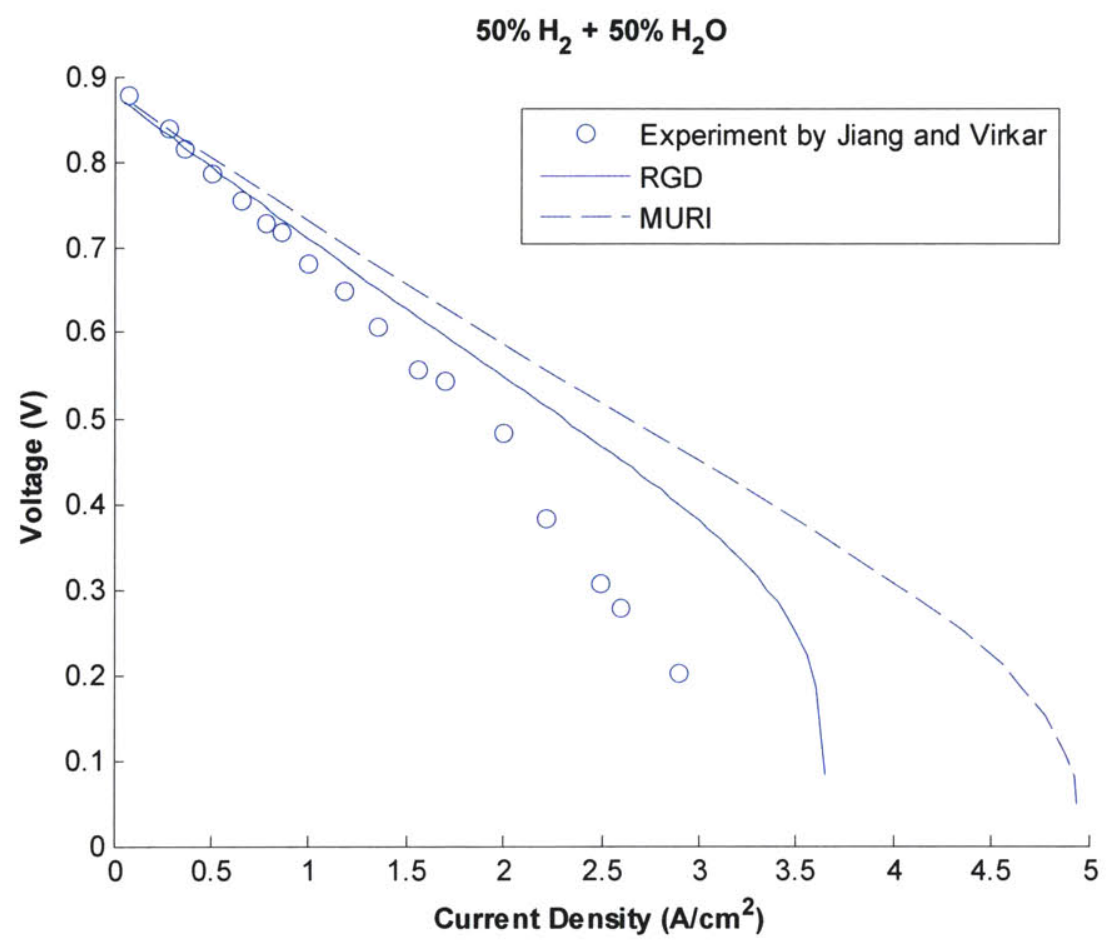

Figure 3-16 Comparison between the Experimental Data, the RGD Model and the MURI Model

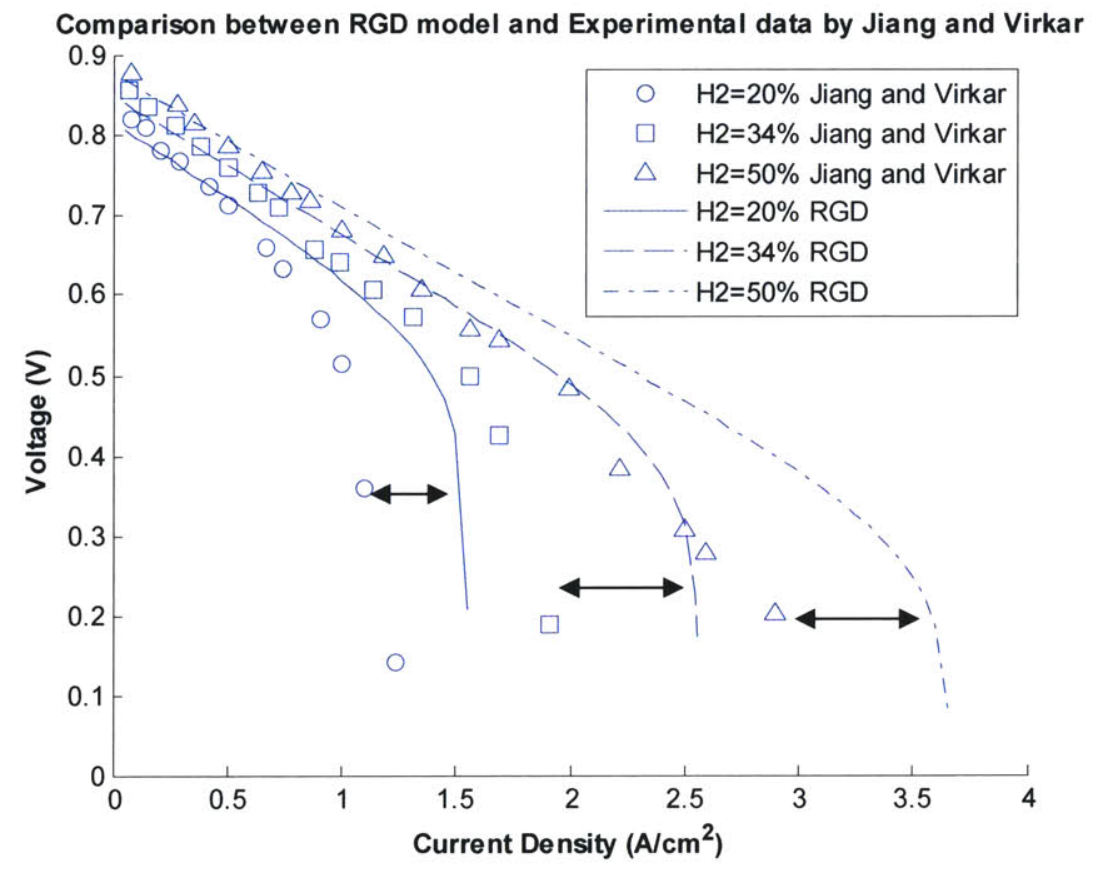

Figure 3-17 Comparison between RGD Model and Experimental Results by Jiang and Virkar 


\subsubsection{Rate-limiting switch-over}

Predicting the limiting current density has been challenging. The limiting current density determines the performance envelope of the device, when fuel utilization approaches $100 \%$, and thus sets goals for improvements. Some MEA models employ anode tortuosities in the range of 10 to 17 to predict the limiting current denstiy $[21,29,42]$. These "unphysically" high tortuosities do not seem reasonable considering that the observed range for porous sintered ceramics is usually $2-10$, and most often in the range of 2-6[21]. Williford et al. [21] tried to introduce the surface diffusion into Fick's diffusion by adjusting the diffusion coefficients assuming that the competitive adsorption and surface diffusion are responsible for the concentration overpotential. However, the adjusted diffusion coefficient was applied through the whole electrodes even though surface diffusion plays a role near the TPB only.

The surface diffusion length of hydrogen is computed to be $22 \mathrm{~nm}$ at $700^{\circ} \mathrm{C}$ and $1 \mathrm{~nm}$ at $1000^{\circ} \mathrm{C}$ based on the residence time and diffusion coefficient of adsorbed hydrogen. This shows that hydrogen that reaches the TPB must be adsorbed only a few nanometer away [33]. Since hydrogen adsorption can be rate-limiting near the limiting current density as we showed at Chapter 3.2, we proposed that the rate-limiting reaction switches from the water formation charge transfer reaction (3) to hydrogen adsorption reaction (1).

Anode activation overpotentials when reaction (1) or (3) is rate-limiting is as

follows. $i_{H_{2}}^{*}$ is adjusted to produce dilute hydrogen button-cell performance consistent with measurements by Jiang and Virkar [22]. 


\begin{tabular}{|c|c|c|c|}
\hline $\begin{array}{c}\text { Rate-limiting } \\
\text { reaction }\end{array}$ & Activation Overpotential & Exchange Current density & $i_{\mathrm{H}_{2}}^{*}$ \\
\hline 1 & $i=i_{0}\left[\exp \left(\frac{0 F \eta_{a}}{R T}\right)-\exp \left(-\frac{2 F \eta_{a}}{R T}\right)\right]$ & $i_{0}=i_{H_{2}}^{*}\left(p_{H_{2}}\right)$ & 0.00165 \\
\hline 3 & $i=i_{0}\left[\exp \left(\frac{3 F \eta_{a}}{2 \Re T}\right)-\exp \left(-\frac{F \eta_{a}}{2 \Re T}\right)\right]$ & $i_{0}=i_{H_{2}}^{*} \frac{\left(K_{1} p_{H_{2}}\right)^{1 / 4}\left(p_{H_{2} O}\right)^{3 / 4}}{1+\left(K_{1} p_{H_{2}}\right)^{1 / 2}}$ & 3.5 \\
\hline
\end{tabular}

Table 3.4 Activation Overpotential for Switch-Over Mechanism

Rate-limiting reaction switch-over for $50 \% \mathrm{H}_{2}+50 \% \mathrm{H}_{2} \mathrm{O}$

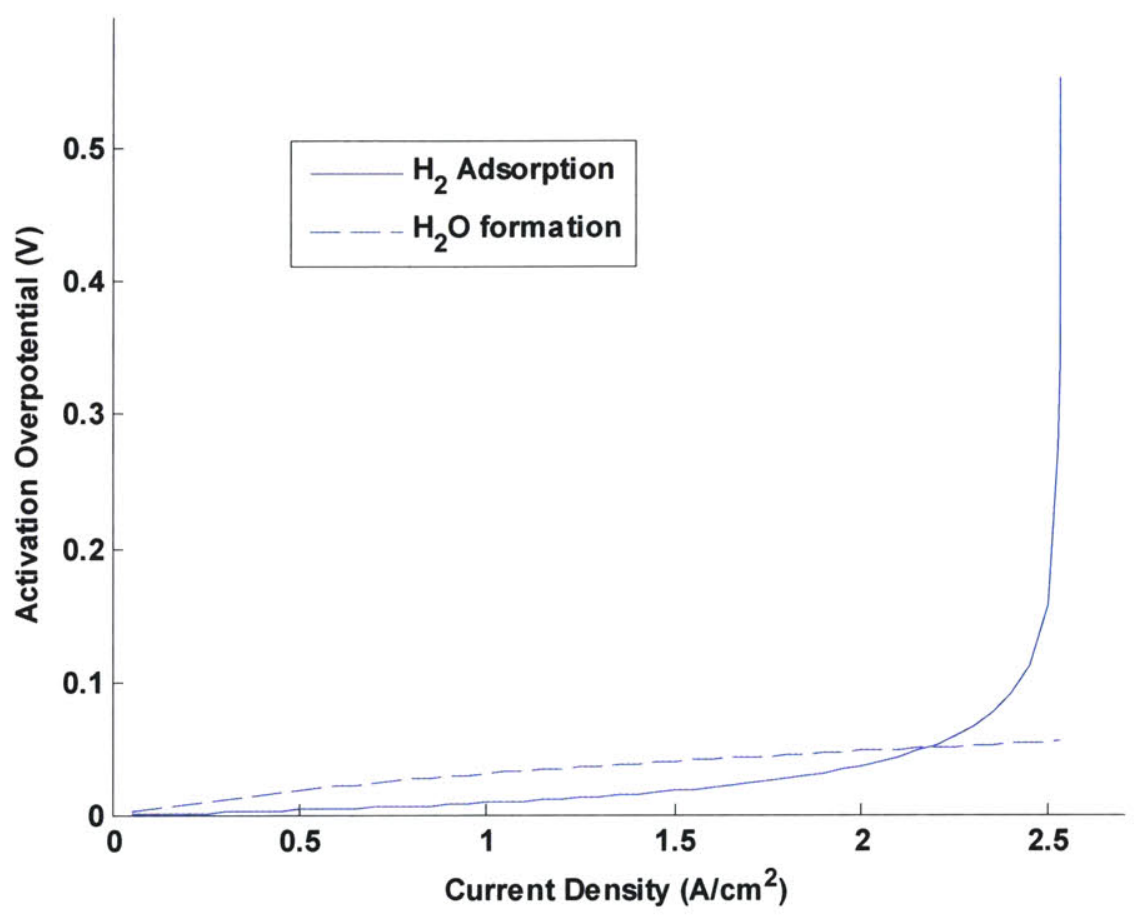

Figure 3-18 Rate-limiting Switch-over

Figure 3-18 shows that the anode activation overpotentials when reaction (1) or reaction (3) is rate-limiting. As the current density increases, the concentration of hydrogen at the interface decreases, which results in the reduction in the exchange current density. The power of the hydrogen concentration in $i_{0}$ is 1 when hydrogen adsorption is ratelimiting reaction, while it is $1 / 4$ when reaction (3) is rate-limiting. Therefore, anode activation overpotential soars when the exchange current density decreases below some 
point when hydrogen adsorption is rate-limiting. We will use the crossing point in Figure 3-18 as the switch-over point as a first guess.

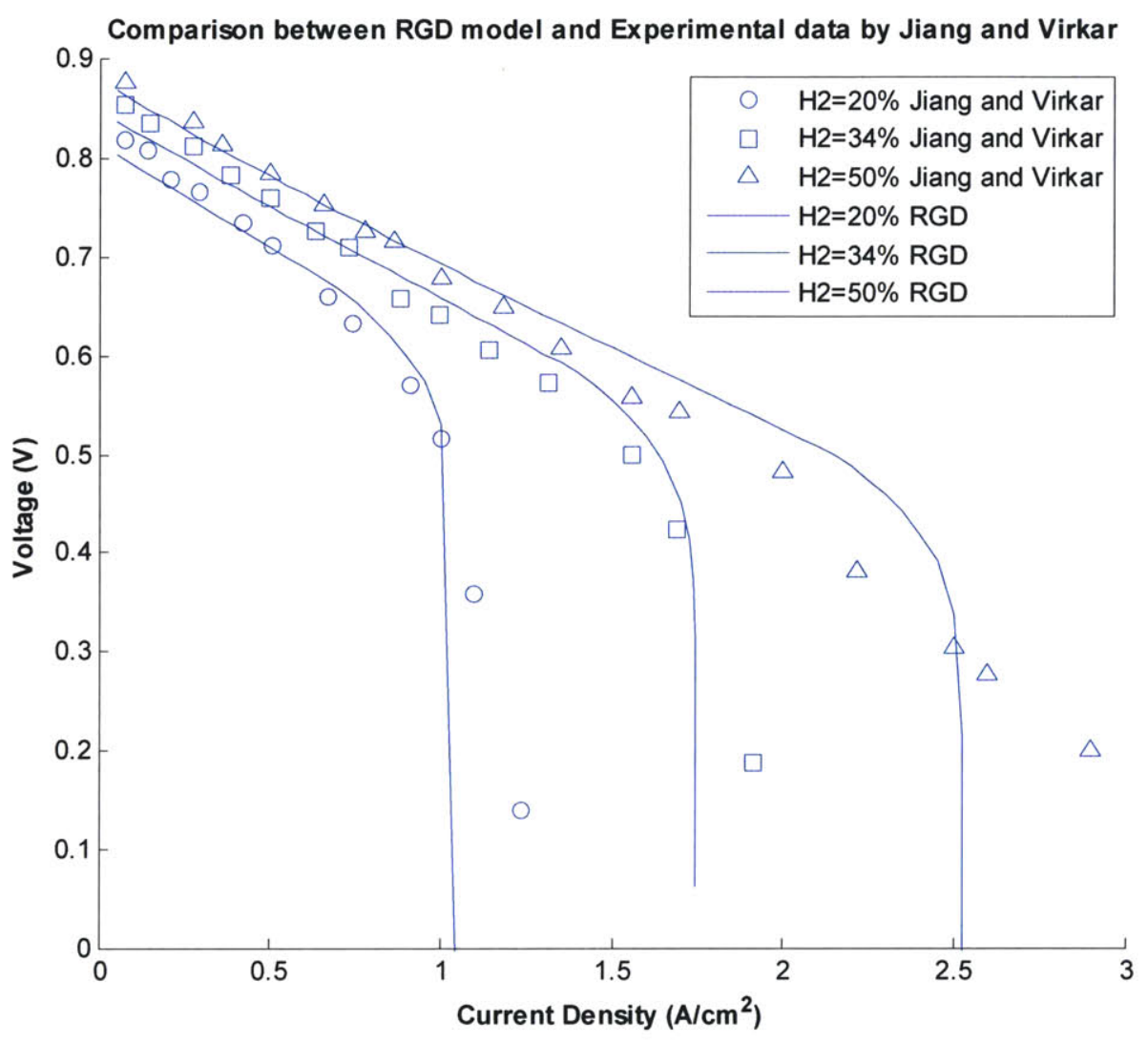

Figure 3-19 Comparison between RGD Model and Experimental Results by Jiang and Virkar

Our model with switch-over mechanism improves the prediction of the limiting current density over a range of $\mathrm{H}_{2}$ concentration in the fuel stream as shown in Figure 3-19.

When the hydrogen adsorption is the rate-limiting reaction, the physical meaning of exchange current density is the current density if all the adsorbed hydrogen reacts as in Eq. 3-22. Table 3.5 indicates the limiting current $\operatorname{density}\left(i_{\text {lim it }}\right)$ and the switching current density, $i_{\text {swich }}$, when it is 0.6 of the exchange current density. The crossing points defined 
in Figure 3-18 is located around the $i_{\text {switch }}$. The switching current density is about 0.8 of the limiting current density.

\begin{tabular}{|c|c|c|c|}
\hline $\begin{array}{c}\text { Hydrogen } \\
\text { composition }\end{array}$ & $i_{\lim i t}\left[A / \mathrm{cm}^{2}\right]$ & $\begin{array}{c}i_{\text {switch }}\left[\mathrm{A} / \mathrm{cm}^{2}\right] \\
@ i_{0} / i=1.67\end{array}$ & $\begin{array}{c}i_{\text {switch }} \\
i_{\lim i t}\end{array}$ \\
\hline $20 \%$ & 2.5273 & 2.02 & 0.79 \\
\hline $34 \%$ & 1.7465 & 1.40 & 0.80 \\
\hline $50 \%$ & 1.05 & 0.85 & 0.81 \\
\hline
\end{tabular}

Table 3.5 Rate-limiting Switch-Over Point

We propose the following hypothesis for the physics near the limiting current density. When hydrogen adsorbs well enough to support the current density, such as 1.67 times, anode activation overpotential is determined by the reaction (3). As soon as the hydrogen adsorption rate decreases below some level, the activation overpotential rises and the electrochemical reaction cannot proceed. We can find the similar analogy in the combustion. As in Figure 3-20, combustion blows out when mass-flow rate exceed some level because the chemistry couldn't follow it. The current density determines the flux boundary conditions at the interface between electrodes and electrolyte. Likewise, in order for the cell to perform, electrochemical reaction should follow the increasing current density. However, as the current density increases, the exchange current density decreases, which means that the reaction becomes sluggish, because the hydrogen concentration decreases to satisfy the required flux condition. When the exchange current density reduces below some level, the electrochemical reaction cannot sustain. 


\section{Temperature}

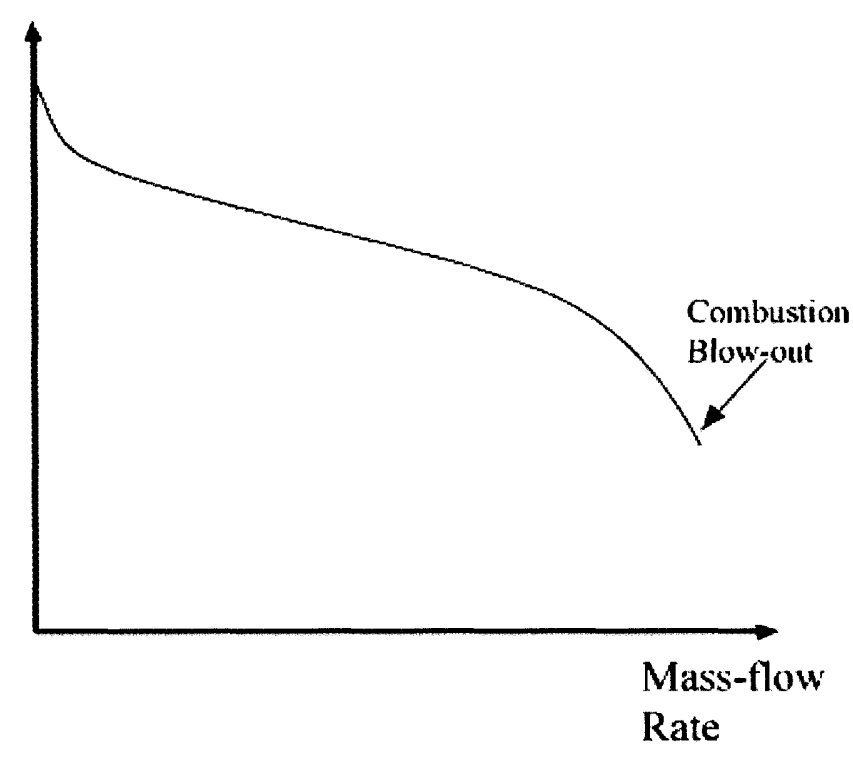

Figure 3-20 Combustion Blow-out

\subsubsection{Contribution of Each Overpotentials}

Figure 3-21, Figure 3-22, and Figure 3-23show the contributions of each overpotential for the fuel compositions of $50 \%, 34 \%$ and $20 \%$ hydrogen in the fuel stream, respectively. When the hydrogen composition is $50 \%$ and $34 \%$, the ohmic overpotential and cathode activation overpotential have the almost same magnitude, twice larger than anode activation overpotential and anode concentration overpotential, except near the limiting current density where anode activation overpotential is dominant. When hydrogen composition is $20 \%$, all overpotentials, except cathode concentration overpotential, have the same magnitude in the region away from the limiting current density. For all cases, the cathode concentration overpotential is negligible. 
For all known hydrogen/oxygen fuel cells, regardless of electrolyte type, it is believed that electrochemical reactions at the cathode are rate limiting(hydrogen electrooxidation is extremely rapid on a wide range of catalysts) and the activation overpotential is almost entirely due to cathode [3]. However, our results show that the ohmic overpotential has the same magnitude with the cathode activation overpotential. The ohmic overpotential is dominated by the ionic resistance in the electrolyte, which is a thermally activated vacancy hopping mechanism. The lower operating temperature of $800^{\circ} \mathrm{C}$, compared with the conventional SOFC, might explain these results. As we expect, the cathode activation overpotential is larger than the anode activation overpotential. However, the electrochemical reaction cannot sustain due to the anode activation overpotential near the limiting current density. When hydrocarbon fuels are utilized, anode kinetics may become rate-limiting. 


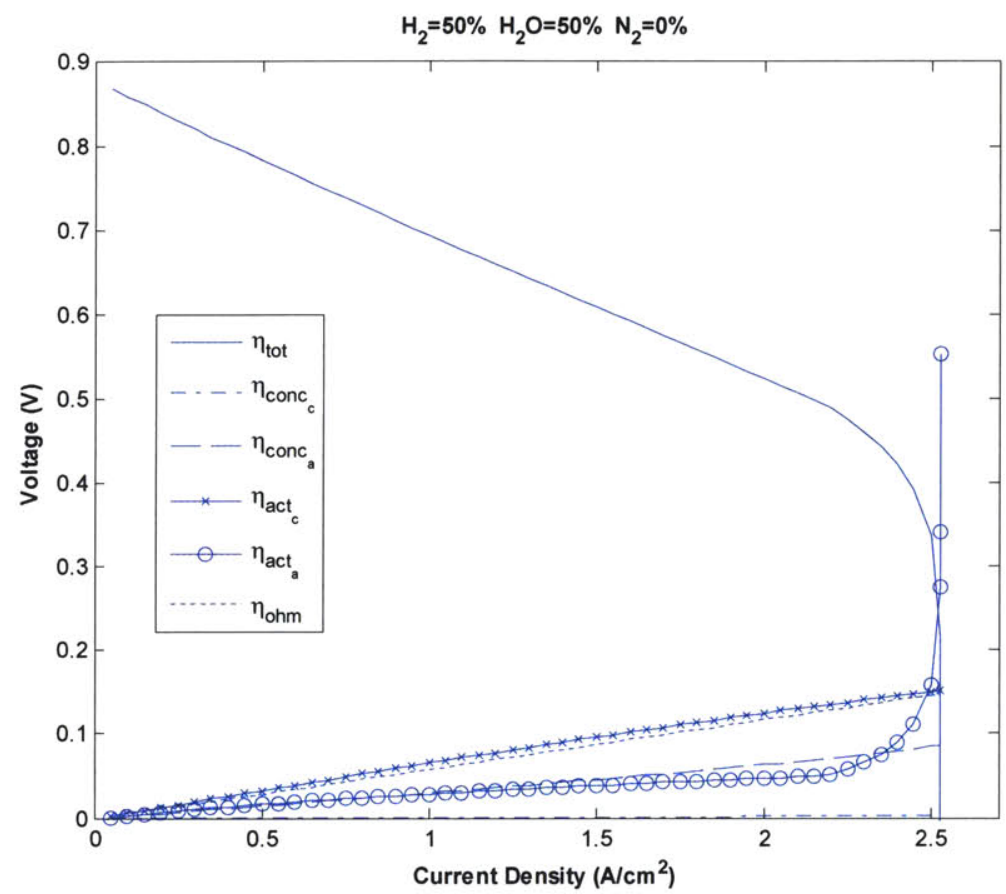

Figure 3-21 Contribution of Five Overpotentials at the fuel of $50 \% \mathrm{H}_{2}$

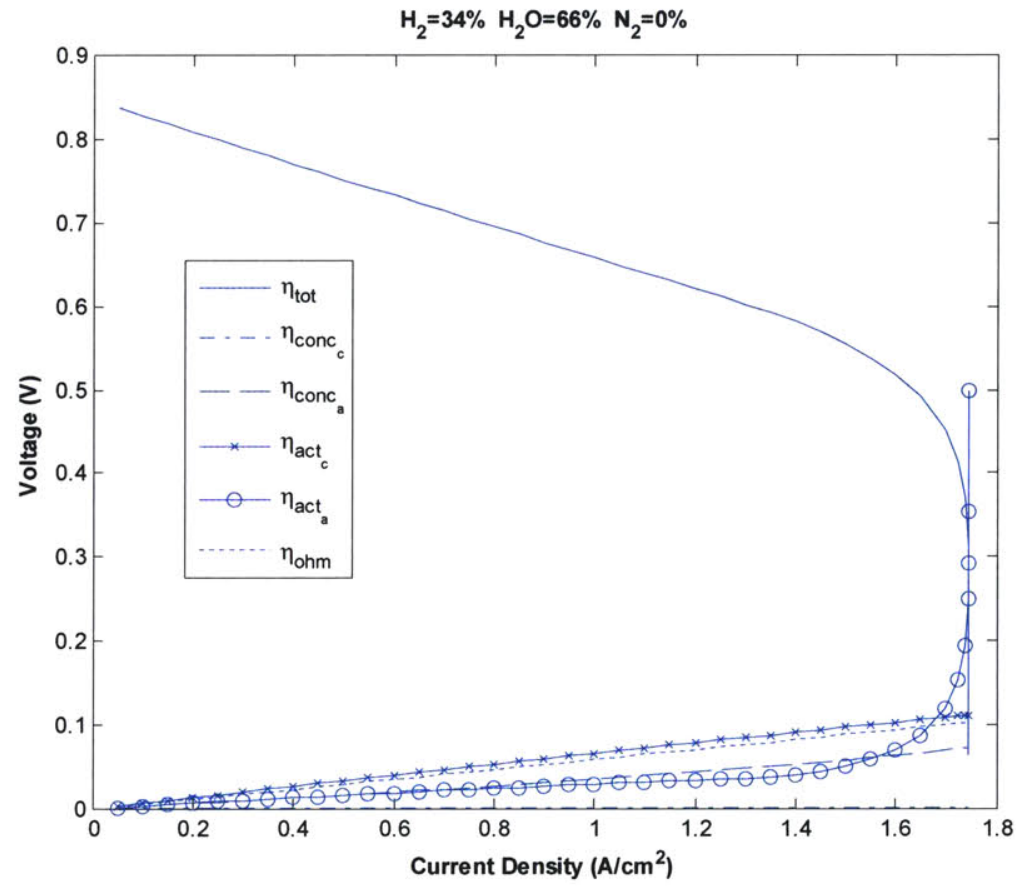


Figure 3-22 Contribution of Five Overpotentials at the fuel of $34 \% \mathrm{H}_{2}$

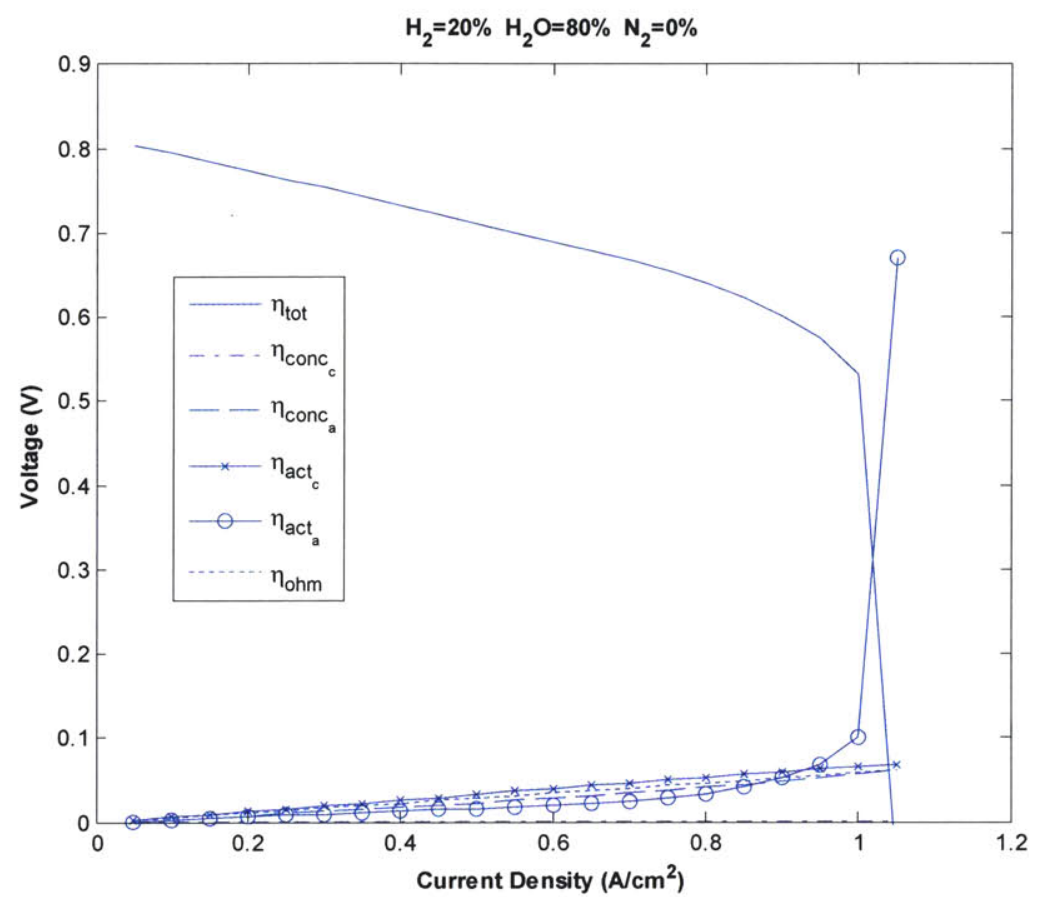

Figure 3-23 Contribution of Five Overpotentials at the fuel of $20 \% \mathrm{H}_{2}$

Existing models have tried to explain the limiting current density using the concentration overpotential, which has been determined by the reduction of available Gibbs energy. The concentration of reactants should be reduced until they lose a significant amount of Gibbs energy in order for the current density to be limited. However, when the rate-limiting swich-over mechanism is applied, the limiting current density happens when the electrochemical reaction rate couldn't support the current density. Or, it is determined by the anode activation overpotential as in Figure 3-24. 


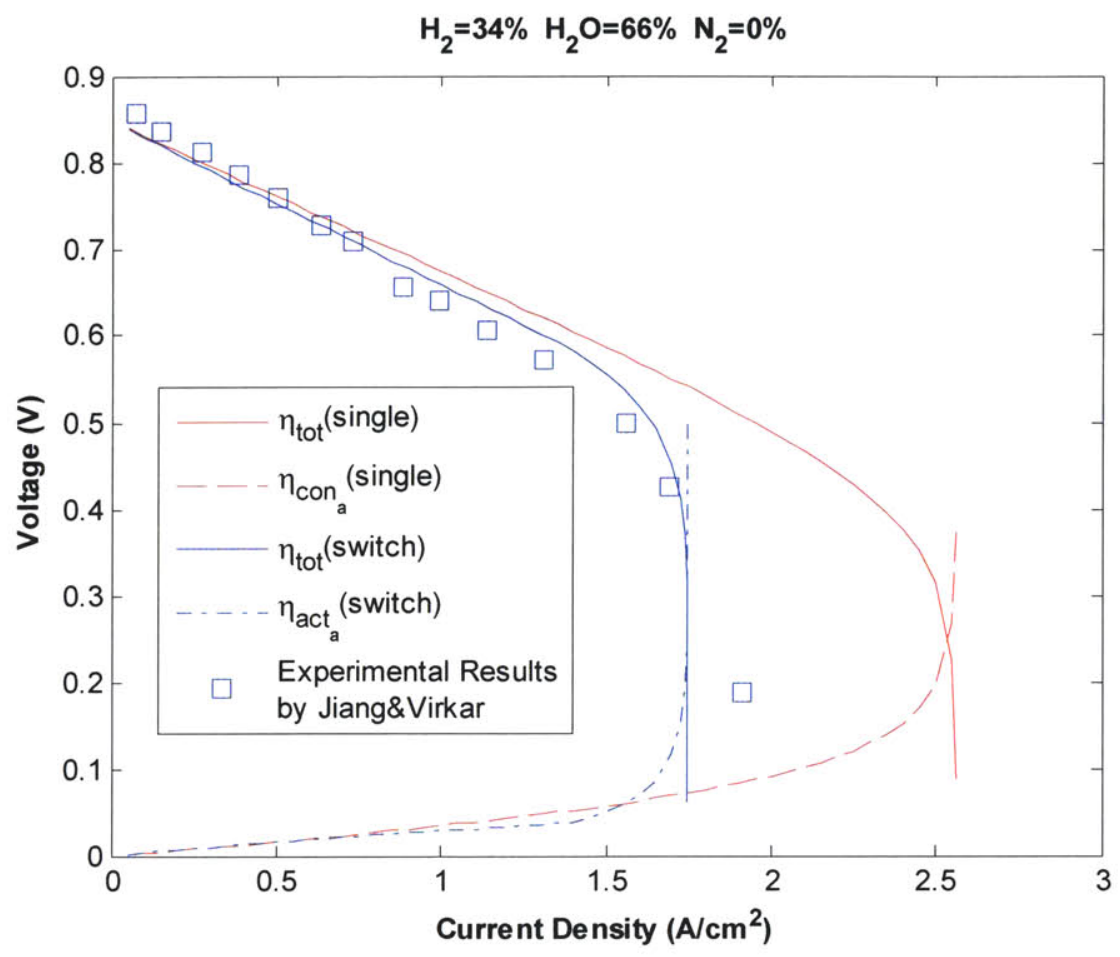

Figure 3-24 Comparison between Singe rate-limiting and Rate-limiting Switch-over

To improve the overall performance of fuel cell, electrolyte ionic resistance should be reduced and new cathode material or structure should be developed to expedite the cathode electrochemical activity. Furthermore, some level of hydrogen adsorption, such as 1.67 times, should be maintained to keep the current from being limited.

\subsection{Conclusion}

We reconstructed the existing anode models based on their original methodologies, but corrected diffusion coefficients and permeability and validated their assumptions. Using DGM with detailed heterogeneous thermo-chemistry is recommended for the anode. Our model is built based on DGM, detailed heterogeneous thermo-chemistry, and detailed electrode kinetics in the unsteady form, correcting the effective Knudsen diffusion 
coefficient and the permeability. The proposed rate-limiting switch-over mechanism has been applied in our model, which substantially improves the prediction of the limiting current density and shows better match with experimental results. Furthermore, our model provides the physical understanding on the current limiting, similar to the explanation on the combustion blow-out. 


\section{Chapter 4 Conclusion}

\subsection{Summary}

We reviewed the current methodologies to calculate each overpotential and corrected errors and additionally analyzed the possibilities which are not examined before. We construct our model based on the most detailed methodologies such as DGM, the detailed heterogeneous thermo-chemistry, and the detailed electrode kinetics. Our model substantially improves the prediction of the limiting current density and shows better match with experimental results.

\subsection{Future Work}

(1) Temperature

Although a uniform temperature is imposed, it is important to understand the thermal consequences of the chemistry and transport. Specifically, the heat release due to thermal chemistry and various overpotential losses should be determined. Note that net heat release is the results of several competing factors. The reforming chemistry is endothermic, but the ohmic resistance associated with ion transport through the electrolyte and inefficiencies associated with charge-transfer chemistry are exothermic.

(2) Elementary chemistry

Within the triple-phase regions, thermal heterogeneous reactions and 
electrochemical charge-transfer reactions proceed concurrently and competitively. For example, adsorbed hydrogen may be recombined and desorb, or it may participate in a charge-transfer reaction. There is current research devoted to developing fully coupled, elementary, thermal and electrochemical reaction mechanism [1]. However, these studies are limited to idealized surfaces (e.g., patterned anodes) and hydrogen chemistry. Nevertheless, it remains a challenging long-tern task to extend this research to hydrocarbon fuels and practical porous ceramic-metallic anode structures.

The current approach assumes weak coupling between thermal heterogeneous chemistry within bulk of the porous anode and charge-transfer chemistry in the relatively thin triple-phase region. The charge-transfer chemistry proceeds according to $\mathrm{H}_{2}$ concentration at the interface between the anode and the dense electrolyte. The hydrogen concentration depends on the heterogeneous reforming chemistry and transport within the porous anode. This approach neglects effect like any charge-transfer inhibition associated with other adsorbed species competing with adsorbed $H(\mathrm{Ni})$. It assumes that all chargetransfer chemistry proceeds through $H_{2}$. Although this is nearly a universal assumption in SOFC modeling, it is also well known that cells can be run on even pure $C O$. Thus, as the incorporation of elementary electrochemistry into SOFC modeling advances, it will be important to include multiple competing charge-transfer pathways in the electrochemical reaction mechanisms.

(3) Inter-layer role

After it was reported that adding an interlayer between electrode and electrolyte 
improves the performance of SOFC[4], experiments have been conducted with the interlayer to show the performance of SOFC. To validate the model correctly against the experimental results, the interlayer should be included for the model. Not much information on the interlayer is available. There is an attempt to include the interlayer in the analysis by Zhao and Virkar [48]. Still, there is a need for a considerate approach.

\section{(4) Code Validation with $\mathrm{CH}_{4}$}

Our anode transport and thermo-chemistry model assumed that the fuel is methane, and the anode is Ni/YSZ. Using methane, it has been observed that SOFC is rapidly deactivated due to carbon deposition on the anode. Using nickel in the anode catalyzes the formation of graphite from hydrocarbons and its deposition on the surface. The conventional approaches to avoid carbon formation are to add steam or oxygen in the fuel stream and to operate SOFC over the narrow range of temperatures between 500 to $700^{\circ} \mathrm{C}$ where carbon formation for methane is not thermodynamically favored [18]. Therefore, almost all experimental results of SOFC using methane as a fuel were conducted while using copper in the anode material[ $[5,18-20]$. There is a need to develop catalytic chemistry models for this case.

Furthermore, the anode electrochemistry model is based on the assumption that all charge-transfer chemistry occurs due to hydrogen electrochemical reaction only. Even though this has been generally assumed, it is also well known that SOFC can work well on pure $C O$ [22]. The charge-transfer reaction mechanism of $C O$ should be investigated before using our simulation model in methane, syngas, or $C O$ fueled cells. 


\section{(5) Impact of Uncertainty on Model Performance}

MEA models are built in the presence of uncertainties of various levels, in the heterogeneous thermo-chemical reaction model, in the electrode kinetics model, and in the electrolyte resistance. These uncertainties impose a limit on the reliability of the MEA model prediction. The uncertainty and sensitivity analysis should be performed using Monte Carlo analysis or Baysian analysis. The sensitivity analysis is also necessary to decide which sub-model is most critical in the prediction of cell performance for different current densities.

(6) Flow Analysis in the Button-Cell

The inaccurate concentration boundary condition at the fuel and oxidant channels might contribute to these discrepancies. Figure 4-1 illustrates that the concentrations of gas species at the interface between the channel and the electrodes may be different from those in the incoming fuel/oxidant.

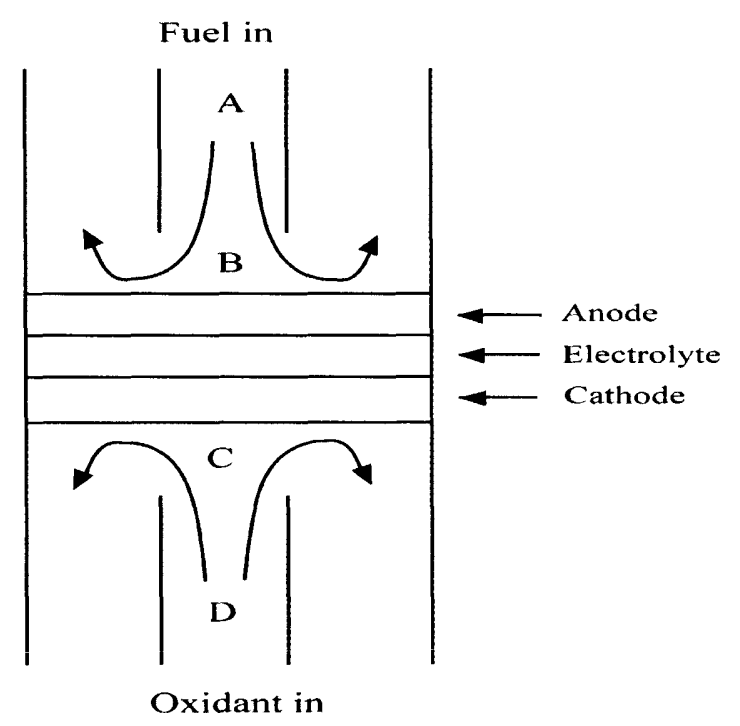

Figure 4-1 Schematics of Button Cell Experimental Set-up 


\section{Reference}

[1] H. Zhu, R. J. Kee, V. M. Janardhanan, O. Deutschmann, and D. G. Goodwin, "Modeling elementary heterogeneous chemistry and electrochemistry in solid-oxide fuel cells," Journal of the Electrochemical Society, vol. 152, pp. 2427-2440, 2005.

[2] EG\&G Technical Services Inc., Fuel Cell Handbook, Seventh ed, 2004.

[3] S. M. Haile, "Fuel cell materials and components," Acta Materialia, vol. 51, pp. 5981-6000, 2003.

[4] T. Tsai and S. A. Barnett, "Increased solid-oxide fuel cell power density using interfacial ceria layers," Solid State Ionics, vol. 98, pp. 191-196, 1997.

[5] R. J. Gorte, H. Kim, and J. M. Vohs, "Novel SOFC anodes for the direct electrochemical oxidation of hydrocarbon," London, 2002.

[6] E. P. Murray, T. Tsai, and S. A. Barnett, "A direct-methane fuel cell with a ceriabased anode," Nature, vol. 400, pp. 649-651, 1999.

[7] R. J. Kee, M. E. Coltrin, and P. Glarborg., Chemically reacting flow : theory and practice New York Wiley-Interscience, 2003.

[8] R. Suwanwarangkul, E. Croiset, M. W. Fowler, P. L. Douglas, E. Entchev, and M. A. Douglas, "Performance comparison of Fick's, dusty-gas and Stefan-Maxwell models to predict the concentration overpotential of a SOFC anode," Journal of Power Sources, vol. 122, pp. 9-18, 2003.

[9] W. Vielstich, A. Lamm, and H. A. Gasteiger., Handbook of fuel cells : fundamentals, technology, and applications Chichester, England ; New York Wiley, 2003.

[10] J. W. Veldsink, R. M. J. van Damme, G. F. Versteeg, and W. P. M. van Swaaij, "Use of the dusty-gas model for the description of mass transport with chemical reaction in porous media," Chemical Engineering Journal and Biochemical Engineering Journal, vol. 57, pp. 115-125, 1995.

[11] E. A. M. a. A. P. Malinauskas., Gas transport in porous media : the dusty-gas model Amsterdam ; New York Elsevier, 1983.

[12] H. Yakabe, M. Hishinuma, M. Uratani, Y. Matsuzaki, and I. Yasuda, "Evaluation and modeling of performance of anode-supported solid oxide fuel cell," Journal of 
Power Sources, vol. 86, pp. 423-431, 2000.

[13] R. Krishna and J. A. Wesselingh, "Maxwell-Stefan approach to mass transfer," Chemical Engineering Science, vol. 52, pp. 861-911, 1997.

[14] R. B. Bird, W. E. Stewart, and E. N. Lightfoot, Transport phenomena 2nd ed. New York John Wiley \& Sons Inc, 2002

[15] J. Bear, Dynamics of fluids in porous media. New York: American Elsevier Pub. Co, 1972.

[16] J. A. Wesselingh and R. Krishna., Mass transfer in multicomponent mixtures Delft, Netherland Delft University Press, 2000.

[17] T. Thampan, S. Malhotra, H. Tang, and R. Datta, "Modeling of conductive transport in proton-exchange membranes for fuel cells," Journal of the Electrochemical Society, vol. 147, pp. 3242-3250, 2000.

[18] C. Lu, S. An, W. L. Worrell, J. M. Vohs, and R. J. Gorte, "Development of intermediate-temperature solid oxide fuel cells for direct utilization of hydrocarbon fuels," Monterey, CA., United States, 2004.

[19] R. J. Gorte, S. Park, J. M. Vohs, and C. Wang, "Anodes for direct oxidation of dry hydrocarbons in a solid-oxide fuel cell," Advanced Materials, vol. 12, pp. 1465$1469,2000$.

[20] S. Park, R. Craciun, J. M. Vohs, and R. J. Gorte, "Direct oxidation of hydrocarbons in a solid oxide fuel cell. I. Methane oxidation," Journal of the Electrochemical Society, vol. 146, pp. 3603-3605, 1999.

[21] R. E. Williford, L. A. Chick, G. D. Maupin, S. P. Simner, and J. W. Stevenson, "Diffusion limitations in the porous anodes of SOFCs," Journal of the Electrochemical Society, vol. 150, pp. 1067-1072, 2003.

[22] Y. Jiang and A. V. Virkar, "Fuel composition and diluent effect on gas transport and performance of anode-supported SOFCs," Journal of the Electrochemical Society, vol. 150, pp. 942-951, 2003.

[23] W. Lehnert, J. Meusinger, and F. Thom, "Modelling of gas transport phenomena in SOFC anodes," Journal of Power Sources, vol. 87, pp. 57-63, 2000.

[24] E. S. Hecht, G. K. Gupta, H. Zhu, A. M. Dean, R. J. Kee, L. Maier, and O. Deutschmann, "Methane reforming kinetics within a Ni-YSZ SOFC anode support," Applied Catalysis A: General, vol. 295, pp. 40-51, 2005. 
[25] O. Deutschmann, S. Tischer, and S. Kleditzsch, "DETCHEM User Manuel," Germany 2005.

[26] E. G. Seebauer, "Quantitative extraction of continuous distributions of energy states and pre-exponential factors from thermal desorption spectra," Surface Science, vol. 316, pp. 391-405, 1994.

[27] G. A. Somorjai, Introduction to surface chemistry and catalysis. New York: John Wiley \& Sonc, Inc. , 1994.

[28] A. V. Virkar, J. Chen, C. W. Tanner, and J.-W. Kim, "Role of electrode microstructure on activation and concentration polarizations in solid oxide fuel cells," Solid State Ionics, vol. 131, pp. 189-198, 2000.

[29] H. Zhu and R. J. Kee, "A general mathematical model for analyzing the performance of fuel-cell membrane-electrode assemblies," Journal of Power Sources, vol. 117, pp. 61-74, 2003.

[30] S. H. Chan, K. A. Khor, and Z. T. Xia, "Complete polarization model of a solid oxide fuel cell and its sensitivity to the change of cell component thickness," Journal of Power Sources, vol. 93, pp. 130-140, 2001.

[31] D. V. Ragone, Thermodynamics of materials. New York: Wiley, 1995.

[32] B. d. Boer, "SOFC Anode: Hydrogen oxidation at porous nickel and nickel/yttriastabilized zirconia cermet electrodes," vol. PhD. Netherlands: University of Twente, 1998.

[33] H. Z. Robert J. Kee, David G. Goodwin, "Solid-oxide fuel cells with hydrocarbon fuels," presented at Proceedings of the Combustion Institute, 2005.

[34] M. Mogensen and S. Skaarup, "Kinetic and geometric aspects of solid oxide fuel cell electrodes," Solid State Ionics, vol. 86-88, pp. 1151-1160, 1996.

[35] J. Mizusaki, H. Tagawa, T. Saito, T. Yamamura, K. Kamitani, K. Hirano, S. Ehara, T. Takagi, T. Hikita, M. Ippommatsu, S. Nakagawa, and K. Hashimoto, "Kinetic studies of the reaction at the nickel pattern electrode on YSZ in $\mathrm{H}_{2}-\mathrm{H}_{2} \mathrm{O}$ atmospheres," Solid State Ionics, vol. 70-71, pp. 52-58, 1994.

[36] Erdey-Gruz, Kinetics of electrode proceses. New York: Wiley-Interscience, 1972.

[37] A. Bieberle, L. P. Meier, and L. J. Gauckler, "The Electrochemistry of Ni Pattern Anodes Used as Solid Oxide Fuel Cell Model Electrodes," Journal of the 
Electrochemical Society, vol. 148, pp. A646 A656, 2001.

[38] A. J. Bard and L. R. Faulkner, Electrochemical methods : Fundamentals and applications, 2nd ed. New York: John Wiley \& Sons, Inc, 2001.

[39] Y. Matsuzaki and I. Yasuda, "Relationship between the steady-state polarization of the SOFC air electrode, $\mathrm{La}_{0.6} \mathrm{Sr}_{0.4} \mathrm{MnO}_{3} / \mathrm{YSZ}$, and its complex impedance measured at the equilibrium potential," Solid State Ionics, vol. 126, pp. 307-313, 1999.

[40] K. Sasaki and J. Maier, "Re-analysis of defect equilibria and transport parameters in $\mathrm{Y}_{2} \mathrm{O}_{3}$-stabilized $\mathrm{ZrO}_{2}$ using EPR and optical relaxation," Solid State Ionics, vol. 134, pp. 303-321, 2000.

[41] E. Hernandez-Pacheco, D. Singh, P. N. Hutton, N. Patel, and M. D. Mann, "A macro-level model for determining the performance characteristics of solid oxide fuel cells," Journal of Power Sources, vol. 138, pp. 174-186, 2004.

[42] J.-W. Kim, A. V. Virkar, K.-Z. Fung, K. Mehta, and S. C. Singhal, "Polarization effects in intermediate temperature, anode-supported solid oxide fuel cells," Journal of the Electrochemical Society, vol. 146, pp. 69-78, 1999.

[43] F. Schuth, K. S. W. Sing, and J. Weitkamp, Handbook of porous solids, vol. 4. Weinheim, Germany: Wiley-VCH, 2002.

[44] F. A. L. Dullien, Porous media : fluid transport and pore structure, 2nd ed. San Diego, California: Academic Press, Inc., 1992.

[45] J. R. Wilson, W. Kobsiriphat, R. Mendoza, H.-Y. Chen, J. M. Hiller, D. J. Miller, K. Thornton, P. W. Voorhees, S. B. Adler, and S. A. Barnett, "Three-dimensional reconstruction of a solid-oxide fuel-cell anode," Nature Materials, vol. 5, pp. 541$544,2006$.

[46] F. H. van Heuveln, H. J. M. Bouwmeester, and F. P. F. van Berkel, "Electrode properties of Sr-doped $\mathrm{LaMnO}_{3}$ on yttria-stabilized zirconia. I. Three-phase boundary area," Journal of the Electrochemical Society, vol. 144, pp. 126-133, 1997.

[47] M. Brown, S. Primdahl, and M. Mogensen, "Structure/performance relations for $\mathrm{Ni} /$ yttria-stabilized zirconia anodes for solid oxide fuel cells," Journal of the Electrochemical Society, vol. 147, pp. 475-485, 2000.

[48] F. Zhao and A. V. Virkar, "Dependence of polarization in anode-supported solid oxide fuel cells on various cell parameters," Journal of Power Sources, vol. 141, pp. 79-95, 2005. 